This report was prepared as an account of work sponsored by an agency of the United States Government. Neither the United States Government nor any agency thereof, nor any of their employees, makes any warranty, express or implied, or assumes any legal liability or responsibility for the accuracy, completeness, or usefulness of any information, apparatus, product, or process disclosed, or represents that its use would not infringe privately owned rights. Reference herein to any specific commercial product, process, or service by trade name, trademark, manufacturer, or otherwise does not necessarily constitute or imply its endorsement, recommendation, or favoring by the United States Government or any agency thereof. The views and opinions of authors expressed herein do not necessarily state or reflect those of the United States Government or any agency thereof.

\title{
Performance Assessment Task Team Progress Report
}

\author{
Donald E. Wood, Chairman \\ Robert U. Curl, Technical Secretary \\ Dennis R. Armstrong \\ James R. Cook \\ Max R. Dolenc \\ David C. Kocher \\ Kirk W. Owens \\ Edward P. Regnier \\ G. W. Roles \\ Roger R. Seitz \\ Marcus I. Wood
}

Published May 1994

\section{Idaho National Engineering Laboratory \\ EG\&G Idaho, Inc. Idaho Falls, Idaho 83415}

\author{
Prepared for the \\ U.S. Department of Energy \\ Office of Environmental Management \\ Under DOE Idaho Operations Office \\ Contract DE-AC07-76ID01570
}





\section{DISCLAIMER}

Portions of this document may be illegible in electronic image products. Images are produced from the best available original document. 


\begin{abstract}
The U.S. Department of Energy (DOE) Headquarters EM-35, established a Performance Assessment Task Team (referred to as the Team) to integrate the activities of the sites that are preparing performance assessments (PAs) for disposal of new low-level waste, as required by Chapter III of DOE Order 5820.2A, "Low-Level Waste Management." The intent of the Team is to achieve a degree of consistency among these PAs as the analyses proceed at the disposal sites. The Team's purpose is to recommend policy and guidance to the DOE on issues that impact the PAs, including release scenarios and parameters, so that the approaches are as consistent as possible across the DOE complex. The Team has identified issues requiring attention and developed discussion papers for those issues. Some issues have been completed, and the recommendations are provided in this document. Other issues are still being discussed, and the status summaries are provided in this document. A major initiative was to establish a subteam to develop a set of test scenarios and parameters for benchmarking codes in use at the various sites. The activities of the Team are reported here through December 1993.
\end{abstract}





\section{EXECUTIVE SUMMARY}

The U.S. Department of Energy Headquarters (DOE-HQ), EM-35, established a Performance Assessment Task Team (referred to as the Team) to integrate the activities of the sites that are preparing performance assessments (PAs) for disposal of new low-level waste as required by Chapter III of DOE Order 5820.2A, "Low-Level Waste Management." The intent of the Team is to achieve a degree of consistency among these PAs as the analyses proceed at the disposal sites. The Team's purpose is to recommend policy and guidance to DOE-HQ on issues that impact the PAs, including release scenarios and parameters, so that the approaches are not only reasonably consistent across the DOE complex but also take into account site-specific and facility-specific differences. Some of the needs recognized are to ensure a consistent level of protection; provide credibility for the analyses; ensure documentation of bases for assumptions, parameters, and release scenarios; provide a basis for developing of facility-specific waste acceptance criteria (with justification for site-specific differences); and avoid having criteria at some sites unnecessarily impacted by assumptions at other sites.

The Team consists of a chairman, members from each of the six DOE sites that are currently disposing of waste, members from DOE's EM-35 and EH-23, and liaison representatives from the Peer Review Panel (PRP) and the U.S. Nuclear Regulatory Commission (NRC). Designated alternate representatives provided additional support as needed.

The Team has met 15 times since forming. During these meetings, the Team identified a number of issues needing attention and began developing issue papers for each one. These issue papers or status summaries are given in this report. It was also determined that the release scenarios and parameters might involve some site-specific data; therefore, the PAs could not be standardized. However, a mechanism was needed to ensure reasonable consistency, so a subteam was formed to examine the codes in use, identify any significant differences, and recommend a set of scenarios and parameters that will be used as test cases to benchmark codes and methods at the sites against each other. Significant differences (orders of magnitude, in some cases) were found and causes identified. The subteam is preparing a report and a summary is given in this progress report. Parameter values for benchmarking will be included, although site-specific variations for site PAs may be appropriate if justified by site data.

A major benefit of the Team's activities and discussions has been better understanding by the members of the problems and issues at other sites and recognizing the need for reasonable consistency to avoid unexpected impacts of individual choices of approaches and scenarios. Several of the meetings included site tours, which also contributed to mutual understanding. Communication among Team members has fostered more consistency in the site technical approaches.

The Team is supporting DOE participation in the International Atomic Energy Agency (IAEA) Coordinated Research Program (CRP) for intercomparison of PA codes and methods. The program involves analyzing predefined test cases by analysts from several nations, comparing results, and examining the reasons for any differences. The results will improve the consistency of analysis with different codes and identify improvements that may be useful. 
A joint briefing for the PA community was conducted by the Team and the PRP in 1991. The briefing provided an up-to-date discussion of the status of DOE work in the field, as well as an opportunity for analysts and others interested to exchange information and ideas. This was especially timely, because all sites active in waste disposal are preparing PAs for their facilities.

Some of the meetings have included day-long workshops on special topics of interest. These have included waste characterization needs and methods, field experiments and data for waste form release rates, and NRC methodology for PAs.

The Team has considered 21 issues and provided recommendations for resolutions. In a few cases, study and discussion will continue, either because the issue contains policy implications which the Team is not able to resolve, or because the issue requires longer-term study. The recommendations of the Team are being incorporated into the revision of DOE Order 5820.2A, which is currently in progress. Several of the Team members are serving on the Technical Working Groups for various chapters of the revised order, and the Team is also reviewing drafts of the revision. 


\section{CONTENTS}

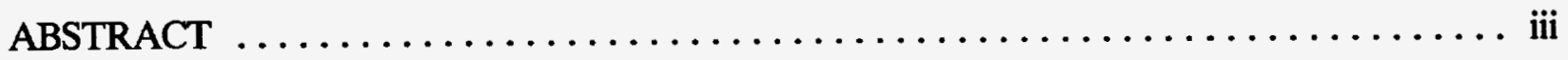

EXECUTIVE SUMMARY $\ldots \ldots \ldots \ldots \ldots \ldots \ldots \ldots \ldots \ldots \ldots \ldots \ldots \ldots \ldots \ldots \ldots$

ACRONYMS $\ldots \ldots \ldots \ldots \ldots \ldots \ldots \ldots \ldots \ldots \ldots \ldots \ldots \ldots \ldots \ldots \ldots \ldots \ldots \ldots \ldots \ldots \ldots$

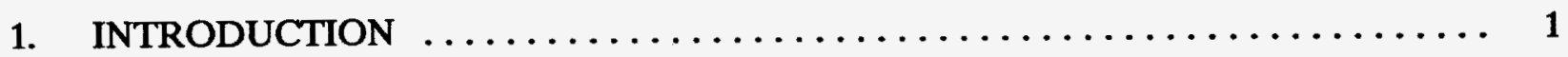

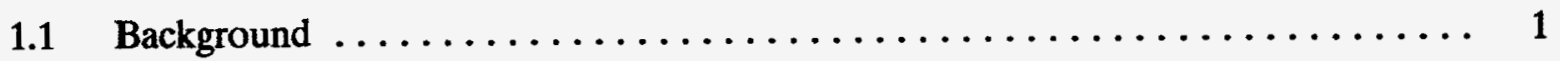

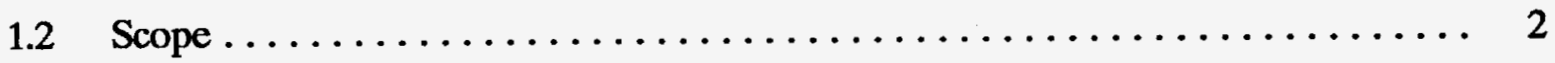

1.3 Objective $\ldots \ldots \ldots \ldots \ldots \ldots \ldots \ldots \ldots \ldots \ldots \ldots \ldots \ldots \ldots \ldots, 2$

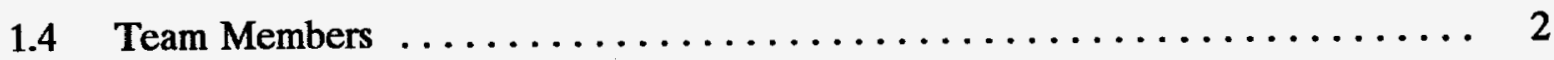

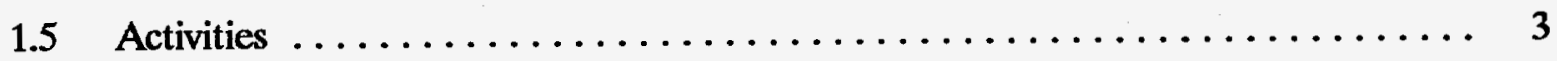

1.6 Assumptions and Ground Rules $\ldots \ldots \ldots \ldots \ldots \ldots \ldots \ldots \ldots \ldots \ldots, 4$

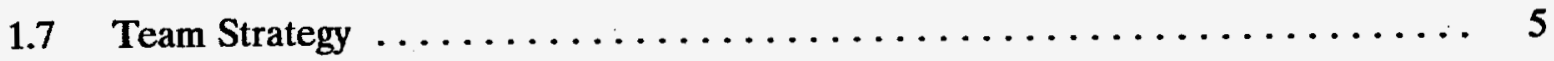

1.8 Benchmarking Subteam $\ldots \ldots \ldots \ldots \ldots \ldots \ldots \ldots \ldots \ldots \ldots \ldots, 5$

2. ISSUES AND RECOMMENDATIONS $\ldots \ldots \ldots \ldots \ldots \ldots \ldots \ldots \ldots \ldots \ldots, 7$

$2.1 \quad$ Reasonable Assurance $\ldots \ldots \ldots \ldots \ldots \ldots \ldots \ldots \ldots \ldots \ldots \ldots \ldots \ldots$

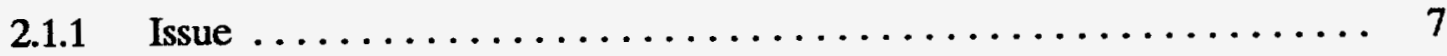

2.1.2 Recommendations ........................... 7

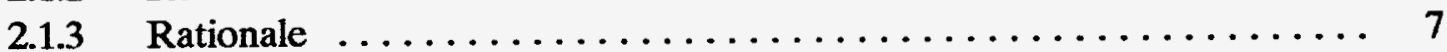

2.2 Passive Controls $\ldots \ldots \ldots \ldots \ldots \ldots \ldots \ldots \ldots \ldots \ldots \ldots \ldots \ldots \ldots, 9$

$2.2 .1 \quad$ Issue $\ldots \ldots \ldots \ldots \ldots \ldots \ldots \ldots \ldots \ldots \ldots \ldots \ldots \ldots \ldots \ldots \ldots, 9$

2.2 .2 Recommendations $. \ldots \ldots \ldots \ldots \ldots \ldots \ldots \ldots \ldots \ldots \ldots, 9$

2.2.3 Rationale $\ldots \ldots \ldots \ldots \ldots \ldots \ldots \ldots \ldots \ldots \ldots \ldots \ldots \ldots, 9$

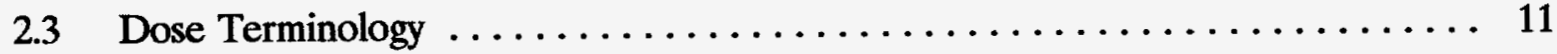

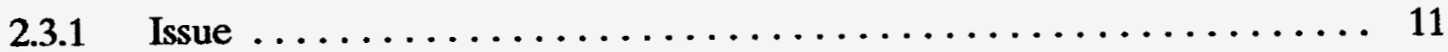

2.3.2 Recommendation $\ldots \ldots \ldots \ldots \ldots \ldots \ldots \ldots \ldots \ldots \ldots \ldots, 11$

2.3.3 Rationale $\ldots \ldots \ldots \ldots \ldots \ldots \ldots \ldots \ldots \ldots \ldots \ldots \ldots \ldots, 11$

2.4 Special-Case Waste $\ldots \ldots \ldots \ldots \ldots \ldots \ldots \ldots \ldots \ldots \ldots \ldots \ldots \ldots \ldots \ldots$ 


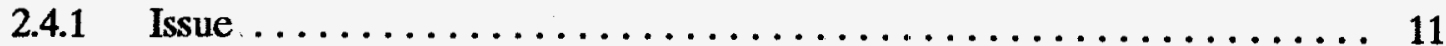

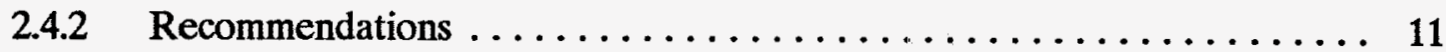

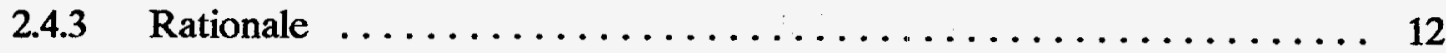

2.5 Software Testing And Control $\ldots \ldots \ldots \ldots \ldots \ldots \ldots \ldots \ldots \ldots \ldots \ldots \ldots$

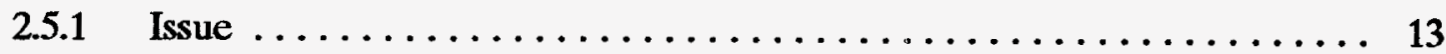

2.5.2 Recommended Policy for Software Testing and Control ......... 13

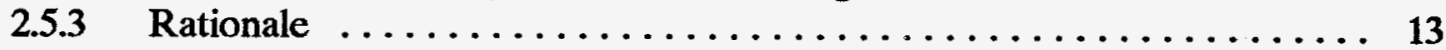

2.5.4 Regulatory Drivers and Supporting Documents $\ldots \ldots \ldots \ldots \ldots \ldots \ldots 14$

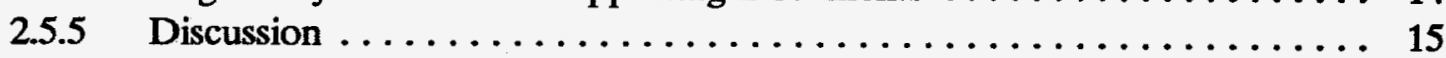

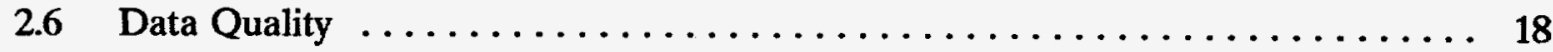

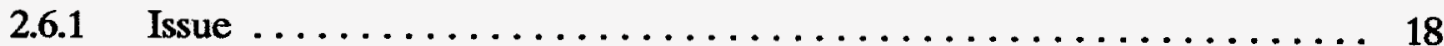

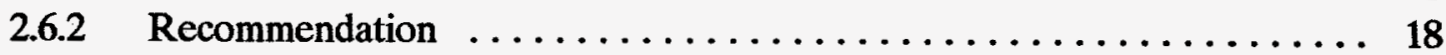

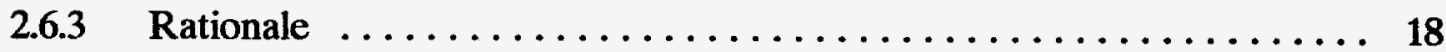

2.7 Site-Specific Groundwater Codes $\ldots \ldots \ldots \ldots \ldots \ldots \ldots \ldots \ldots \ldots \ldots \ldots$

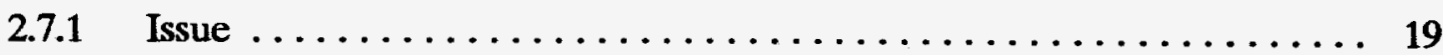

2.7.2 Recommendations ........................ 19

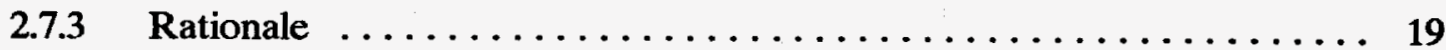

2.8 Apportionment of Dose Objectives $\ldots \ldots \ldots \ldots \ldots \ldots \ldots \ldots \ldots \ldots \ldots \ldots$

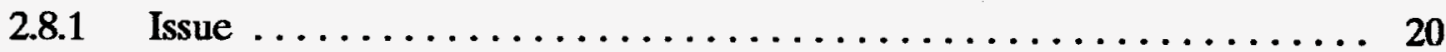

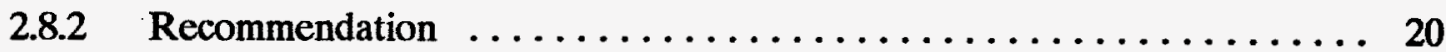

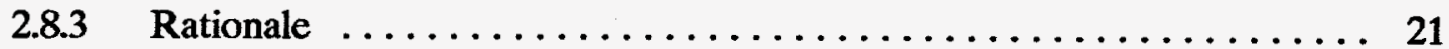

2.9 Point of Compliance $\ldots \ldots \ldots \ldots \ldots \ldots \ldots \ldots \ldots \ldots \ldots \ldots \ldots \ldots \ldots \ldots$

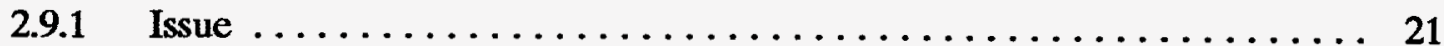

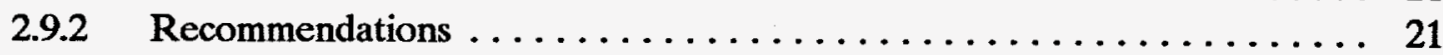

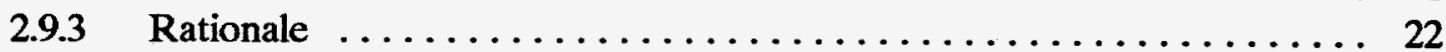

2.10 Groundwater Dose Objective and Compliance $\ldots \ldots \ldots \ldots \ldots \ldots$

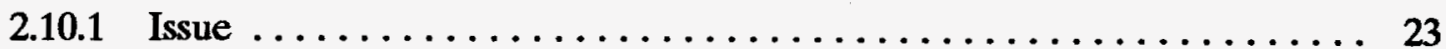

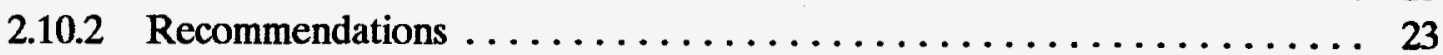

2.10 .3 Rationale $\ldots \ldots \ldots \ldots \ldots \ldots \ldots \ldots \ldots \ldots \ldots \ldots \ldots \ldots \ldots \ldots$

2.11 Long-Term Changes and Effects $\ldots \ldots \ldots \ldots \ldots \ldots \ldots \ldots \ldots \ldots \ldots$

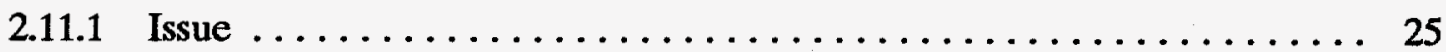

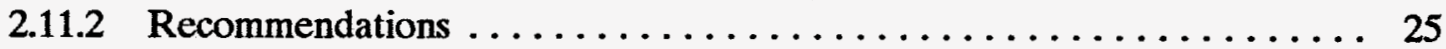

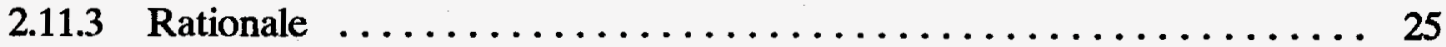


2.12 Performance Assessment Approval, Compliance Requirements, and

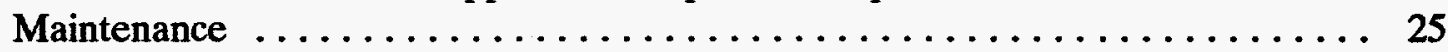

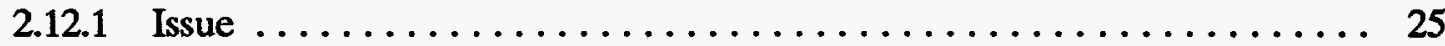

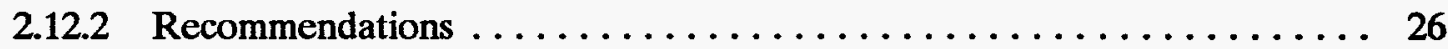

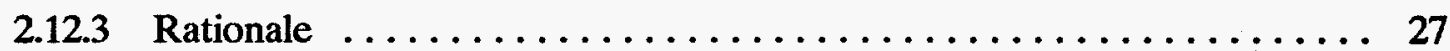

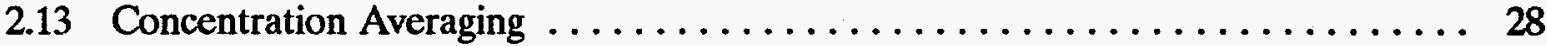

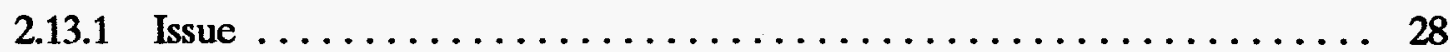

2.13.2 Recommendations ........................ 28

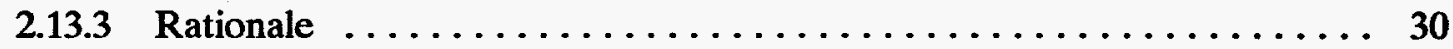

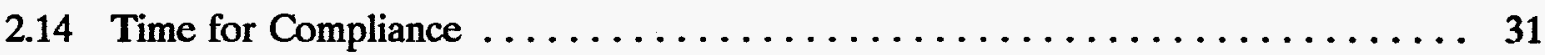

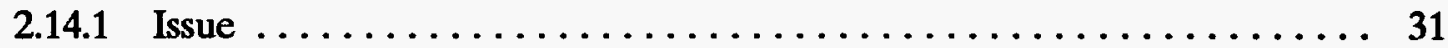

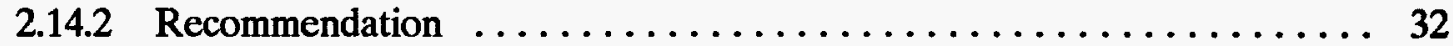

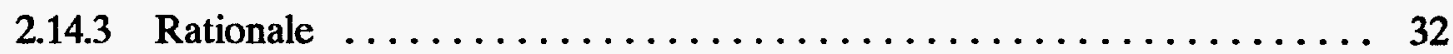

2.15 Development and Application of Exposure Scenarios $\ldots \ldots \ldots \ldots \ldots \ldots$

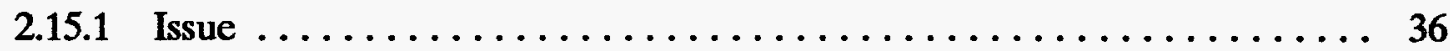

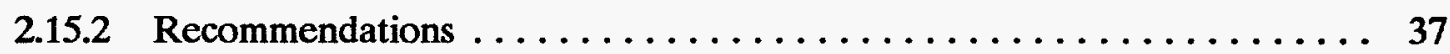

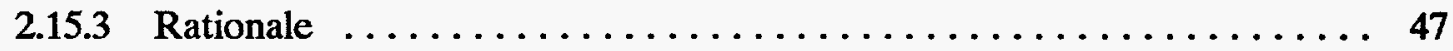

2.16 Waste Characterization $\ldots \ldots \ldots \ldots \ldots \ldots \ldots \ldots \ldots \ldots \ldots \ldots \ldots \ldots$

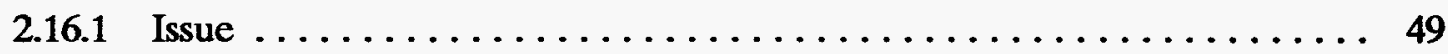

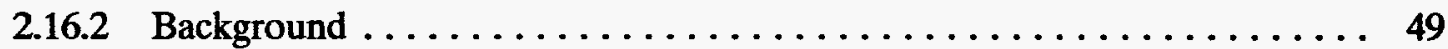

2.16 .3 Recommendations ........................ 49

2.16 .4 Rationale $\ldots \ldots \ldots \ldots \ldots \ldots \ldots \ldots \ldots \ldots \ldots \ldots \ldots \ldots \ldots \ldots$

2.17 Quantification of Waste Form Release Rates $\ldots \ldots \ldots \ldots \ldots \ldots \ldots$

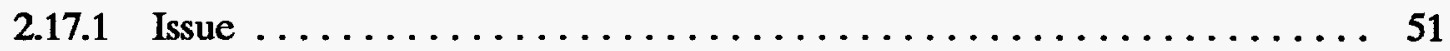

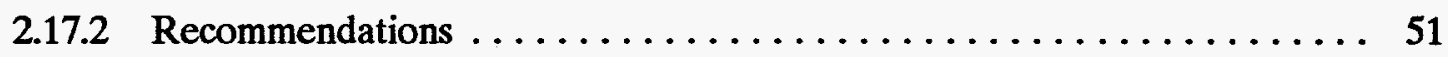

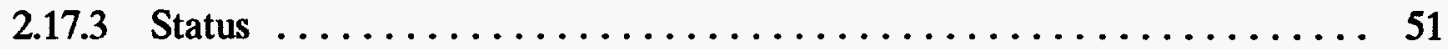

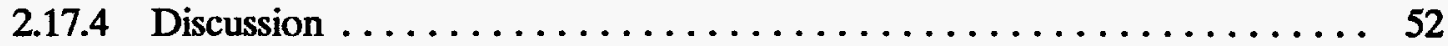

2.18 Radionuclide Screening $\ldots \ldots \ldots \ldots \ldots \ldots \ldots \ldots \ldots \ldots \ldots \ldots \ldots \ldots$

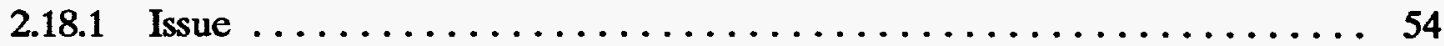

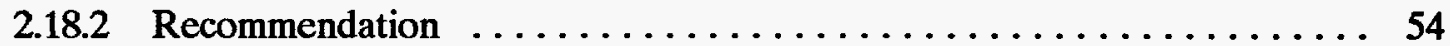

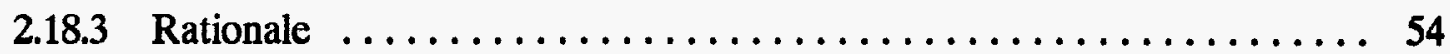

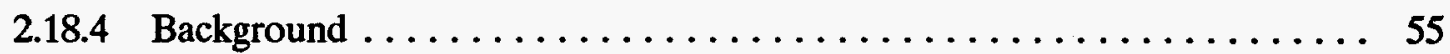

2.18.5 Benefits of Using Screening Models $\ldots \ldots \ldots \ldots \ldots \ldots \ldots \ldots \ldots \ldots$

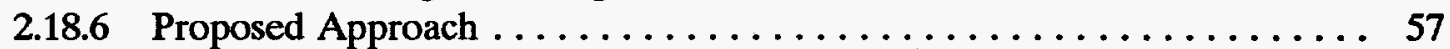




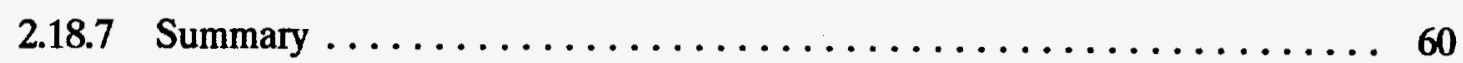

2.19 The Intruder and the All-Pathways Analyses $\ldots \ldots \ldots \ldots \ldots \ldots$

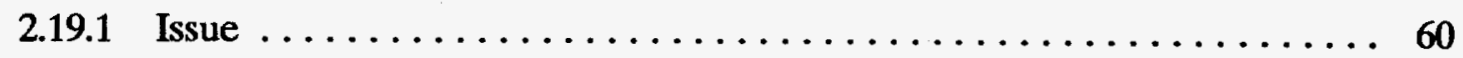

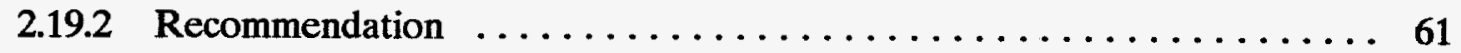

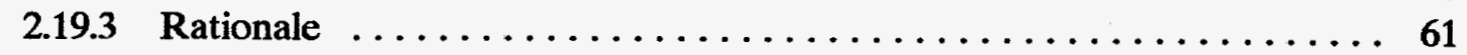

2.20 Inadvertent Intruder Dose Objective $\ldots \ldots \ldots \ldots \ldots \ldots \ldots \ldots \ldots \ldots \ldots \ldots \ldots$

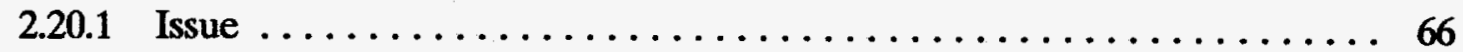

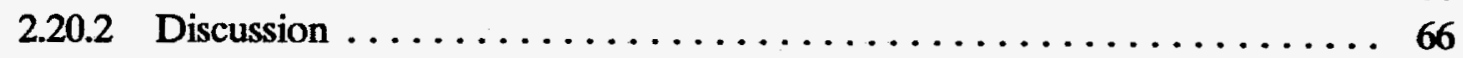

2.21 Near-Surface Disposal of Uranium and Thorium $\ldots \ldots \ldots \ldots \ldots$

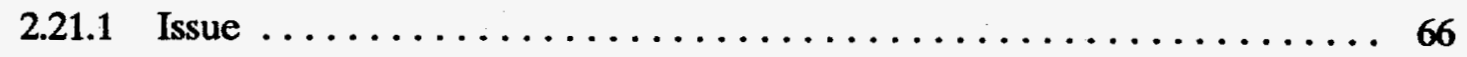

2.21.2 Recommendations and Discussion $\ldots \ldots \ldots \ldots \ldots \ldots \ldots \ldots \ldots$

3. BENCHMARK SUBTEAM $\ldots \ldots \ldots \ldots \ldots \ldots \ldots \ldots \ldots \ldots \ldots \ldots \ldots \ldots \ldots$

4. INTERNATIONAL ATOMIC ENERGY AGENCY COORDINATED RESEARCH

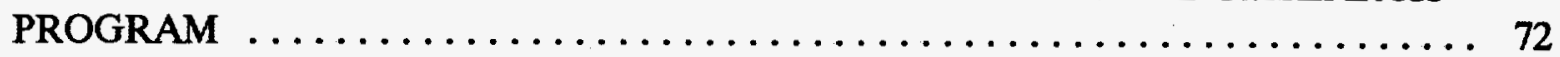

5. DOE WASTE CLASSIFICATION SYSTEM $\ldots \ldots \ldots \ldots \ldots \ldots \ldots \ldots \ldots$

6. FUTURE PLANS $\ldots \ldots \ldots \ldots \ldots \ldots \ldots \ldots \ldots \ldots \ldots \ldots \ldots \ldots \ldots \ldots \ldots$

7. REFERENCES $\ldots \ldots \ldots \ldots \ldots \ldots \ldots \ldots \ldots \ldots \ldots \ldots \ldots \ldots \ldots \ldots \ldots$

Appendix A-Glossary $\ldots \ldots \ldots \ldots \ldots \ldots \ldots \ldots \ldots \ldots \ldots \ldots \ldots \ldots \ldots \ldots \ldots \ldots \ldots$

Appendix B-Meeting Agendas $\ldots \ldots \ldots \ldots \ldots \ldots \ldots \ldots \ldots \ldots \ldots \ldots \ldots \ldots$ B-1 


\section{ACRONYMS}

ALARA

ANSI

ASME

DLLWMP

DOE-HQ

EIS

EPA

HLW

IAEA

ICRP

IEEE

INEL

LANL

LLW

MCL

NAS

NEPA

NLLWMP

NRC

NTS

ORNL

OSR

PA as low as reasonably achievable

American National Standards Institute

American Society for Mechanical Engineers

Defense Low-Level Waste Management Program

U.S. Department of Energy-Headquarters

environmental impact statement

U.S. Environmental Protection Agency

high-level waste

International Atomic Energy Agency

International Commission on Radiological Protection

Institute of Electrical and Electronic Engineers

Idaho National Engineering Laboratory

Los Alamos National Laboratory

low-level radioactive waste

maximum contamination level

National Academy of Sciences

National Environmental Policy Act

National Low-Level Waste Management Program

U.S. Nuclear Regulatory Commission

Nevada Test Site

Oak Ridge National Laboratory

operational safety requirement

performance assessment 
PAL performance assessment limiting

PNL Pacific Northwest Laboratories

PRP

Peer Review Panel

REECo

Reynolds Electrical \& Engineering Company, Inc.

SAR

safety analysis report

SCW

special-case waste

SRP

Savannah River Plant

TSP

Technical Support Program

TSAs

technical safety requirements

WAC

waste acceptance criteria

WHC

Westinghouse Hanford Company

WSRC

Westinghouse Savannah River Company 


\section{Performance Assessment Task Team Progress Report}

\section{INTRODUCTION}

U.S. Department of Energy Headquarters (DOE-HQ), EM-35, established a Performance Assessment Task Team (referred to as the Team) to integrate the activities of the sites that are preparing performance assessments (PAs) for disposal of new low-level radioactive waste (LLW) as required by Chapter III of DOE Order 5820.2A, "Low-Level Waste Management." The intent is to achieve a degree of consistency among these PAs as the analyses proceed at the disposal sites. The Team's purpose is to recommend policy and guidance to DOE-HQ on issues that impact the PAs, including release scenarios and parameters, so that the results are reasonably consistent across the DOE complex. These activities are reported in this document through December 1993. Appendix A is a glossary of terms used in this report, and Appendix B is a compilation of the Team's meeting agendas.

\subsection{Background}

Compliance with the performance objectives in DOE Order 5820.2A, Chapter III, Section 3.a. requires demonstrating compliance through a PA, as specified in Section 3.b of the Order. ${ }^{1}$ The six sites actively involved in disposal of new LLW are in various stages of conducting these assessments. However, the release and exposure scenarios and parameters in use are not necessarily the same, so there are perceived inconsistencies in the results. Site experts and others have expressed concern about these perceived inconsistencies as the work progressed, and a survey $^{2}$ of DOE Order 5820.2A compliance confirmed the need to correct this situation. Therefore, DOE-HQ requested formation of the Team ${ }^{\mathrm{a}}$ consisting of representatives from disposal sites and DOE-HQ. The Team's purpose was to develop and recommend policy and supporting rationale to make the PAs reasonably consistent, recognizing that some aspects will, of necessity, be specific to individual sites and disposal system designs. A Technical Secretary was provided by the EG\&G Idaho, Inc., Technical Support Program (TSP). Representatives from DOE (EM-35 and EH-23) are included. A representative from the U.S. Nuclear Regulatory Commission (NRC) was added.

Review and evaluation of PAs are the responsibilities of the PA Peer Review Panel (PRP). The Team coordinates closely with the PRP, who will review the results of the Team effort. The Technical Secretary of the Team also serves as the Technical Secretary of the PRP. The chairmen of the Team and PRP are invited to both the PRP and Team meetings, and meeting minutes are exchanged.

a. Memorandum from Jill E. Lytle, Associate Director, Office of Waste Operations Environmental Restoration and Waste Management, "Performance Assessment Guidance Task Team," June 27, 1990. 


\subsection{Scope}

The scope of the PA guidance to be provided by the Team includes radiological PAs for the disposal of LLW that had not been disposed of before DOE Order 5820.2A was issued on September 26, 1988.

\subsection{Objective}

The Team's objective is to produce consensus policy and rationale for radiological PAs that will be used in evaluating compliance with the performance objectives in DOE Order 5820.2A, Chapter III. As stated in the June 27, 1990 call letter, "The purpose of the Task Team is to raise and propose resolution to issues that impact the radiological performance assessments and ultimately recommend policy and guidance to DOE-HQ." The intent is to make these PAs reasonably uniform, while allowing for site-specific and facility-specific differences. Some of the needs recognized are to ensure a consistent level of protection; provide credibility for the analyses; ensure documentation of bases for assumptions, parameters, and release scenarios; provide a basis for developing facility-specific waste acceptance criteria (with justification for any site-specific differences); and avoid having criteria at some sites unnecessarily impacted by assumptions at other sites. The recommendations have been provided to DOE-HQ for use in the current revision of DOE Order 5820.2A.

\subsection{Team Members}

Team members and liaison include

Chairman:

Technical secretary:

Hanford:

Idaho National Engineering

Laboratory (INEL):

Nevada Test Site (NTS):

Los Alamos National

Laboratory (LANL):

Oak Ridge National

Laboratory (ORNL):

ORNL-Grand Junction:
Donald E. Wood [Westinghouse Hanford Company (WHC)]

Robert U. Curl (EG\&G Idaho, TSP)

Marcus I. Wood (WHC)

Alternate: Bruce A. Napier [Pacific Northwest Laboratories (PNL)]

Roger R. Seitz (EG\&G Idaho)

Alternate: Swen O. Magnuson, (EG\&G Idaho)

Max R. Dolenc [Reynolds Electrical \& Engineering Company, Inc. (REECo)]

Dennis R. Armstrong (LANL)

Alternate: Daniel P. Taggart (LANL)

David C. Kocher (ORNL)

David Thorne (ORNL-GJ)

b. See footnote a. 
Savannah River Plant (SRP):

DOE EH-23:

DOE EM-30 Liaison:

DOE EM-35:

NRC Liaison:
James R. Cook [Westinghouse Savannah River Company (WSRC)]

Alternate: Robert A. Hiergesell

Edward P. Regnier

Alternate: G. W. Roles

David G. Huizenga

Gregory J. Duggan and Kirk W. Owens (SAIC)

Fredrick W. Ross

Alternate: Andrew C. Campbell

Elmer L. Wilhite, (WSRC), PRP Chairman

PRP Liaison:

Jeff Baldwin (ORNL), Tom Buhl (LANL), and Mac Ennis (LANL) are past members of the Team.

\subsection{Activities}

Meetings have been held as follows (agendas are provided in Appendix B):

July 25-26, 1990, Gaithersburg, MD August 29-30, 1990, Chicago, IL December 4-6, 1990, Knoxville, TN February 5-7, 1991, Las Vegas, NV April 17-18, 1991, Gaithersburg, MD June 12-13, 1991, Gaithersburg, MD August 27-28, 1991, Idaho Falls, ID October 30, 1991, Denver, CO
January 21-23, 1992, Augusta, GA May 6-7, 1992, Gaithersburg, MD August 4-6, 1992, Santa Fe, NM December 8-10, 1992, Rockville, MD April 20-22, 1993, Richland, WA August 3-5, 1993, Denver, CO November 16-18, 1993, Gaithersburg, MD

At the first meeting, the Team identified some of the key issues, selected an approach to the problem of obtaining a degree of consistency in PAs, and assigned tasks to several members. The approach used identified current methods in terms of release scenarios and parameters, selected items not site-specific that could be standardized, identified site-specific items and provided rationale for differences, and identified issues needing discussion and rationale. The issue statements are compiled in this report and used to support recommendations that have been made to DOE-HQ for revising DOE Order 5820.2A.

Meetings at Knoxville, Las Vegas, Idaho Falls, Augusta, Santa Fe, Richland, and Denver included site tours to give Team members a better understanding of issues at the wide range of sites and facilities in the DOE system. Guest speakers have occasionally been invited to provide insight into special issues affecting the PAs. Further details of Team activities are available in the minutes for each meeting. The work is done primarily by the Team members and experts available to them at their own sites. For tasks requiring additional resources, the TSP (at EG\&G 
Idaho) provides assistance. One such task (Waste Classification Rationale) was identified and a draft report was prepared (summarized in Section 5).

Information developed by the Team was provided to DOE-HQ through their representatives at the meetings, meeting minutes, copies of Team communications, and personal briefings. Additional information was provided through a joint briefing with the PRP for the DOE LLW PA community, summary papers at the Waste Management '92 and '93 Symposiums and the 13th and 14th Annual DOE LLW Management Conferences, and this report. Recommendations are being used in developing DOE Order 5820.2B, the revision of Order 5820.2A.

A subteam for scenario analysis and benchmarking was formed because early comparisons showed wide differences among the sites' results (see Section 1.8). The subteam consisted of Marcus I. Wood, Roger R. Seitz, James R. Cook, and Bruce A. Napier. Paul Rittman (WHC) served as advisor and alternate for Bruce A. Napier. The subteam has resolved most of the differences and is preparing a report of their activities and results of the comparison.

The eleventh meeting included a workshop on field data requirements to support source release rate determination. A need for a survey and evaluation of this data was identified, and a proposed work scope and cost estimate were provided to DOE-HQ.

A subteam on waste characterization was formed. The subteam developed a workshop for the twelfth meeting, which revealed a broad range of issues and needs. Subsequently, DOE-HQ formed a Working Group to continue evaluating characterization as part of overall LLW management practices, not just the PA aspects.

The NRC has been developing PA methodology for several years, with the intent of producing a regulatory guide on the topic. At the fifteenth meeting, NRC staff provided a daylong presentation on their methodology and status.

\subsection{Assumptions and Ground Rules}

Some assumptions about the range of issues to be addressed by the Team led to the following set of ground rules.

- Scope limitations. The scope of the Team's efforts includes

- The radiological PA for disposal but not the waste management systems PA referred to in DOE Order 5820.2A, Chapter III.

- $\quad$ LLW (not other types of waste) disposed of after September 26, 1988.

- Waste disposal, but not operations. The period of interest is post-closure, primarily beyond the 100 -year period of active institutional control specified in DOE Order 5820.2A.

- The recommendations are intended primarily for use in PAs for compliance evaluations, although they may be useful for other purposes, such as National 
Environmental Policy Act (NEPA) analyses, design analyses, waste acceptance criteria development, and volume projections. A waste classification system will not be developed, but the PA methods and guidance will be useful in developing analyses that are specific to each site and to the disposal facility to be used.

- The product will be a statement of proposed policy and supporting rationale. Compliance policy will not address specifics of facility design. If a design feature is used to attenuate releases for a specified length of time, it is the responsibility of the assessor to provide a credible design analysis.

- Stochastic modeling will not be used for compliance assessments, although such techniques may be useful for uncertainty, sensitivity, and trade-off studies.

\subsection{Team Strategy}

At the first meeting, the Team developed a list of issues and identified four methods for analyzing those issues.

- Provide direct guidance from the Team in the form of issue papers or discussion in the final report. Recommended policy statements will be provided when useful.

- Request others to develop the information by request through DOE-HQ to the TSP or contractors.

- Provide rationale for not addressing an issue found to be peripheral or beyond the scope of the Team but still requiring explanation.

- Identifying an issue as irrelevant and requiring no further discussion.

An initial driver for the effort was the desire to improve credibility, understanding, and acceptance of DOE's LLW disposal efforts by providing consistency, to the degree reasonable, among waste acceptance and disposal criteria across the DOE complex. However, it is recognized that site-specific conditions will influence the kinds and amounts of waste that can safely be disposed of in a specific disposal system at a particular site. Further discussion revealed that the isolation capability of disposal systems varies widely among the DOE sites and that standardization of the PAs might lead to restrictive disposal criteria (suitable for sites with the least degree of natural isolation) being applied to sites with a higher degree of natural isolation. Thus, the focus turned to the degree of consistency that could be achieved in the PAs themselves, without unduly restricting site-specific practices and waste acceptance criteria.

\subsection{Benchmarking Subteam}

The formation of a methods comparison (Benchmarking) Subteam was a major decision that led to substantial progress toward a reasonable degree of consistency. This decision followed from several discussions of site approaches to PAs. 
Release scenarios in use at the various sites were discussed and compared in terms of general similarities and qualitative differences. These scenarios naturally divided into two groups, those leading to offsite releases (primarily through groundwater transport) and those affecting intruders. It was agreed that groundwater models needed to be site-specific, and the Team then looked into possible consistency in intruder scenarios. Results from intrusion scenarios in PAs being performed at the sites with different methods and codes were compared in terms of the implied concentration limits. The results varied by several orders of magnitude. Some variation was expected, because the sites were using their own scenarios and parameters, but the large magnitude of the variation was not anticipated.

The Team arbitrarily defined specific example scenarios as test cases and used their own codes and methods again, but the results still differed by two or three orders of magnitude. Then two simple cases were defined to isolate and test different pathways: (1) growing crops in uniformly contaminated soil to test the food-web portion of the analysis and (2) resuspension of ${ }^{239} \mathrm{Pu}$ from a post-drilling habitation scenario to test the soil dilution and dust loading parameters for the inhalation pathway. There was still over an order of magnitude spread in the dose predictions from the major codes in use, GENII ${ }^{3}$ and PATHRAE. ${ }^{4}$ However, examination of the input parameters identified some major differences, and the cases were simple enough that it was possible to consider modifications that would achieve reasonable agreement. Some of the parameters in GENII and PATHRAE were not easily accessible to change or even to identify, so there was a need for further analysis.

The subteam was formed to study the issue more closely. They found the sources of difference for the ingestion and inhalation pathways and achieved agreement (within 10\%) for the codes with common input parameters. 


\section{ISSUES AND RECOMMENDATIONS}

The Team has considered 21 issues and provided recommendations for resolving most of them. In a few cases, the recommendations are interim, since the issue requires further study or requires policy resolution. The issue statements are given below in the form of a statement of the issue, recommendations, and supporting rationale and discussion. Recommended language changes are specific to the issue being addressed and do not signify de facto approval of matters not specifically addressed.

\subsection{Reasonable Assurance}

\subsubsection{Issue}

The degree of confidence with which the performance objectives in DOE Order 5820.2A must be met is unclear. The objectives state "assure that" the limits will not be exceeded, but the degree of assurance required is not specified. Recommended language changes are specific to the issues being addressed, and do not signify de facto approval of matters not specifically addressed.

\subsubsection{Recommendations}

The Team recommends that the first sentence in Section III.3.a.(2) of DOE Order 5820.2A be replaced with "Disposal systems shall be designed, operated, closed, and controlled after closure to provide reasonable assurance that annual effective dose equivalents to individual members of the public beyond the boundary of the disposal site will not exceed 25 mrem $(0.25 \mathrm{mSv})$ from all exposure pathways." The degree of assurance required in meeting the performance objectives shall not be specified in advance. Instead, determinations of reasonable assurance shall be left to the judgement of the PRP and other reviewers.

The performance objective for protection of inadvertent intruders and groundwater resources (if quantified) shall also be interpreted in terms of "reasonable assurance."

The Team also recommends adding the following sentence to DOE Order 5820.2A, Section III.3.b(1): "Assessments for demonstrating compliance with the performance objectives can be based on assumptions (including exposure scenarios and pathways) judged to be reasonable for the particular disposal site but need not be based on assumptions judged to be unreasonable." (Note: This sentence is under consideration by the Technical Working Group for revision of Order 5820.2A. It will probably be used as guidance, with "reasonable assurance" included in the performance objectives.)

\subsubsection{Rationale}

The concept of reasonable assurance is an essential aspect of all licensing decisions by the NRC and its predecessor agency, the Atomic Energy Commission, and was first used in decisions

c. The Team is continuing discussion of the use of intruder dose objectives. For further discussion, see Section 2.20, "Inadvertent Intruder Dose Objectives." 
regarding construction and operating licenses for nuclear power reactors. Use of this concept takes into account that issuance of a license is the result of a judicial proceeding in which objective scientific proof of the future performance of any type of facility is not required and cannot be obtained. All that is required is reasonable assurance based on the preponderance of available evidence, including subjective judgements and mathematical analysis, that a facility will perform as required or expected. As described below, the concept of reasonable assurance has been adopted explicitly in regulations for radioactive waste disposal.

The NRC addresses the issue of reasonable assurance in its licensing criteria for geologic repositories intended for disposal of spent nuclear fuel and high-level waste in 10 CFR Part 60 in these terms: "While these performance objectives are generally stated in unqualified terms, it is not expected that complete assurance that they will be met can be presented. A reasonable assurance, on the basis of the record before the Commission, that the objectives and criteria will be met is the general standard that is required. For 60.112 , and other portions of this subpart that impose objectives and criteria for repository performance over long times into the future, there will inevitably be greater uncertainties. Proof of the future performance of engineered barrier systems and the geologic setting over time periods of many hundreds or many thousands of years is not to be had in the ordinary sense of the word. For such long-term objectives and criteria, what is required is reasonable assurance, making allowance for the time period, hazards, and uncertainties involved, that the outcome will be in conformance with such objectives and criteria. Demonstration of compliance with such objectives and criteria will involve the use of data from accelerated tests and predictive models that are supported by such measures as field and laboratory tests, monitoring data, and natural analog studies. ${ }^{15}$ Similar language regarding low-level waste is included in $10 \mathrm{CFR} 61.40 .^{6}$

The NRC, not the applicant, makes the finding of reasonable assurance. Thus, the applicant is expected to present the case and technical judgements, with all available supporting information, and leave it to the NRC to make the finding.

A similar philosophy is behind the phrase "reasonable expectation," used by the U.S. Environmental Protection Agency (EPA) in its containment requirements for disposal of spent fuel, high-level waste, and transuranic waste in 40 CFR Part $191,{ }^{7}$ and the EPA describes the meaning of reasonable expectation using much of the same language as in the description of reasonable assurance in the NRC's 10 CFR Part 60 given above. The test for compliance with release limits appears to be quantitative, at least in terms of a probability distribution, but the events selected and some of the input data are subjective judgements, to which the test of reasonable expectation applies. The individual protection requirement contains no probabilistic test.

The DOE format and content guidance document ${ }^{8}$ suggests providing justification and being conservative, but reasonable, rather than just analyzing the worst case. The results of the PA are to be reviewed at several levels, including by DOE-HQ and the PRP.

The degree to which predictions of events and consequences in the distant future can be compared to specific numerical limits is a matter of judgement, not mathematics. The DOE, NRC, and EPA appear to leave that judgement to independent review, and no better resolution of the issue has been suggested elsewhere. 
Discussions with site experts reveal that the wording of "assure that" sounds different, and perhaps stronger, than the objectives stated by other agencies in terms of design and reasonable assurance. The wording in the DOE Order 5820.2A should be changed to be consistent with the concepts of reasonable assurance and reasonable expectation incorporated in existing NRC and EPA regulations for radioactive waste disposal. Disposal of low-level waste in the near-surface environment presents the same challenges as disposal of spent fuel, high-level waste, and transuranic waste in geologic repositories in regard to the necessity of dealing with subjective judgements and large uncertainties in predicting the long-term performance of disposal systems.

\subsection{Passive Controls}

\subsubsection{Issue}

The current language for the dose objective in Section III.3.a.(3) of DOE Order 5820.2A implies that all controls cease at 100 years after disposal, which means that release scenarios should be applied at that time. Provision for passive controls, which include both institutional controls and engineered features, should be added. Otherwise, disposal could be restricted to

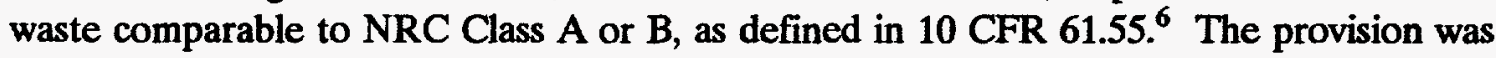
incorporated in the $1987 \mathrm{draft}$ of the DOE Order 5820.2A but was removed from the final version.

\subsubsection{Recommendations}

Language in Section III.3.a.(3) of DOE Order 5820.2A [loss of active institutional control (100 years)] has sometimes been taken to mean loss of all controls 100 years after disposal, which was not the intent. Instead, it is intended that disposal systems shall be designed to provide reasonable assurance that the potential dose to individuals who may inadvertently intrude into the facility after the active institutional control period (taken to be 100 years after closure) will not exceed 500 mrem for a single exposure or 100 mrem per year for exposure continuing over several years. Passive controls, including both engineered features and institutional controls (e.g., physical barriers, markers, long-term government ownership and control, and use restrictions), may be incorporated into the design to provide reasonable assurance that the performance objectives will be met. The time of effectiveness of passive controls must be specified and shall be justified.

\subsubsection{Rationale}

One of the objectives for disposal systems design involves protecting inadvertent intruders. The protection of deliberate intruders is neither feasible nor considered necessary in the history of rulemaking for disposal of low-level waste. For example, the NRC states in its draft Environmental Impact Statement (EIS) ${ }^{9}$ on 10 CFR 61, that the "NRC believes that deliberate intrusion into the disposal facility cannot reasonably be protected against, and it is not considered further." It is also not reasonable to try to provide any absolute guarantees, since future activities and events are uncertain. The EPA Science Advisory Board stated ${ }^{10}$ "We believe it is impractical to provide absolute protection to every individual for all postulated events or for very long time periods." 
Thus, the issue becomes protection of inadvertent intruders generally provided by institutional controls that may be active or passive. Active institutional controls include fences, patrols, alarms, monitoring instruments, and other activities requiring active attention, enforcement, and interdiction. It is generally agreed that active institutional controls should not be relied upon for more than 100 years. If protection beyond that time is needed, passive controls (both institutional and engineered features) may be provided. Passive institutional controls may include land use restrictions, government ownership, site dedication to nonintrusive uses, and other passive institutional means to limit access to the waste. Passive controls also include engineered features, such as long-lived markers, engineered barriers, special waste forms, burial depth, and special materials incorporated into the site closure system.

The intent of these controls is to notify or deter inadvertent intruders through official records and recognizable markers, alerting them by the presence of unusual materials in the system (recognizable as something other than dirt), or deterring them by system features that make intrusion difficult during normal activities. The NRC also considers a recognizable waste form to be a barrier to the more active types of intrusion. For example, NUREG- $0782^{9}$ states that "It is not credible to suppose that an individual would attempt to construct a house on or grow crops in a location characterized by large stacked metal cylinders filled with concrete."

Intruder exposures will generally be dominated by short-lived radionuclides $\left({ }^{137} \mathrm{Cs}\right.$ and $\left.{ }^{90} \mathrm{Sr}\right)$ for a few hundred years and by transuranic radionuclides for longer times. The former can be isolated by engineered systems, whether deep or shallow, but the latter will require separation from the effects of near-surface activities, since survival of engineered systems may not be credible over time frames beyond 1 or 2 millennia. Thus, greater depth, as well as notification, may be required to effect isolation of the waste.

From the above considerations, it is reasonable to expect the PA to identify waste from which intruders should be protected (i.e., remains hazardous beyond 100 years), through analyzing excavation and garden scenarios at 100 years after disposal, assessed against a dose objective of 500 mrem per year for acute exposures (or 100 mrem per year for exposures lasting several years or more). The intruder barrier could consist of $5 \mathrm{~m}$ of cover or an engineered barrier that would notify and deter inadvertent intruders for at least several hundred years. Application of the same scenarios at several hundred years would identify waste that requires a higher degree of protection.

If some of the waste requires a greater degree of protection, the designer may choose to provide a disposal system that essentially eliminates the effects of surface events (e.g., erosion, housing construction, or deep-rooted plants). Such systems would still be accessible by drilling, although "drilling inhibitors" such as basalt riprap or irregular concrete shapes (which would deflect the drill bit unpredictably and appear unusual in sediments) might be considered for additional protection. The time for application of the drilling scenario would be several hundred years, unless a longer period were justified by the designer and analyst, based on the longevity of a barrier that could be credibly demonstrated or predicted. 


\subsection{Dose Terminology}

\subsubsection{Issue}

The dose limits in DOE Order 5820.2A need to be consistent. At present, Section III-3.a.(2) of the order states the limit as "effective dose equivalent," whereas Section III-3.a.(3) states the limit as "committed effective dose equivalent," which appears to exclude external dose.

\subsubsection{Recommendation}

Dose limits are to be expressed as effective dose equivalent. The definition shall be the same as the definition in DOE Order $5400.5^{11}$ and International Commission on Radiological Protection (ICRP)-42, ${ }^{12}$ which included the committed dose (50 years) from internal deposition and the dose received from external exposure.

\subsubsection{Rationale}

There have been some differences in the past regarding the meaning of the terms "effective dose equivalent" and "committed effective dose equivalent." DOE Order 5820.2A uses both but does not provide definitions. Dose limits should include both external dose and committed dose from internal deposition. The term "effective dose equivalent," as defined in DOE Order 5400.5 and ICRP-42, includes both and should be used as the basis for other dose limits.

\subsection{Special-Case Waste}

\subsubsection{Issue}

Clarification of the definition of special-case waste (SCW) is needed. There is also a need to define disposal requirements for those kinds of SCW that are limited by PA, rather than by policy considerations.

\subsubsection{Recommendations}

The Team provided the following recommendations:

1. Define SCW according to current practice as "those wastes that have limited or no planned disposal alternatives."

2. Each disposal site shall develop specific limits on radionuclide concentrations or amounts for LLW through PA specific to the site and disposal system. Low-level waste that exceeds the limits for all planned disposal facilities at a DOE site is termed "performance assessment limited (PAL) waste" and may be disposed of at another DOE site having a disposal system that would be acceptable for that waste. Low-level waste that exceeds the limits for the disposal system having the highest degree of isolation 
within the entire DOE system shall be disposed of in a geologic repository or other suitable disposal facility newly designed for disposal of such waste.

3. Special case waste may be stored until disposal capability is developed.

\subsubsection{Rationale}

There are several types of SCW, including noncertificable defense transuranics, nondefense transuranics, fuel and fuel debris, sealed sources, DOE-titled (held by licensees), and excess nuclear materials. From the technical standpoint, those SCW wastes that are low level can be analyzed for disposal in the manner previously described. Some of these wastes are restricted by waste class or policy, neither of which is a PA issue.

The type of SCW of most interest to the Team is a category called PAL waste. This waste contains concentrations or amounts of radionuclides that might result in exceeding DOE performance objectives if disposed of in a specified disposal system at a specified site. Disposal systems having a greater degree of confinement might be feasible at such a site but not planned for institutional or economic reasons. Thus, PAL waste may exceed the limits for the specified disposal system but will not necessarily exceed the limits for the entire DOE site under consideration or for other sites.

For some potential PAL waste streams, disposal systems can be designed with the aid of current PA methodology, so that the necessary engineered features are included to provide the required degree of isolation. Some sites may have a low degree of natural isolation and may, therefore, find it cost effective to send PAL waste to a site or facility having a greater degree of isolation.

The site-specific PA will usually include an intrusion analysis (onsite) and a transport analysis through all pathways, including drinking water, to individuals at offsite locations. The intruder scenarios include excavation and agriculture and are usually applied at 100 years after disposal. These results should identify wastes that require intruder protection (natural or engineered features, including increased depth of disposal or better waste form) for periods beyond the time allotted for active institutional controls (100 years). If waste-disturbing scenarios such as agriculture and excavation are precluded by depth, passive controls, or other design features, the controlling scenario may be drilling at some future date. It is reasonable to expect that radionuclides with half-lives shorter than 50 years (e.g., ${ }^{90} \mathrm{Sr},{ }^{137} \mathrm{Cs}$ ) can be isolated for their entire period of decay by appropriate passive controls and engineered features. Long-lived radionuclides that are transportable in groundwater (e.g., ${ }^{14} \mathrm{C},{ }^{99} \mathrm{Tc},{ }^{129} \mathrm{I},{ }^{79} \mathrm{Se},{ }^{237} \mathrm{~Np}$ ) may be limited in amount or areal density through the groundwater pathway and the all-pathways dose limit. Thus, the primary result of the drilling scenario may be a limit on weakly transported, long-lived alpha-emitters such as ${ }^{239} \mathrm{Pu}$.

Some SCW is high in concentration but is contained in a very small volume (e.g., some sealed sources) and represents a relatively small amount of activity. This point is discussed later in "Concentration Averaging" (see Section 2.13). 


\subsection{Software Testing And Control}

\subsubsection{Issue}

Guidance is needed to determine the level of controls and testing required for software to be used for PA. Emphasis is needed on the importance of using site-specific data to provide a basis for demonstrating the ability of the code to model performance of a specific site.

\subsubsection{Recommended Policy for Software Testing and Control}

Software testing and control shall be applied within the existing framework of site quality assurance plans and policies. The exception to the software testing and control requirement is when regulations/regulators specify the use of specific software to provide data as required by regulations. The following paragraphs provide suggestions to improve confidence in PA codes, but are simply provided as information and not intended to be a substitute for existing quality assurance plans and policies.

A combination of verification and benchmark testing can be used to build confidence in the ability of the code and embodied model(s) to simulate macroscopic (plume-scale) behavior of a site-specific disposal system. Such testing is necessary for all codes used in support of a PA. When appropriate (e.g., groundwater and atmospheric transport codes) and sufficient data are available, calibration/validation experiments can also be conducted to build confidence in the ability of a code to predict site-specific laboratory or field-scale behavior. Since performance is typically evaluated at a macroscopic (plume) scale, calibration exercises should be conducted using existing plumes to demonstrate that the computer code can reproduce current conditions using parameter values within ranges found at the site. Existing characterization data should be used to the greatest possible extent. Predictions of future behavior can be made using the calibrated model that will be compared with future monitoring data as collected.

The following can be useful as part of the testing process: (a) software analysis of the programming in the computer codes, (b) input data for the test cases address conditions representative of the site to be modeled, (c) all options executed during the proposed application are exercised during testing, (d) a record of tested and untested options in the code is provided with the test results, and (e) computer codes documented and controlled through the use of a software management program as specified in DOE Order 1330.1C "Computer Software Management." ${ }^{13}$ Independent peer review of the testing process and results is also useful.

\subsubsection{Rationale}

Formal software testing and control have recently become issues of concern with respect to PA software. American National Standards Institute (ANSI) and Institute of Electrical and Electronic Engineers (IEEE) software engineering standards have been recognized and followed for many years in industry (e.g., banking, manufacturing). On the other hand, in the past, environmental models tended to be more academic or research oriented, and formal testing and control have not been required. Requirements for licensing a high-level waste repository were a primary driver in identifying the need to formally demonstrate the veracity of environmental modeling computer codes used as PA tools. Furthermore, the National Academy of Sciences has 
recently published a book emphasizing the need for appropriate use and testing of groundwater models for regulatory applications. ${ }^{14}$

Several regulatory standards and supporting documents that address software testing and control have been published. This information varies from generally applicable standards and requirements to documents and requirements addressing PA-specific issues and recommendations. These materials will be discussed first to provide background for the basis for the recommended approach. The testing approach discussed in this rationale is intended to build confidence in the capabilities of a computer code to model a given site as opposed to confirming that a code and the embodied mathematical models are correct representations of each of the processes considered by a code. The emphasis is on groundwater codes, but most of the concepts are directly applicable to other pathway codes as well.

\subsubsection{Regulatory Drivers and Supporting Documents}

American Society for Mechanical Engineers (ASME) NQA-1 and NQA-2 discuss a general set of quality assurance requirements applicable to nuclear facilities. Specific quality assurance (QA) requirements related to computer software are specified in Draft NQA-2, Part 2.7 (ASME NQA-2) ${ }^{15}$ and Supplement 11S-2 to NQA-1 (ASME NQA-1). ${ }^{16}$ NQA-2, Part 2.7 prescribes an approach to software management based on standards developed by the American National Standards Institute and the Institute of Electrical and Electronic Engineers (ANSI and IEEE.) ${ }^{17}$ NQA-1 (11S-2) discusses software test control. DOE Order $1330.1 \mathrm{C}^{13}$ establishes policies for software management in the DOE system. In general, DOE Order 5820.2A simply requires that a software management program based on an accepted software management methodology be developed at each site. These requirements are intended to be generally applied to all software; thus, some specifics may not be productive when applied to PA software. Furthermore, PA software has additional testing requirements not addressed by general standards; therefore, general guidance needs to be supplemented by guidance specific to PA software.

ANSI and IEEE have developed time proven, widely accepted Software Engineering Standards for software testing and control. The ANSI/IEEE standards are guidelines for developing, testing, and controlling of software from a variety of different industries. ${ }^{17} \mathrm{~A}$ handbook for software quality assurance techniques, which is based on ANSI/IEEE approaches, has also been prepared for the nuclear industry in general. ${ }^{18}$ These two sources are good resource documents for general software management methodologies but do not address some concerns specific to PA models.

Software testing and control requirements are mandated for license applications for commercial facilities in the NRC Standard Format and Content of a License Application for a Low-Level Radioactive Waste Disposal Facility ${ }^{19}$ and the corresponding review plan. ${ }^{20}$ Requirements specific to PA software are identified, including configuration management, documentation, verification, and calibration. Although DOE is not required to follow these requirements, it would be wise to maintain a level of consistency with the NRC commercial programs.

More specific guidance for documentation, testing, and control of PA software has been provided for the High-Level Waste Repository Program in two documents. ${ }^{21,22}$ The National 
Low-Level Waste Management Program (NLLWMP) has prepared Guidelines for Acquisition, Installation, and Testing of Performance Assessment Software, which provides guidelines for, and examples of, testing and control methods for PA software. ${ }^{23}$ A document discussing documentation and testing of groundwater codes has also been prepared for the EPA. ${ }^{24}$ Davis et al., ${ }^{25}$ which was prepared for the High-Level Waste Program, specifically discusses model validation. Each of these documents provides approaches for ensuring the veracity of results predicted by a computer code.

A book prepared by the National Academy of Sciences (NAS) ${ }^{14}$ addresses the proper use and testing of groundwater models for regulatory applications. The book includes recommendations for testing and documenting groundwater models. The book also emphasizes the need for realistic expectations for models used to aid in the regulatory decisionmaking process. Furthermore, discussions of the state-of-the-art and limitations of groundwater modeling when applied as long-term predictive tools are provided.

\subsubsection{Discussion}

The primary driver for software testing and control in the DOE system is DOE Order 1330.1C. ${ }^{13}$ More global QA-related drivers that address computer software are NQA-1 and NQA-2, Part 2.7. ${ }^{15}$ Such general QA requirements typically demand some form of software management program. Such a general program includes software configuration management and verification and validation testing throughout the life cycle for the software. Several sources for approaches to software management were discussed previously. The following text discusses specific concerns for PA software.

Many of the general requirements and standards are written to apply to a variety of industries that use software. As expected, some aspects of the standards do not directly apply to PA software. The primary conflict with PA software is related to the software development cycle as prescribed in NQA-2, Part 2.7 and ANSI/IEEE. Computer codes used for PAs have already been developed. Comprehensive testing for the intended application is critical, but backtracking documentation to address the development process is not as critical. Thus, PA software is typically documented as existing software. Likewise, testing emphasizes capabilities of the existing code as opposed to backtracking through development. The PA-related documents ${ }^{14,21,22,23}$ are applicable to existing software and focus less on the development process. However, new codes that are being developed should address software life-cycle requirements in accordance with ANSI/IEEE and NQA-2, Part 2.7.

An appropriate approach for documentation and control of software can be developed based on the approaches discussed in one or more of the documents from the previous section (i.e., References 13,15, 17, 20, and 21). Because of widespread acceptance of the general standards, it is recommended that the selected approach conform (understanding the limitations related to existing software) to the approaches described by ANSI/IEEE ${ }^{17}$ and NQA-2, Part 2.7.15 Wilkinson and Runkle ${ }^{22}$ provide a self-contained approach that references ANSI/IEEE, NUREG$0856,{ }^{21}$ and other standards. In this respect, Wilkinson and Runkle ${ }^{22}$ is a good single source for an approach to PA software management. However, more detailed considerations and examples related to testing are provided by $\mathrm{NAS}^{14}$ and Seitz et al. ${ }^{23}$ 
The NAS ${ }^{14}$ book expressed concerns about the application of groundwater models. Many of these concerns apply to other models as well. A number of independent reviews of the application of models for regulatory compliance have been conducted. These reviews severely criticized the way models have been used for regulatory assessments. The following testing approach is intended to address many of these concerns.

Generally applicable regulations typically require computer code verification and validation. Validation is defined two different ways; in a general sense, it refers to ensuring that the computer code meets all the requirements specified before development. This generally applicable definition for validation is "the process of evaluating software at the end of the software development process to ensure compliance with software requirements. ${ }^{17}$ Validation with respect to PA codes relates more to the ability of the mathematical model embodied in the computer code to represent processes as they occur in the field. A definition for validation in this respect is "assurance that a model as embodied in a computer code is a correct representation of the process or system for which it is intended."21 Validation of PA models has been a matter of doing some site-specific laboratory and (or) field testing to build confidence as opposed to actually "validating" a model for predicting long-term performance of a waste disposal system. Validation for long-term PA applications is discussed further in Seitz et al., ${ }^{23}$ van der Heijde, ${ }^{24}$ and Davis et al. ${ }^{25}$

As previously stated, two types of testing are recommended: verification and validation (as defined for PA models). For the purposes of this rationale, each of the categories is divided into two categories, with four types of testing: verification, benchmarking, calibration, and validation. Furthermore, an additional type of testing that should be conducted as part of the verification/benchmarking process is software analysis. Seitz et al. ${ }^{23}$ and van der Heijde ${ }^{24}$ provide more detail regarding the following testing approaches. Each type of testing is briefly discussed in the following paragraphs.

Software analysis is used to check the accuracy of programming and to identify the extent of the code that is tested by the test cases. Three different types of software analyses are discussed in Seitz et al.:23 (1) cross reference, (2) complexity, and (3) coverage. Cross-reference analysis examines the proper use and storage of variables in the code. Complexity analysis identifies the most complex (i.e., error-prone) subroutines in a computer code. Coverage analysis identifies areas of the code exercised by a test case. The need for software analysis is also discussed in van der Heijde. ${ }^{24}$

Verification testing is conducted to assess the accuracy of the programming or numerical approach implemented in a computer code. Such testing is conducted by comparing the results predicted by the computer code to results obtained with an analytic or pseudoanalytic solution for a given problem. Analytic or pseudoanalytic solutions are generally only available for relatively simple problems. However, the comparisons for these simple problems are a direct reflection of the accuracy of the numerical approximation obtained with the computer code.

Benchmark testing is an extension of verification testing to include more complex application-oriented problems. Since analytic or pseudoanalytic solutions are not generally available for relatively complex problems, the comparisons are made using one or more other computer codes that can model similar processes. In this respect, the comparison is not a direct 
reflection of the accuracy of the solution. However, benchmarking builds confidence in the capability of a code by providing an indication of the consistency between the results of two or more computer codes. Therefore, it is important that the comparison codes have some recognition in the technical community. Benchmarking also provides an indication of the ability of a computer code to model conditions for a specific site.

Where applicable, calibration and validation are included to assess the ability of a computer code (and mathematical model) to represent a site-specific field system (some tests may be laboratory scale) as opposed to matching results of an analytic solution or another computer code. Because this is a comparison with actual field data, there is a need to collect a relatively large amount of site-specific data for the comparisons. Furthermore, to actually validate the accuracy of a model, one would have to extrapolate field conditions for at least 1,000 years, possibly millions of years (if peak concentration is the compliance standard regardless of time). It is clear that we cannot predict field conditions for those time frames with much accuracy; thus, it should be clear that a model most likely cannot be "validated" for a waste disposal system that will remain hazardous for long periods. In this regard, calibration and validation are used to build confidence in the ability of a computer code and model to predict system behavior as opposed to "validating" that the model can accurately predict long-term behavior.

Based on the above concerns, an approach is needed to provide some justification for the ability of a computer code and model to predict site-specific system behavior. The limitation stated previously was the result of a lack of data. At DOE sites this may not be as large a concern as at commercial sites, because a large amount of data have been collected over time for a variety of purposes. The most efficient approach to calibration/validation would be to take advantage of data that already exist (and collect additional data as needed). For example, DOE Order 5820.2A, Chapter III, Section 3b(3) states "Where practical, monitoring measurements to evaluate actual and prospective performance should be made at locations as required, within and outside each facility and disposal site. Monitoring data should also be used to validate or modify the models used in performance assessments." ${ }^{11}$ Thus, an effective means of building confidence in the ability of a model to predict performance is to use data collected for plumes that exist on the site.

The models should first be calibrated using the best available ranges of site parameters to reproduce the current or past conditions at the site. This demonstrates the ability to reproduce past system behavior. The next step would be to predict performance into the future and then collect monitoring data to assess the accuracy of the predictions. This would provide limited evidence of the ability to predict future performance. Further discussion is provided in Seitz et al., ${ }^{23}$ van der Heijde, ${ }^{24}$ and Davis et al. ${ }^{25}$ A case study illustrating such an approach to calibration and validation is presented in the book by the NAS. ${ }^{14}$

Some general considerations about the testing process should be discussed. First, test cases should be conducted as much as possible for conditions expected at the site. A test case considering 100 in. of rainfall a year does not provide much evidence about a model's capability to model the NTS. This is obviously the purpose of calibration/validation testing, but it also applies in verification and benchmarking. Also, testing documents should include a discussion of the tested and untested options in the code. All options used for a given application should have been tested. In this respect, it is not necessary to demonstrate that the whole code has been 
tested, but the parts used for the application need to be tested. Furthermore, independent peer review of the testing program should be conducted to increase defensibility of the PA predictions based on the use of a given computer code.

\subsection{Data Quality}

\subsection{1 lssue}

How shall data quality be established for a PA?

\subsubsection{Recommendation}

The PA data base shall be documented in a manner that will allow evaluation of data representativeness, accuracy, precision, and ranges of applicability. Data quality is achieved when there is sufficient documentation of the data to ensure auditability and traceability.

\subsubsection{Rationale}

The validity and defensibility of long-term predictions of isolation performance depend greatly on the quality of the data used. The conduct of a PA for a low-level waste site typically requires a broad spectrum of data, e.g., hydrology, geology, geochemistry, and meteorology. Some of these data are used in the interpretation of site characteristics and the formulation of conceptual models for specific mechanisms and processes. Other data are directly used as input to PA computer models.

The process of developing a PA data base for a specific site typically involves a high degree of synthesis. In other words, the data base is synthesized from historic information, recently collected laboratory and field data, and generic or reference data from handbooks, textbooks, and scientific literature, and technical data bases. These data will possess different degrees of documentation.

These data should be "qualified" by a review process that establishes

- Auditability and traceability of the measurement and interpretation techniques

- Pedigree of the data in terms of accuracy, precision, and ranges of applicability

- Representativeness of data relative to the site characteristics and conditions.

The review process can qualify the data on the basis of the availability of appropriate sampling and analysis plans, detailed technical reports on the laboratory or field measurement and its interpretation, comparison of data with other indirect evidence, and acceptance of the source document (i.e., textbook, handbook, and data base) by the technical community. 
For the purposes of auditability and traceability, the data files used as input PA computer codes should be archived on electronic storage media, e.g., PC diskettes, magnetic tape, or cartridges.

\subsection{Site-Specific Groundwater Codes}

\subsection{1 lssue}

How should computer codes used for the groundwater pathway be selected for low-level waste site PAs?

\subsubsection{Recommendations}

Groundwater flow and transport codes shall be selected on the basis of their applicability to the hydrogeologic setting of the waste site and compliance instrument requirements. At any given site, the codes shall be standardized to a reasonable degree. The selected computer codes shall be

- Well documented in the form of a theory document and user's manual

- Maintained under a structured software QA and configuration management

- Verified and benchmarked as applicable to the site in a formal manner.

In addition, the applicability of the selected computer codes shall be demonstrated, to the extent possible, by validation testing, i.e., comparing model results with field data.

\subsubsection{Rationale}

Modeling of the groundwater pathway generally requires applications of several computer codes to predict (a) infiltration rates, (b) seepage velocities and contaminant transport through the vadose zone, and (c) groundwater flow fields and contaminant plumes. To apply these codes, various data base and preprocessor codes are applied to generate input data (e.g., porosity and permeability distributions, boundary conditions, and computational grid). In addition, the output of the simulation codes must be postprocessed to generate performance indicators such as

- $\quad$ Flow path (streamlines or pathlines) and travel time maps

- Contaminant fluxes at designated boundaries

- Concentration histories at the point of compliance.

Thus, standardization of codes for the groundwater pathway would require standardization of a broad set of codes (i.e., flow and transport codes, preprocessor, postprocessor, and data base codes). 
Although the concept of having a standardized set of computer codes is appealing, a number of problems and limitations are associated with standardization of groundwater codes. Some of the major problems associated with standardization are

- No single set of codes has been demonstrated to be scientifically valid and applicable to the diverse hydrogeologic setting of all the DOE facilities. In fact, recent benchmarked testing $^{26}$ of popular DOE groundwater codes demonstrated that the codes have distinct ranges of applicability.

- A requirement to use a specific set of computer codes would stifle innovation and use of newer more reliable predictive tools

- The use of a so-called standardized set of DOE-approved codes would create an "implied warranty" of the model reliability and accuracy that could lead to misuse of the codes

- Each of the major DOE laboratories has developed fluid flow and contaminant transport codes that apply to the unique hydrogeologic setting of their sites. These site-specific codes have been developed, tested, and applied over several years. Changing to a different set would, therefore, represent a significant loss to many of the DOE sites.

A study by the National Research Council on the scientific and regulatory applications of groundwater models recently concluded that "...Agencies cannot specify a list of governmentapproved models. A model that is appropriate for one problem may not be, and probably is not, applicable to another problem..."14

\subsection{Apportionment of Dose Objectives}

\subsection{1 lssue}

Some sites may have the potential for releases to groundwater or other pathways from more than one facility, and it might be possible for plumes resulting from such releases to overlap. Application of PA objectives to such cases needs clarification.

\subsubsection{Recommendation}

If there is a potential for future exposures from more than one facility subject to the requirements of DOE Order 5820.2A to overlap, the PA shall consider the combined impacts and present data for the combined exposure at the point and time of maximum impact for comparison with dose limits. The predictions may consider the times at which exposures might occur, so that impacts are combined at the specific times predicted, rather than simply adding peak impacts at different times. 


\subsubsection{Rationale}

The performance objectives apply to total site impact of LLW regulated by Section III.3.a of DOE Order 5820.2A rather than to each facility individually. However, space and time separation of potential plumes should be considered rather than arbitrarily adding peaks that may occur at different times and places.

\subsection{Point of Compliance}

\subsubsection{Issue}

DOE Order 5820.2A specifies performance objectives for disposal of low-level waste at DOE sites. The performance objectives are intended to provide protection of (a) members of the public who might be exposed to radionuclides released to the general environment, (b) inadvertent intruders onto disposal sites following loss of active institutional control, and (c) groundwater resources that might be contaminated by releases of hazardous materials from disposal facilities. The order also defines a low-level waste disposal site as consisting of disposal units (i.e., discrete portions of the disposal site into which waste is placed for disposal) and a surrounding buffer zone, which is defined as the smallest region beyond disposal units that is required as controlled space for monitoring and for taking any needed mitigative measures.

Given the different performance objectives for members of the public and inadvertent intruders and the definition of a disposal site as including a buffer zone around disposal units, it seems reasonable to presume that the boundary of the buffer zone would separate the regions that could be occupied by members of the public and inadvertent intruders. However, there are two issues that are not resolved in the order.

1. What is the extent of the buffer zone; i.e., how far from disposal units can the buffer zone be assumed to extend for purposes of distinguishing between regions occupied by members of the public and inadvertent intruders?

2. At what locations should the performance objectives for protection of groundwater resources be applied? In particular, should the performance objective apply at any location, or should locations within the disposal site be excluded?

\subsubsection{Recommendations}

(1) The recommendation on the point of compliance for the performance objective for members of the public, as defined by the buffer zone, is stated as follows.

The buffer zone separating regions assumed to be occupied by members of the public and inadvertent intruders shall be defined in the site-specific PA but shall not extend more than $100 \mathrm{~m}$ from any disposal unit. However, during the period of active institutional control over the disposal site, the disposal site operator may assume, with proper justification to be given in the PA, that control will be maintained over a larger region (e.g., up to the present boundary of the reservation at the particular DOE site). 
The recommendation that the extent of the buffer zone be defined in the site-specific PA takes into account the possibility that, at some disposal sites, uncontrolled areas accessible to members of the public at the present time could be located within $100 \mathrm{~m}$ of disposal units. However, at sites where disposal facilities are located a considerable distance from any uncontrolled areas, a buffer zone up to $100 \mathrm{~m}$ in extent may be assumed in a PA. The second part of this recommendation requires that active institutional controls be maintained over a substantial area for up to $\mathbf{1 0 0}$ years after closure of the disposal facility.

(2) The recommendation on the point of compliance for the performance objective for protection of groundwater resources is stated as follows.

The performance objective for protection of groundwater resources may be applied only at locations outside the boundary of the buffer zone.

As in the recommendation on the point of compliance for members of the public, it is expected in most cases that a buffer zone of $100 \mathrm{~m}$ will be assumed in assessing compliance with the performance objective for protection of groundwater resources.

Given these recommendations, the performance objectives for offsite members of the public and protection of groundwater resources shall be applied at the locations where the predicted doses to offsite individuals and radionuclide concentrations in groundwater attain their maximum values. Two points should be noted concerning these locations. First, the maximum dose to offsite individuals and radionuclide concentrations in groundwater may not occur at the boundary of the buffer zone. Rather, they could occur at some distance beyond the buffer zone, e.g., if contaminant plumes from different disposal units intersect beyond the boundary. Second, the locations of maximum dose to offsite individuals and maximum radionuclide concentrations in groundwater are not necessarily the same. Different locations for applying the two performance objectives could result, for example, if offsite releases of radionuclides by transport pathways other than groundwater contribute significantly to the dose to offsite individuals.

\subsubsection{Rationale}

The definition of the buffer zone as extending no more than $100 \mathrm{~m}$ from any disposal unit is somewhat arbitrary but is based essentially on two factors. First, as stated previously, the buffer zone is defined in the DOE order as the smallest region beyond the disposal unit that would be required for monitoring and taking any necessary remedial actions. The Team believes that a buffer zone of $100 \mathrm{~m}$ would be sufficient, but not unreasonably large, for the stated purposes. Second, a buffer zone of $100 \mathrm{~m}$ is sufficiently small that the number of individuals who could be classified as inadvertent intruders (hypothetical individuals who come into contact with the waste or contaminated soil between disposal units) by occupying the disposal site would not be large. The notion that inadvertent intruders would be few is implicit in the DOE performance objectives and in the NRC's performance objectives for commercial disposal facilities in 10 CFR Part 61.

In recommending that the disposal site operator may assume that, during the period of active institutional control over the disposal facility, members of the public would be restricted to the region beyond the buffer zone and up to the present boundary of the reservation at the particular DOE site, the Team assumes that there are likely to be other ongoing activities (e.g., 
research, development, production, or environmental restoration) on the reservation and that such activities would require controls over the larger region. However, the use of this assumption must be justified in the PA. The Team also notes that, if disposal facilities perform as expected, the location of the compliance point for members of the public at distances well beyond the 100-m buffer zone for the first $\mathbf{1 0 0}$ years after facility closure should have little effect on the acceptability of disposals, because releases of radionuclides beyond the boundary of the disposal site should be insignificant during that time.

The recommendation to apply the performance objective for protection of groundwater resources only at locations beyond the boundary of the buffer zone also is somewhat arbitrary and is based essentially on two factors. First, the Team presumes that groundwater is a resource to be protected for use by members of the public but that the term "members of the public" in this context reasonably can exclude the small number of potential inadvertent intruders. This rationale is consistent with the groundwater protection requirements, developed by the EPA for high-level waste disposal, in 40 CFR Part $191 .^{7}$ Within the controlled area above a repository, the EPA focused on protecting only so-called special sources of groundwater, which presumably are not present at DOE LLW disposal sites. Second, because the buffer zone extends only a small distance from disposal units, the Team presumes it to be unlikely that the maximum concentrations of radionuclides in groundwater at the disposal site would be very much greater than the maximum concentrations beyond the buffer zone. Thus, inadvertent intruders would still be afforded a reasonable degree of protection from use of contaminated groundwater at the disposal site.

In recommending that the performance objective for protection of groundwater resources be applied only beyond the boundary of the buffer zone, the Team also recognizes that the states may impose more restrictive requirements. That is, the states may require that the performance objective be applied at some or all locations at the disposal site itself. If more stringent requirements are imposed, then they shall be included in the performance objectives to be met by the disposal facility.

\subsection{Groundwater Dose Objective and Compliance}

\subsubsection{Issue}

The performance objectives in DOE Order 5820.2A currently defer to other federal and state standards for groundwater protection limits, although existing drinking water sources have specific limits. The issue is whether a specific groundwater limit should be set for PAs in response to the developing intent to protect groundwater as a resource. For such protection, it is not clear how compliance is to be demonstrated in terms of modeling lateral and vertical dispersion, potential pumping rate and well size, or well completion and use practices that may define the effective source volume at the point of groundwater use.

\subsubsection{Recommendations}

The current performance objective of complying with existing federal and state standards should remain, while recognizing that the EPA has proposed that the beta-gamma limit of 
$4 \mathrm{mrem} / \mathrm{year}$ should be stated in terms of effective dose equivalent rather than organ dose and that specific limits for alpha-emitters have also been proposed. ${ }^{27}$

If no specific standards for groundwater are in effect at a given site, analysts have the option of using Maximum Contamination Levels (MCLs), based on the Proposed Rule, ${ }^{27}$ as benchmarks for comparisons with modeling predictions. This practice may sometimes be useful in demonstrating protection of groundwater as a resource, a requirement that is expected in the near future. Protection should be defined in terms of the concentrations at the wellhead (or surface discharge zone, if applicable) for the appropriate drinking water or irrigation uses. Area-specific aquifer parameters, water use practices (i.e., well size, usage rate, and irrigation practices), and well-completion practices (i.e., screen depth and other appropriate parameters) may be used to define the effective source volume.

\subsubsection{Rationale}

The EPA sets limits for existing water supply systems but generally defers protection of groundwater to the states, with a generic goal of protecting groundwater as a future resource (meaning undefined). In addition, the EPA has proposed revised maximum contaminant levels (MCLs) (based on the new dose system), and some states are in the process of developing policy and standards. Considering the current regulatory uncertainty, the present form of the DOE performance objective is proper. However, groundwater protection policy is developing rapidly in some states, so some sites may need to consider a more specific objective. At least as a benchmark for comparison with groundwater modeling results, the proposed MCLs provide a reasonable set for comparison.

Aquifer properties, water use practices, and well completion practices vary widely, so areaspecific practices and parameters should be used for modeling. The purpose would be to show protection of groundwater for drinking water, and the analysis should consider appropriate well sizes, pumping rates, completion practices for the potential use, and EPA or state practices for monitoring contaminant concentrations at the wellhead or discharge point to surface water (including mixing zone, if appropriate).

One factor that may be difficult to model is the vertical distribution of potential contaminants. However, the vertical extent of the zone from which water is drawn is defined by the length of the screened opening installed in the well, and this length could be used as a minimum unless modeling or measurements show that a greater vertical extent is reasonable. A brief survey of the sites revealed screen lengths of $15 \mathrm{ft}$ at Hanford (specified by EPA Region X), 15 to $28 \mathrm{ft}$ at ORNL for monitoring at SWSA-6, $20 \mathrm{ft}$ at SRP, 22 to $200 \mathrm{ft}$ at INEL, and up to several hundred feet at LANL. It is appropriate to use a screen depth near the minimum, unless local factors or models justify some other assumption.

Another insight is available from the EPA comments on the groundwater model used in development of the NRC Rule for disposal of LLW. The NRC took a very conservative approach to dilution in the draft $\mathrm{EIS}^{9}$ for $10 \mathrm{CFR}$ 61. Leachate transported through the soil from the waste was diluted by only the amount of water pumped from the well, either $550 \mathrm{~m}^{3} / \mathrm{d}$ or $20 \mathrm{~m}^{3} / \mathrm{d}$ for two different scenarios, thus taking no credit for dispersion whether vertical or horizontal. It appears that further analysis of this conservatism was not considered to be 
necessary because percolation through the waste site was assumed to be relatively high $(3 \mathrm{~cm} / \mathrm{year}$ or more), so the percolating water already supplied substantial dilution. Thus, substantial averaging was recommended, including use of the full depth of the aquifer. The full depth might be too much in cases where the top aquifer is many tens of meters thick, although appropriate for those that are only a few meters thick.

\subsection{Long-Term Changes and Effects}

\subsubsection{Issue}

Long-term changes, such as climate change, ice ages, volcanism, earthquakes, or erosion, may impact the performance of the disposal system. The issue is the degree to which these potential impacts should be included.

\subsubsection{Recommendations}

Each site PA should consider the effects of expected long-term changes to the degree that such changes may significantly impact the isolation capability of their disposal systems within the time period covered by the PA. Events and processes with small impact and probability should be omitted. Generally, a qualitative discussion will suffice.

To demonstrate compliance with performance objectives, long-term calculations based on present conditions (including present rates of natural processes such as erosion) should be carried out.

\subsubsection{Rationale}

Projection of impacts from disposal sites frequently goes far into the future, so that longterm processes and infrequent events may need to be considered. The events and processes are highly site-specific, so each site should choose to include only those that are pertinent to the individual site. Events and processes with small impact and low probability should not be allowed to dominate the facility design. They should be included only if the time frame for the analysis and the longevity of the hazard combined indicate that the event or process is actually expected over the time period of the assessment. Examples are mesa erosion at LANL, ice age effects at Hanford in the 10,000-year time frame, climate change at some sites, and volcanism at the INEL.

\subsection{Performance Assessment Approval, Compliance Requirements, and Maintenance}

\subsection{1 lssue}

The process for review and approval of PAs needs to be established. Design, operating, and closure criteria resulting from the PA need to be defined, documented, and enforced, since the PA provides the long-term safety basis for the facility. The requirements to maintain a PA and use monitoring to validate and modify the models need to be defined. 


\subsubsection{Recommendations}

Performance assessments, prepared for disposal activities to provide reasonable assurance of meeting the performance objectives, must be reviewed and approved by the Deputy Assistant Secretary for Waste Management (EM-30). Review will be conducted by the Office of Waste Operations (EM-32) to assess consistency with site mission and goals; by the Office of Program Support (EM-33) to assess compliance with DOE orders and applicable regulations; and by the Office of Technical Support (EM-35) to assess technical adequacy and consistency.

For new disposal facilities, the preliminary performance assessment will be submitted to, and approved by, the responsible operations office before construction begins. The final performance assessment will be submitted to, and approved by, the Deputy Assistant Secretary for Waste Management (EM-30) before operation of the disposal facility. For existing facilities that continue to accept waste for disposal, the final performance assessment will be submitted to EM-30 within one year after the effective date of this order, or the facility will discontinue accepting waste for disposal. Operations offices will provide information to EM-30 regarding status and schedule for the performance assessments for existing facilities, along with a summary of results (if available) and any indications that modifications of current practices might be necessary.

Technical review shall be provided by experts in the field organizations and the PRP. The internal peer review process shall be documented in the PA. Any additional review shall be specified by EM-30 before submittal of the final PA.

The PA results shall be used to establish any design, operating, and closure criteria that may be essential to maintaining public health and safety and protecting the environment after the facility is closed. Design and operating requirements that affect long-term safety or result from the PA (limits on concentrations or amounts of radionuclides, limits on void spaces, stability requirements, others) shall be documented in appropriate facility design and operating manuals and procedures. Criteria not involving immediate safety issues need not be incorporated as operational safety requirements (OSRs) but must be in a document format that is enforceable and auditable. Related design requirements shall be incorporated into the facility design criteria. Operating requirements shall include, but not be limited to, the waste acceptance criteria required by Section 3.e. of Chapter III of DOE Order 5820.2A. Environmental criteria related to final closure shall be documented in the Closure Plan required by Section 3.j.(1) of Chapter III. It is expected that the PA, related requirements documents, and closure plan will be part of the transmittal package in support of a request for approval of facility construction.

The PA shall be maintained and updated, as needed, during the life of the facility. Field experiments needed to verify PA assumptions and improve the credibility and defensibility of performance projections shall be planned and performed as part of facility operations. This may include lysimeter (or other) tests with example waste forms to establish infiltration rates, cover performance, release rates, and parameters affecting release rate and transport. The planned experimental program shall be documented as part of Section 4.4, "Continued Work," of the PA. 
The PA shall be periodically reviewed and updated, if needed, to incorporate changes in operations and conditions, new data that may be developed, and any new design features that may be added. The review shall be performed at least every five years and before closure.

Facility managers shall establish an enforcement program to ensure that waste acceptance criteria, operating criteria, and eventual closure criteria are met. The program should include audits, verification of generator certification methods and operations, selective verification of arriving waste shipments, reporting and technical review of waste data, and the periodic updates.

\subsubsection{Rationale}

Regulation of waste disposal facilities is somewhat different from regulation of other nuclear facilities, in that safety and environmental issues beyond the operating period must be addressed. For nondisposal facilities, the safety analysis report (SAR) is used to define the safety envelope and technical safety requirements (TSRs), as well as establishing monitorable release limits. For a disposal facility, the SAR stops at closure and the PA continues the safety analysis into the indefinite future. The disposal facility will be monitored but generally the releases to the environment should be zero, so adherence to limits must be based on the PA predictions and experimental tests of near-field performance. Those predictions depend directly on the radioactive inventory, and that inventory must be characterized and controlled, since monitoring is not likely to provide any confirmation of the source term and release properties.

One of the purposes of the PA is to establish design features and waste acceptance criteria. For this purpose, it is necessary to have the results available in time to affect design and construction, which means before construction is authorized, although not necessarily before design is initiated. This schedule will help to ensure that the facility will comply with applicable requirements before major commitment of resources.

Some results of the PA may influence facility design, operations and closure requirements, determine waste acceptance criteria. Those requirements need to be reflected in appropriate requirements documents to ensure that initial assumptions in the PA are carried through to the actual facility. Design requirements could include such items as trench depth and vault mechanical parameters (if used). Operating requirements could include backfill techniques for minimizing voids, interim cover practices, and control of surface water and infiltration. Closure requirements, especially the final engineered barrier, are critical PA inputs, since these usually determine the level of intruder and groundwater protection. However, few, if any, of these requirements will be of such immediate importance to safety that they would need to be incorporated into TSRs. Nevertheless, some means to track and enforce the requirements is necessary, and each site will need to select such a method.

Maintenance of a PA includes activities needed to ensure that the long-term release and dose limits will be met, essentially as a surrogate for the real-time monitoring of an operating facility. There are two major factors: (1) monitoring the construction, operation, and waste receipts to see that they conform to the assumptions in the PA, and (2) a long-term, iterative process of model development, verification, and field and laboratory experimentation throughout the life of the facility, including determination and refinement of values for parameters critical to the PA. Monitoring the operational phase should include periodic comparisons of activities 
against the PA, and reanalysis of performance, if necessary. This should be done whenever any major deviation from projections is noted, otherwise at least every five years, and before closure to support a closure application. The long-term process will be highly site-specific, so a plan for this activity should be submitted as part of Section 4.4 of the PA for review. Measurements of actual releases to the environment may not be possible, but some combination of vadose zone monitoring, waste form release tests (lysimeters), infiltration tests, and tests involving proposed final covers should be conducted. This activity will improve the credibility and defensibility of the PA, and support a closure decision.

\subsection{Concentration Averaging}

\subsection{1 lesue}

For disposal of DOE low-level waste, analyses of scenarios for transport of radionuclides into groundwater and inadvertent intrusion into disposal facilities will be used to develop sitespecific waste acceptance criteria in the form of limits on concentrations and/or inventories of radionuclides. In developing such waste acceptance criteria, guidance is needed on the extent to which radionuclide concentrations can be averaged over particular volumes larger than the volume of individual waste forms or packages. If some form of volume averaging is permitted, guidance is needed on systems for tracking past waste disposals and applying controls on future disposals, in order to ensure that the waste acceptance criteria will be met when disposals are complete.

\subsubsection{Recommendations}

In developing recommendations concerning the types of volume averaging of radionuclide concentrations in low-level waste that should be permitted in establishing waste acceptance criteria at DOE disposal sites, the Team assumes that any disposal facility has a known volume established by engineering design. Therefore, regardless of whether waste acceptance criteria are based on analyses of scenarios for direct intrusion into disposal units, which would lead to limits on radionuclide concentrations, or on analyses of scenarios for release to groundwater, which usually would lead to limits on radionuclide inventories, the resulting acceptance criteria essentially are the same-namely, limits on average concentrations of radionuclides that are acceptable for disposal-because, for a fixed volume of a disposal facility, limits on average concentrations of radionuclides are equivalent to limits on total inventories.

Given the equivalence between average concentrations and total inventories of radionuclides in a particular disposal facility, the Team makes the following recommendations on acceptable procedures for concentration averaging of radionuclides for purposes of establishing site-specific waste acceptance criteria.

1. The use of any method for averaging radionuclide concentrations in waste that would permit concentrations in individual waste forms, waste packages, or waste streams to exceed limits established in the waste acceptance criteria for a particular disposal facility shall be described and justified in the site-specific performance assessment.

2. If a disposal facility consists of more than one type of disposal unit intended for disposal of different types of waste, then methods for averaging radionuclide 
concentrations shall be applied separately to each type of disposal unit (i.e., concentration averaging over different types of disposal units within a disposal facility shall not be permitted).

3. Regardless of any method for averaging radionuclide concentrations in waste that might be used at DOE disposal sites, the concentrations of radionuclides in individual waste streams or waste forms prior to disposal shall not exceed the Class-C limits for commercial waste established by the NRC in 10 CFR Part 61.

4. Averaging of radionuclide concentrations over the volume of individual waste packages after disposal (including the volume of any overpacks intended for use as an engineered barrier in the disposal system) normally should be permitted, provided the size of the waste package and any overpacks is appropriate for the disposal system. A possible exception is discussed in the seventh recommendation.

5. If acceptable disposals are based on a scenario in which multiple disposal units of the same type and at the same general location are assumed to be accessed, then the appropriate volume for averaging radionuclide concentrations would be the entire volume of the disposal facility, including any uncontaminated regions between individual disposal units and within each unit. Examples where such an averaging procedure normally should be appropriate include scenarios for release of radionuclides to groundwater and scenarios for inadvertent intrusion involving an excavation of considerable areal extent (e.g., in constructing a foundation for a home). However, the appropriateness of this type of averaging procedure for intrusion scenarios would depend on the assumed size of an excavation relative to the size of individual disposal units and the spacing between units.

6. If acceptable disposals are based on a scenario in which only individual disposal units are assumed to be accessed, then the appropriate volume for averaging radionuclide concentrations would be the volume of individual disposal units (including any uncontaminated regions within each unit) but the uncontaminated regions between individual disposal units would not be included. An example where such an averaging procedure normally should be appropriate is a scenario for inadvertent intrusion involving drilling into a disposal facility, because only a volume smaller than the volume of individual disposal units would be accessed.

7. If acceptable disposals are based on a scenario in which only individual waste forms are assumed to be accessed, then an averaging of radionuclide concentrations even over the volume of individual waste packages may be inappropriate. An example could be a scenario for inadvertent intrusion involving direct contact with an intact, activated-metal waste form.

The recommendations presented above describe how concentration averaging of radionuclides may be used in a performance assessment to establish site-specific waste acceptance criteria. The Team then makes the following recommendations on procedures for implementing waste acceptance criteria that would permit concentration averaging of radionuclides. 
1. Unless a disposal site operator chooses to apply concentration limits of radionuclides (as obtained from a performance assessment for inadvertent intrusion or releases to groundwater) to individual waste packages or waste forms, implementation of any method that permits concentration averaging over individual disposal units or an entire disposal facility requires development of a recordkeeping system to track concentrations and inventories in past disposals and to provide updated information to waste generators on disposals that would be acceptable in the future in order to ensure that the average concentrations at the time of facility closure meet the site-specific waste acceptance criteria.

2. In developing a recordkeeping system for implementing methods for concentration averaging of radionuclides in waste, special consideration should be given to those few waste packages or waste forms in which radionuclide concentrations exceed the limits of waste acceptance criteria by a substantial amount (e.g., a factor of ten or more), or the radionuclide inventories exceed a substantial fraction of the limits (e.g., 10\% or more). The types of considerations that might be needed in these cases include both requirements for advance warning and/or special approvals before shipping for disposal and provisions in the design of the disposal facility to ensure that such unusual wastes would be relatively inaccessible after disposal.

3. Increases in the size of disposal facilities merely to provide a greater dilution of wastes (i.e., reductions in average concentrations over the disposal facility) shall not be permitted. Considerations on the optimal size of disposal facilities should take into account such factors as cost, site conditions, the amount of land dedicated to disposal, the extent of environmental degradation resulting from facility construction and operation, and the expected concentrations and inventories of radionuclides in waste intended for disposal in the facility.

\subsubsection{Rationale}

The Team's recommendations concerning concentration averaging of radionuclides are based essentially on the consideration that, in most scenarios, the predicted doses to inadvertent intruders or releases of radionuclides to groundwater depend on some type of average concentration of radionuclides in a disposal facility, rather than on the concentrations in individual waste forms, waste packages, or waste streams before disposal. Therefore, for purposes of demonstrating compliance with the performance objectives in DOE Order 5820.2A, it could be unnecessarily restrictive to apply limits on radionuclide concentrations obtained from a sitespecific performance assessment to individual waste forms, waste packages, or waste streams. In many scenarios used in developing waste acceptance criteria, the uncontaminated regions within and between individual disposal units are important in determining the dose to inadvertent intruders or radionuclide concentrations in groundwater. This is because these uncontaminated regions would be accessed by an intruder or infiltrating water; it should be permissible to take this type of dilution into account.

The most important considerations in developing any method for concentration averaging of radionuclides in waste are the definitions of the appropriate exposure or release scenarios from a disposal facility. Permissible methods for concentration averaging must be consistent with the 
exposure or release scenarios assumed in the performance assessment when developing sitespecific waste acceptance criteria.

The recommendations concerning permissible methods for concentration averaging also assume that an inadvertent intruder would access a disposal unit or multiple units at random locations, rather than only at the locations where the maximum concentrations of radionuclides occur. Thus, the performance objective for inadvertent intruders essentially is assumed to apply to the average dose that might be received according to the assumed exposure scenarios. This approach is consistent with ICRP recommendations that dose limits for individuals should be applied to average exposure situations for members of critical population groups, rather than to the subgroup of such individuals who might receive the highest doses. Although an inadvertent intruder could access waste at locations with relatively high concentrations of radionuclides, thus receiving a dose in excess of the performance objective, such a scenario would have only a low probability of occurrence at any site. Therefore, the risk and the probability of occurrence of the exposure, would still be consistent with the present performance objective expressed as a dose limit for scenarios that are assumed to occur with a probability of unity.

The recommendations concerning concentration averaging or radionuclides appear to be at odds with a draft technical position on waste classification being prepared by the NRC. In determining if waste is Class A, B, C, or greater-than-Class C, as defined in 10 CFR Part 61, the NRC intends to allow little averaging of concentrations over volumes larger than the waste itself. For example, concentration averaging over the volume of individual waste packages and overpacks usually would not be allowed for purposes of waste classification. However, the NRC's waste classification system was based, in part, on intruder dose analyses that used as input the concentrations of radionuclides averaged over a volume considerably larger than the volume of a single container, rather than the maximum concentrations in any waste. Thus, the Team's recommendations are reasonably consistent with the approach used by the NRC in developing 10 CFR 61.

The other recommendations address considerations that must be given to implementing any method for limiting average concentrations (or total inventories) of radionuclides in waste while permitting disposal of some wastes with concentrations above the limits on average values. These recommendations are intended to reflect a common sense approach to ensuring acceptable disposals and to preventing abuses of reasonable methods of concentration averaging.

The Team's recommendations concerning concentration averaging of radionuclides in waste depend on the present form of the performance objective for inadvertent intruders in DOE Order 5820.2A. If this performance objective were changed significantly-for example, expressed as limits on concentrations of radionuclides that would be acceptable for disposal-then the recommendations concerning concentration averaging may not be appropriate.

\subsection{Time for Compliance}

\subsubsection{Issue}

The performance objectives in DOE Order 5820.2A are stated in terms of dose to individuals, but the time over which these objectives are to be met is not specified. For some 
release modes, the time at which the dose might occur can be thousands to hundreds of thousands of years after the facility is closed, which is much longer than the times that engineered structures may remain intact, and even longer than times for which climatic, geological, and anthropological events can be predicted. Furthermore, other agency requirements do not require analysis into the indefinite future. The issue is the selection of a length of time for compliance that will be long enough to demonstrate an appropriate level of protection of public health and the environment, without requiring an analysis that might be impossible to support with any degree of credibility. The purpose of very long-term analysis should be to guide site selection, facility design, and waste acceptance, since actual compliance cannot be monitored with any degree of assurance, and predictions are highly uncertain. The Team has not found a scientific basis for any specific length of time, although the regulatory and legal history shows a tendency toward 10,000 years as an appropriate time. Thus the issue becomes one of policy, and the recommended policy statement is given below.

\subsubsection{Recommendation}

With regard to the dose objectives for protection of the general public and groundwater, the performance assessment shall identify the processes and events that are likely to affect the disposal system, examine the effects of these processes and events on the performance of the disposal system, undisturbed by human intrusion and unlikely natural events, and estimate potential exposures for 10,000 years, with consideration for the associated uncertainties.

\subsubsection{Rationale}

The regulatory literature regarding the required time for compliance with specific numerical dose limits has been examined for a number of related activities. It was found that DOE-RL Order $5820.2 \mathrm{~A}^{28}$ contains requirements for public and groundwater protection that apply for 1,000 years for disposal of LLW. Beyond that time an as low as reasonably achievable (ALARA) requirement is imposed, with a collective dose of 500 person-rem/yr defined as compliance, although justification of higher values could be allowed. No other applicable limit was found for LLW, and the range of possible times varied from 100 years to the indefinite future.

One purpose of disposal systems is to maintain environmental quality for future generations, and ensure that radioactive waste does not pose an unreasonable risk to human health and the environment (from Criteria for Radioactive Wastes). ${ }^{29}$ The general principle is that future generations should not be subjected to potential exposures that are greater than those accepted by the current generation. Therefore the current exposure limits are usually used as the compliance test, with exposure models similar to those now in use to predict potential exposure from other facilities currently being designed. Existing design practices and exposure modeling should be used for projections up to some time when the predictions might lose validity and credibility.

Guidance is also needed on how to project doses into the far future, and for how long into the future, for situations where the dose projection has not reached a peak within 1,000-10,000 years. The issue arises because good design practices may lead to predicted releases far beyond the time when credible modeling predictions can be provided. In addition, analysis of all variations that may occur in the future will likely lead to at least a few cases that may exceed 
specific dose limits, even though those cases may not be very likely. It is also possible that using long-term dose limits for unlikely cases will lead to design features that are counter to basic radiation protection principles (ALARA), waste management principles (design for slow degradation and release), and good siting practice (seek long travel times rather than immediate large dilution factors). Thus long-term analyses should be provided to reviewers and decisionmakers, but as a possible range of results, rather than predicted system performance.

If some of the results exceed current limits, the authors and reviewers should consider whether those cases are of sufficient concern (both in likelihood and consequence) to justify modifying the facility. The discussion should consider the impacts of such modifications, and their value. For example, it might not be appropriate to make a major commitment of current natural and human resources to reduce a projected dose of a few times current limits at times in the future longer than human history. However, if the projected dose is in a range corresponding to nonstochastic effects, a modification would certainly be considered.

Two basic principles apply to disposal of radioactive waste. The first is to contain the waste while it decays to acceptable levels, in terms of a defined acceptable individual exposure through reasonable exposure scenarios. This principle applies to short-lived radionuclides that can be contained by natural or engineered structures that can reasonably be expected to remain intact for a few hundred to a few thousand years. For long-lived radionuclides, complete containment may not be possible, or at least it may be difficult to demonstrate with credibility that such containment has been achieved. This situation requires use of the second principle, which is to control the release rate and amount so that potential individual exposures from those releases will not be excessive. For example, the NRC refers to "control of releases within acceptable limits" in the Summary of Comments ${ }^{30}$ on 10 CFR 61. Slow release implies that the containment features degrade slowly, with no abrupt failures that might lead to short spikes in the projected doses.

Good siting practice for waste containing long-lived, transportable radionuclides involves consideration of natural isolation features, such as long travel times to the accessible environment. For groundwater transport, this includes a combination of long distance and low recharge rate through unsaturated zones, and long distance to discharge zone and slow groundwater velocity in the saturated zone (both typical of dry climates). This combination can defer releases to very long times, but concentrations (and projected doses) can be higher than those that might occur in wet climates, where substantial natural dilution is present. Thus expression of a limit as a concentration or dose tends to place emphasis on dilution, rather than containment, which is counterintuitive, because it tends to increase collective dose (a measure of total environmental impact) in order to minimize maximum individual dose, which violates the ALARA principle. The only reasonable solution to such a dilemma is to design for slow release at long times, which implies design features (engineered or natural) that degrade slowly, and more or less predictably.

The issue of the time for which dose limits are to be specified for future performance has appeared in a number of sources, although not necessarily with relevance to LLW disposal. An examination of past studies indicates that the time is not infinite, and a specific time limit is usually included. No regulation has been found that requires compliance with specific numerical limits for all future times. 
It is important to note that future activities and events are uncertain, so that it is not really possible to provide any guarantee (or total assurance) that no individual will receive an exposure exceeding any specified limit, regardless of the activities that he may conduct. The EPA Science Advisory Board has stated ${ }^{10}$ "We believe it is impractical to provide absolute protection to every individual for all postulated events or for very long time periods." This statement contains a strong implication that compliance with specific numerical limits should not be required forever.

The EPA final rule for disposal of $\mathrm{HLW}^{7}$ (40 CFR 191.13), issued in 1985, required that disposal systems be designed to provide a reasonable expectation that the release limits (cumulative over 10,000 years) would be met, based on performance assessments that include events and processes in specified probability ranges. Human intrusion was included, but with specified consequence limits. The rule also required that the individual and groundwater dose limits be met for 1,000 years after disposal, based on undisturbed performance of the disposal system, where "undisturbed" means exclusion of human intrusion and unlikely natural events.

The time periods were challenged in a lawsuit by the Natural Resources Defense Council. The decision [824 F.2d 1258 (1st Cir. 1987)] accepted the challenge to the 1,000 years on the basis that the EPA had not provided an adequate explanation for the criterion, but supported the 10,000-year period as being adequately explained, and rejected the 10-year challenge. The EPA chose 10,000 years as a length of time that was "long enough to distinguish geological repositories with relatively good capabilities to isolate wastes from those with relatively poor capabilities," and yet short enough "so that major geological changes are unlikely and repository performance might reasonably be projected." The decision further states "Thus, the 10,000 year period was chosen to give sufficiently reliable data; and as the Agency explained, scientifically reliable assessments are unattainable for longer periods of time." The court found the 10,000-year period to be supported, but required that the 1,000-year period be supported or changed.

The final rule was reissued on December 20,1993. ${ }^{31}$ In the reissue, the EPA chose to extend the length of time for compliance with the individual protection and groundwater protection requirements to 10,000 years.

The NRC (10 CFR 61) requires that "facilities must be sited, designed, operated, closed, and controlled after closure so that reasonable assurance exists that exposures" will be within those specified in Subpart C. No performance time is specified, but there is a requirement under site selection to evaluate site characteristics for at least 500 years, and a clause requiring 5 meters of cover or "intruder barriers that are designed to protect against inadvertent intrusion for at least 500 years" for Class $\mathrm{C}$ waste. Thus, the emphasis for long-term performance is on good design and reasonable expectation (or reasonable assurance) of future performance.

The EPA has also considered the time issue in the context of mill tailings covers in 40 CFR 192. ${ }^{32}$ Subpart D, Section 192.32(b)(1) states that disposal areas (including covers) "shall be designed to provide reasonable assurance of control of radiological hazards to (i) Be effective for 1,000 years, to the extent reasonably achievable, and, in any case, for at least 200 years, ..." The difference between design objectives and monitorable performance is emphasized by a later statement in a Proposed Rule on remedial actions.:33 "It is not intended that monitoring be carried out for the 200- to 1,000-year period over which the disposal is designed to be effective." The NRC picks up the time requirement in a Draft Technical Position Paper ${ }^{34}$ on "Information 
Needs to Demonstrate Compliance With EPA's Proposed Groundwater Protection Standards in 40 CFR 192, Subparts A-C." "The performance assessment should provide estimated hazardous constituent concentrations in the uppermost aquifer downgradient from disposal units for the design life of the units (e.g., 1,000 years)."

Another indication of the philosophy at EPA is given in 40 CFR 148, on hazardous waste injection restrictions. Section 148.20, regarding "no-migration petitions" for exemption from the injection prohibition, requires "demonstrating that, to a reasonable degree of certainty, there will be no migration of hazardous constituents from the injection zone ..." The demonstration can be made either by showing that the waste will no longer be hazardous by the time the fluid migrates, or by showing that the injected fluids will not migrate out of the injection zone for a period of 10,000 years. A similar statement concerning land disposal restrictions is contained in 40 CFR 268.

Guidance from the NRC concerning compliance time is given in the Summary of Comments to $10 \mathrm{CFR} 61:^{30}$ "The siting, design, and waste form requirements relate to both stability of the disposal site and control of releases within acceptable limits. Reliance must be placed for a longer time on the site since the waste form and design features will decrease in effectiveness over time. Therefore, each of the siting requirements should be considered applicable over the indefinite future and should be evaluated for at least a 500-year time frame. A 500-year time frame for design basis natural events or phenomena should also be applied." The time of peak release (or exposure) is not addressed directly, and there is a general impression that peak release would occur within a few hundred years after disposal. However, that is not necessarily the case for arid sites, so longer times should be considered in some fashion. The method of considering long-term releases may be something other than complete scenario and dose analysis, since uncertainties will reduce the meaning and credibility of such predictions. In NUREG-0945 35 (Final EIS on 10 CFR 61), erosion effects are considered for up to 2,000 years, and population exposure is estimated over 10,000 years, but these are used as a perspective on long-term stability, rather than as a compliance test.

Out of the number of time periods discussed above, the 10,000-year time frame seems to have substantial support in the literature. Shorter times would be subject to challenge, and longer times would lack scientific reliability, so 10,000 years has been chosen as the time for compliance.

If the analysis to a specific time cutoff does not include the time of peak release, modeling should continue beyond that time, although more as a mathematical exercise, rather than as a compliance prediction, since major climatic, geological, and anthropological changes may occur at later times. These projections are not intended to meet any specific dose limit. The intent of the long-term prediction is to guide system design and waste with gradual and reasonably predictable releases, rather than to require compliance with numerical objectives for times too long to be credibly modeled. Reasonable variations should be included to demonstrate that system designers have seriously considered slow and controlled release as a major driver in design.

It might be useful to mathematically extrapolate the undisturbed system to the peak time, using current conditions. Another perspective would be to take the analysis of a reasonably expected case (including some degradation) to a time when a major change might occur that would make the site unrecognizable, or the future status unpredictable. A range of reasonably 
likely changes in natural conditions and degradation of engineered barriers should be incorporated, along with perspectives on the likelihood of such changes for review by stakeholders and decisionmakers. It is expected that at least some of the projections will exceed current limits (otherwise there is no issue), and the intention is to give a broad picture of what could happen (and the likelihood), so that reviewers can decide for themselves what is desirable and what is not.

To complete the picture, the analysis should discuss what options are available for disposal of wastes that are responsible for the higher range of the projected doses, if above current limits. Impacts of those options should be included, in terms of potential commitment of natural resources (land, ecological effects, materials consumed, others), and human resources (labor diverted from other use, radiological and nonradiological risks incurred, dollars not available for other purposes, and delays in other desirable objectives). The objective is to avoid allowing a hypothetical projection of a dose a few times the current limits to one, or a few, individuals cause a major commitment of current resources. However, if the projection is in the range of nonstochastic effects, strong consideration should be given to alternatives.

\subsection{Development and Application of Exposure Scenarios}

\subsubsection{Issue}

DOE Order 5820.2A includes performance objectives for disposal of low-level radioactive waste that specify limits on dose equivalent from all exposure pathways for offsite members of the public and inadvertent intruders. In estimating maximum doses for either group of individuals, assumed exposure scenarios first must be defined. Then, for each exposure scenario, assumed exposure pathways must be specified and models developed and implemented for estimating dose from each pathway. The inputs to the models for estimating dose from various exposure pathways are the estimated radionuclide concentrations in various environmental media (i.e., water, soil, air, and disposal units) at assumed human receptor locations. These concentrations are obtained from analyses of the performance of the disposal facility and disposal site.

An important issue is the extent to which the development and application of exposure scenarios for the purpose of estimating doses to offsite individuals and inadvertent intruders should be standardized at the different DOE disposal sites, i.e., the extent to which each DOE site should assume the same exposure scenarios, exposure pathways and pathway models, and model parameter values. The development and application of exposure scenarios often must be based on assumptions for models and parameter values that cannot be supported by site-specific information. In the absence of site-specific data, it could be desirable to standardize the exposure scenarios, exposure pathway models, and model parameter values to be used at the different DOE disposal sites to ensure consistency among the dose assessments and, perhaps, enhance their credibility. However, such an approach has the disadvantage that little flexibility would be permitted in taking into account important site-specific factors in a dose assessment. The challenge, then, is to balance the desire for consistency in the scenarios, models, and parameter values used at each DOE site with the need to take into account important site-specific factors that would influence the estimates of dose and, thus, the acceptability of waste disposals at the different sites. 


\subsubsection{Recommendations}

The Team's recommendations on the development and application of exposure scenarios include (1) recommendations of a general nature on approaches to the problem, (2) recommendations on the types of exposure scenarios that should be considered in estimating dose to offsite individuals and inadvertent intruders, (3) recommendations on the types of models that should be used for different exposure pathways, and (4) recommendations on the selection of parameter values for use in dose assessment models.

General Recommendations. In considering the issue of development and application of exposure scenarios, the Team first makes the following general recommendations.

1. While the use of standard (i.e., generic) assumptions at all DOE sites is warranted for some aspects of a dose assessment (e.g., standard sets of dose conversion factors for ingestion and inhalation of radionuclides), the use of standard assumptions at all DOE sites for all aspects of scenario development and application (i.e., the definition of exposure scenarios, the choice of exposure pathways and pathway models, and the selection of model parameter values) is not recommended.

2. At each DOE disposal site, consistent assumptions regarding exposure scenarios, exposure pathways and pathway models, and model parameter values should be used for offsite individuals and inadvertent intruders to the extent reasonable.

3. The responsibility for development and application of exposure scenarios should rest with the performance analysts at each DOE disposal site, and the performance assessment for each disposal site should provide adequate justifications for the exposure scenarios, exposure pathways and pathway models, and model parameter values used in all dose analyses.

Recommendations on Exposure Scenarios for Offsite Individuals. At most DOE disposal sites, transport of radionuclides to locations beyond the boundary of the disposal site is expected to occur primarily by the groundwater pathway. However, other transport pathways could be important at some sites and for some radionuclides (e.g., the atmospheric pathway for volatile radionuclides, overland transport by surface erosion). The Team makes the following recommendations on the types of exposure scenarios that should be considered for offsite individuals.

1. If groundwater is expected to be contaminated by offsite transport of radionuclides, then an exposure scenario involving use of the contaminated groundwater as a domestic drinking water supply and for agricultural purposes (i.e., watering livestock, irrigating a vegetable garden, and irrigating pasture grass consumed by livestock) should be considered. However, such a scenario should be evaluated only if contaminated groundwater reasonably could be used by offsite individuals under present conditions. For example, only contaminated groundwater at depths that do not exceed the depth of a well that reasonably could be constructed using the types of drilling techniques normally used near the disposal site should be considered; the quantity of water that could be drawn from the contaminated aquifer should be sufficient for domestic use; 
the ambient water quality in the aquifer should be acceptable for domestic use without the need for treatment; and doses from irrigation need not be considered if irrigation is not commonly practiced near the disposal site.

2. If releases of radionuclides to surface waters are potentially important at offsite locations, then the same scenario described above involving use of contaminated groundwater should be considered. In addition, use of surface waters for recreational purposes (e.g., swimming, boating) and consumption of contaminated fish should be considered, provided such scenarios are reasonable under present conditions for surface waters near the disposal site.

3. If releases of radionuclides to the atmosphere are potentially important, e.g., for such volatile radionuclides as ${ }^{3} \mathrm{H},{ }^{14} \mathrm{C}$, and radon, then a scenario for offsite individuals involving exposure to airborne radioactivity should be considered.

The Team emphasizes that a recommendation to consider a particular scenario does not mean that exposure pathway models should be developed and doses estimated. Depending on the characteristics of the waste, the disposal facility, and the disposal site, scenarios can be considered only qualitatively but then excluded from a quantitative dose assessment, provided adequate justification is given.

Recommendations on Exposure Scenarios for Inadvertent Intruders. The development of the NRC's 10 CFR Part 61 has led to the use of a standard set of exposure scenarios involving direct intrusion into disposal units by individuals who are assumed to come onto the disposal site after loss of active institutional control and with no prior knowledge of waste disposal activities at the site. Given the present performance objective for protecting inadvertent intruders in the DOE order, which includes explicit dose limits for inadvertent intruders, the Team endorses the general types of exposure scenarios that were developed by the NRC and recommends that dose assessments for inadvertent intruders consider the following types of scenarios involving either chronic exposures over a lifetime or a single, acute exposure:

1. An acute construction scenario and a chronic agriculture (homesteader) scenario involving excavation into disposal units, mixing exhumed waste in an intruder's vegetable garden, and permanent residence in a home on top of disposal units;

2. An acute discovery scenario and a chronic resident scenario involving an attempted excavation into disposal units, which is assumed to be precluded by the presence of intact engineered barriers; and

3. An acute drilling scenario and a chronic post-drilling scenario involving drilling through disposal units and mixing the drilling waste in an intruder's vegetable garden.

However, the Team does not recommend that standard definitions of these scenarios be used at all DOE disposal sites. Rather, the Team recommends that the definition and application of exposure scenarios for inadvertent intruders be tailored to the particular characteristics of the waste, disposal facility, and disposal site, with adequate justifications again provided in the performance assessment. 
Although the exposure scenarios for inadvertent intruders described above have been used in most generic assessments and are expected to be appropriate for use at many DOE sites, the Team also recognizes two other possibilities. First, it may be reasonable for the conditions at the disposal site and the nature of the waste and the disposal facility that none of these scenarios are credible or, indeed, that there are no exposure scenarios for inadvertent intruders that would be reasonably likely to occur. In the latter case, acceptable disposals then would be determined only by the performance objectives for offsite individuals and protection of groundwater resources and by the current DOE policy that waste with concentrations of radionuclides greater than the Class-C limits specified in the NRC's 10 CFR Part 61 is not acceptable for disposal at DOE low-level waste sites. Second, other types of scenarios for inadvertent intrusion not identified above could be reasonable for particular combinations of site, waste, and disposal facility, and such a possibility should be considered appropriate.

Recommendations on Models for Exposure Pathways. Selecting a particular exposure scenario for offsite individuals or inadvertent intruders leads to the assumption of certain exposure pathways. For each pathway, a model must be developed to relate radionuclide concentrations in the appropriate environmental media to dose to an exposed individual. The different modes of exposure to radionuclides that must be considered generally include ingestion, inhalation, and external (direct) exposure.

A model for any exposure pathway essentially provides an estimate of the dose per unit concentration of radionuclides in an environmental medium. The dose estimates resulting from such a model depend in general on the following three factors:

1. A transfer factor from the environment to exposed individuals (e.g., through terrestrial or aquatic foodchains, suspension from surface soil into the atmosphere), which is used only for exposure pathways involving intakes of radionuclides by ingestion or inhalation;

2. A usage factor, i.e., intakes of contaminated foodstuffs, water, air, or soil by humans or livestock for exposure pathways involving intakes of radionuclides or an exposure time for external exposure; and

3. A dose conversion factor, i.e., the committed dose equivalent per unit activity intake of a radionuclide for ingestion or inhalation or the dose-equivalent rate per unit activity concentration of a radionuclide in air, water, or soil for external exposure.

Particularly for terrestrial foodchain pathways, a transfer factor may depend on several parameters. For example, if pasture grass is irrigated with contaminated water, transfer of radionuclides from the water to exposed individuals would depend on factors describing retention of deposited radionuclides on plant surfaces and in the soil root zone, transfer of radionuclides from soil to pasture grass, and transfer of the radionuclides from pasture grass consumed by livestock to milk or meat.

The Team recommends the use of simple, multiplicative-chain models in developing models for the different exposure pathways. This type of model assumes that radionuclide concentrations are at equilibrium in the exposure environment (e.g., that the concentrations in different compartments of a terrestrial foodchain pathway are constant multiples of the concentrations in 
soil or water). The Team believes that the use of multiplicative-chain models is reasonable because of the long-term, prospective nature of performance assessments for low-level waste disposal and the primary importance of chronic exposure scenarios for offsite individuals and inadvertent intruders. More complex, dynamic exposure pathway models, such as those developed to evaluate the consequences of accidental releases to the environment, generally are not needed.

Ingestion of vegetables grown in contaminated soil and ingestion of milk and meat obtained from livestock that consume contaminated water or eat pasture grass grown in contaminated soil are exposure pathways that often must be evaluated in a dose assessment for offsite individuals or inadvertent intruders. In some models for the vegetable pathway, separate transfer factors are used for such subcategories as leafy and nonleafy vegetables. Similarly, models for the milk pathway may consider goat's milk as well as cow's milk, and models for the meat pathway may consider pork, chicken, and eggs as well as beef. However, in dose assessments for low-level waste disposal, the Team recommends that it is not necessary to distinguish between different kinds of vegetables, milk, and meat, primarily because much of the data on transfer and usage factors will be generic rather than site-specific. Thus, the Team believes it is reasonable to develop a single set of transfer and usage factors for each of the vegetable, milk, and meat pathways, although more detailed models can be used if so desired.

Similarly, for ingestion of aquatic foodstuffs, dose assessments often distinguish among fish, molluscs, and crustaceans. However, for performance assessments for low-level waste disposal, the Team believes that it is adequate to develop a single set of transfer factors and single usage factor for the fish pathway.

The Team recognizes that the choice of a model for the inhalation pathway involving suspension of radionuclides attached to particulates in surface soil is problematic at any site. Distinct models have been developed based on the concepts of a resuspension factor, resuspension rate, or atmospheric mass loading. Inhalation of suspended radionuclides in particulate form is expected to be of greatest importance in dose assessments for inadvertent intruders. In this case, the Team recommends the use of a mass loading model, which is based on observations at a variety of locations of airborne concentrations of such naturally occurring radionuclides as uranium and thorium relative to their concentrations in surface soil. Alternatively, a model based on a resuspension factor may be used, except the value of this parameter is likely to be highly uncertain for many activities at most disposal sites. More complex models that require assumptions about meteorological or soil conditions, such as a model based on a resuspension rate, are not recommended in dose assessments for inadvertent intruders. On the other hand, if suspension of radionuclides in particulate form is important in the dose assessment for offsite individuals, then a model based on a resuspension rate may be appropriate because a resuspension rate provides the appropriate input for an atmospheric transport model. However, the choice of a resuspension rate for use at any site is likely to be quite uncertain.

In estimating atmospheric releases of volatile radionuclides from waste disposal sites, a relatively simple diffusion model should be adequate. Particularly for ${ }^{222} \mathrm{Rn}$, the known average background release rate relative to the average concentration of naturally occurring ${ }^{226} \mathrm{Ra}$ in surface soil provides an important benchmark for testing any model. 
Recommendations on Selection of Model Parameter Values. In regard to selecting parameter values (i.e., the transfer factors, usage factors, and dose conversion factors) for use in dose assessment models, the Team first makes the following general recommendations.

1. Generic dose conversion factors for reference adults, particularly those factors based on recommendations of the International Commission on Radiological Protection (ICRP), are appropriate for estimating dose from ingestion, inhalation, and external exposure.

2. Site-specific data for transfer factors and usage factors should be used whenever they are available and relevant to low-level waste disposal at the site. However, the Team recognizes that site-specific data for these parameters often are not available, in which case generic values obtained from the literature must be used. On the other hand, the Team emphasizes the potential importance of considering the applicability of selected sets of generic data to particular sites, because some generic data may be inappropriate for expected site conditions.

3. In selecting parameter values for use in dose assessment models, particularly in selecting values from generic data, values that are believed to represent reasonable average conditions that could occur (i.e., "best estimates") should be emphasized, rather than values that are presumably conservative in most instances. The Team believes this approach is reasonable, with adequate justification, primarily because the definitions of the exposure scenarios themselves (e.g., the assumption that groundwater used by offsite individuals is obtained from the location of maximum concentration, the assumption that intruders onto a disposal site will mix waste with native soil in a vegetable garden) usually would ensure that doses to almost all individuals would be less than the estimated doses.

4. The previous recommendation notwithstanding, the Team also recognizes that conservative assumptions for model parameter values are appropriate for use in screening models and also may be appropriate in dose assessments for offsite individuals and inadvertent intruders for purposes of demonstrating compliance with the performance objectives, particularly if more realistic assumptions would be difficult or expensive to defend. The choice between conservative and more realistic assumptions should rest on the judgment of the analyst and presumably depends, at least in part, on whether the use of conservative assumptions results in significant quantities of waste that are unacceptable for disposal.

5. For some parameters, particularly those used in describing transport of radionuclides through terrestrial foodchain pathways, generic data may be obtained from several compilations. In selecting parameter values for a large number of radionuclides, a minimum number of sources of data should be used; i.e., mixing data from a large number of sources should be avoided unless it can be justified. Although the use of generic data from any source presumably is problematic at any disposal site, the recommended approach has the advantage that the data should be internally consistent and reflect the biases of relatively few compilers and evaluators. 
However, the Team again emphasizes its recommendation that the selection of parameter values for use in dose assessment models should be the responsibility of the performance analysts for a particular site. Therefore, deviations from the Team's recommendations could be reasonable, provided adequate justification is given.

The remainder of this section discusses particular sources of generic data on dose conversion factors, usage factors, and transfer factors that the Team recommends for use in performance assessments for low-level waste disposal. Use of data from these sources should require a minimum of justification.

The Team makes the following recommendations on sources of dose conversion factors for ingestion or inhalation of radionuclides and external exposure to radionuclides in the environment.

The preferred source of dose conversion factors for ingestion or inhalation of radionuclides is the EPA's Federal Guidance Report No. 11. ${ }^{36}$ Internal dose conversion factors contained in a DOE compilation ${ }^{37}$ also can be used. There are differences in the dose conversion factors for some radionuclides in these two compilations, but the differences generally are not significant.

For ingestion of a radionuclide, dose conversion factors often are given for more than one value of the GI-tract absorption fraction, denoted by $f_{1}$. For ingestion of radionuclides in water or foodstuffs, the dose conversion factor corresponding to the higher GI-tract absorption fraction normally should be used, because the radionuclide should be in relatively soluble form. This assumption usually gives the higher dose conversion factor. The same assumption can be made for direct ingestion of radionuclides in soil. However, if the chemical form of the radionuclide in soil is expected to be relatively insoluble, the dose conversion factor corresponding to the lower GI-tract absorption fraction can be used for this exposure pathway.

For inhalation of a radionuclide, dose conversion factors often are given for two or three lung clearance (i.e., solubility) classes, denoted by Class D, W, or Y for relatively soluble, moderately soluble, and relatively insoluble chemical forms, respectively. If information on the chemical form of radionuclides in low-level waste is not available, the assumed clearance class should be that which maximizes the dose conversion factor for the most important isotopes of a given element. It usually is not appropriate to assume one clearance class for one isotope of a given element and another clearance class for another isotope of the same element, in order to maximize the dose conversion factors for each isotope, because all isotopes of a given element presumably have the same solubility unless there is evidence to the contrary based on knowledge of differing chemical forms. The Team also notes that if the largest inhalation dose conversion factor occurs for Class $\mathrm{W}$ for one isotope but for Class $\mathrm{Y}$ for another isotope of the same element, the differences in the dose conversion factors for the different clearance classes for the two isotopes usually are not significant.

At the present time, it is not necessary to use dose conversion factors for ingestion and inhalation based on the new recommendations in ICRP Publication $60 .{ }^{38}$ Use of such dose conversion factors should await adoption by federal agencies of the new ICRP recommendations, particularly regarding the new quantity "effective dose." 
It also is not necessary to use age-specific dose conversion factors for ingestion and inhalation, such as those developed in ICRP Publication 56. ${ }^{39}$ Although offsite members of the public and inadvertent intruders presumably would include infants and children as well as adults, the use of dose conversion factors for reference adults is appropriate when (1) the performance objectives for low-level waste disposal in the DOE order are expressed as limits on dose in any year but scenarios for chronic exposure are expected to be of primary importance in demonstrating compliance with the performance objectives and (2) age-specific dose conversion factors are available for a limited number of radionuclides. Furthermore, the DOE did not consider exposures of infants and children in developing the performance objectives.

External dose-rate conversion factors for immersion in a contaminated atmospheric cloud, submersion in contaminated water, and exposure to soil that is contaminated to various depths should be obtained from the EPA's Federal Guidance Report No. $12 .{ }^{40}$ Federal Guidance Report No. $11^{36}$ also includes external dose-rate conversion factors for immersion in an atmospheric cloud containing noble-gas radionuclides, but these data have been superseded by the data in Federal Guidance Report No. $12 .^{40}$

External dose-rate conversion factors for air immersion and water submersion also can be obtained from a DOE compilation, ${ }^{41}$ but the user should be aware that these data contain small errors that probably result in underestimates of external dose by a few tens of percent. The DOE compilation also contains dose-rate conversion factors for exposure to a contaminated ground surface, but these data are not expected to be relevant for exposure scenarios for low-level waste disposal.

External dose-rate conversion factors for exposure to contaminated soil also can be based on absorbed dose rates in air above ground per unit concentration of monoenergetic photon sources in soil calculated by Kocher and Sjoreen ${ }^{42}$ or on well documented and tested computer codes, such as ISOSHLD and MICROSHLD. However, the dose-rate conversion factors in Federal Guidance Report No. $12^{40}$ are preferred because they take into account for the first time the proper energy and angular dependence of the radiation field above ground for sources distributed in soil and, thus, correct small errors in previous calculations. If the calculations of Kocher and Sjoreen ${ }^{42}$ are used, absorbed doses in air must be converted to effective dose equivalents, and an assumption that 1 rad in air corresponds to 0.8 rem effective dose equivalent is satisfactory for the higher-energy photons of greatest importance to external dose.

The dose conversion factors for external exposure to radionuclides distributed in soil ${ }^{40,42}$ discussed above apply to source regions that are infinite in lateral extent, but different assumptions for the depth of the source region in soil can be made. If finite lateral dimensions for the source region also are assumed (e.g., in estimating external dose from sources in a trench), then a numerical method implemented by a computer code probably would be necessary. The Team cautions that any code that uses a numerical solution technique to estimate external dose should be carefully benchmarked (e.g., against the known external dose from naturally occurring radium and its decay products in surface soil), because even widely used codes (such as PATHRAE and MICROSHLD) have been known to give erroneous results if not used properly.

In summary, a variety of options is available for selecting or computing dose conversion factors for ingestion, inhalation, and external exposure. However, the Team emphasizes that any 
differences in values based on using different options probably are not significant in a dose assessment for low-level waste disposal, because the differences are likely to be insignificant compared with uncertainties in other parameters in an exposure pathway model, particularly the transfer factors.

The Team makes the following recommendations on generic data on usage factors, particularly intake rates of foodstuffs, water, air, and soil by humans or livestock. Again, however, site-specific data should be used if they are available. An example of appropriate site-specific data is the evaluation by Hamby ${ }^{43}$ of usage factors for food-chain pathways near the Savannah River Site.

Recommended sources of generic data on human consumption of foodstuffs and water include the evaluations by Rupp ${ }^{44}$ and Yang and Nelson. ${ }^{45}$ Data in the NRC's Regulatory Guide $1.109^{46}$ also could be used, except the Team reiterates its recommendation that average consumption rates for adults, rather than the maximum values, should be used. In selecting data on consumption of foodstuffs, attention must be given to whether the data are reported on a dryweight or fresh-weight basis, in order for the consumption rates to be compatible with the plantto-soil concentration ratios for food crops discussed below.

If an exposure pathway involving direct ingestion of contaminated soil is included in a dose assessment, a consumption rate of soil by adults must be selected. On the basis of data for various ages up to 18 years reported by the $\mathrm{EPA}^{47}$ a reasonable average consumption rate appears to be about $0.01 \mathrm{~g}$ per day, and a value of $0.1 \mathrm{~g}$ per day should be reasonable if a more conservative value is desired.

Consumption rates of water and pasture grass by livestock may be obtained from the NRC's Regulatory Guide 1.109.46 Another recommended source of data on consumption rates of pasture grass by dairy cattle is the review by Shor and Fields. ${ }^{48}$ In selecting data on consumption rates of pasture grass by dairy and beef cattle, attention must be given to whether the data are reported on a dry-weight or fresh-weight basis.

Breathing rates for humans may be obtained from ICRP Publication $23{ }^{49}$ Similar data are found in the NRC's Regulatory Guide 1.109 .46

Exposure times for external exposure usually can be based on the judgment of the analyst. Values that should be acceptable for different exposure scenarios for low-level waste disposal can be found in the NRC's Regulatory Guide $1.109^{46}$ and in reports on the NRC's dose assessment methodology for 10 CFR Part 61. ${ }^{50,51}$

In summary, a variety of options is available for selecting usage factors. However, the Team emphasizes that any differences in values using different options probably are not significant in a performance assessment for low-level waste disposal, because the differences are likely to be insignificant compared with uncertainties in other parameters in an exposure pathway model, particularly the transfer factors.

The Team makes the following recommendations on generic data on parameters that determine transfer factors for radionuclides in terrestrial and aquatic foodchains and for the 
inhalation pathway resulting from suspension of radionuclides attached to particulates in surface soil. However, the Team emphasizes the potential importance of using site-specific data for these parameters whenever they are available and relevant. The Team also recommends that generic data based on actual measurements are preferable to data based on indirect evidence or assumptions, e.g., that a transfer factor for a particular element can be based on the transfer factor for a chemical homolog.

For the pathway involving consumption of vegetables grown in contaminated soil, the most important parameter is the plant-to-soil concentration ratio, usually denoted by $B_{v}$. Similarly for the milk and meat pathways, the most important parameters are the intake-to-milk and intake-to-meat transfer coefficients for dairy and beef cattle, respectively, usually denoted by $F_{m}$ and $F_{\mathrm{f}}$. Recommended sources of generic data for these parameters include the compilations by $\mathrm{Ng},{ }^{52} \mathrm{Ng}$ et al., ${ }^{53-55}$ and Baes $e t a l .{ }^{56}$ The compilation of various data by Baes et al. ${ }^{56}$ appears to be particularly useful for prospective dose assessments involving a potentially large number of radionuclides, because default values are provided for nearly all elements and the data were obtained in an internally consistent manner with a relatively uniform bias. This single source provides almost all of the transfer factors that would be needed in estimating dose for terrestrial foodchain pathways.

Other potentially useful sources of data on plant-to-soil concentration ratios include (1) the compilation by Peterson, ${ }^{57}$ which particularly addresses the difference between root uptake and foliar deposition as the source of activity in vegetation for elements with very low plant-to-soil concentration ratios; (2) the ongoing compilations by the International Union of Radioecologists, which provide an extensive data base for a limited number of radionuclides but are presently unavailable to the Team; and (3) a paper by Sheppard et al., ${ }^{58}$ which presents the first direct measurements on root uptake of ${ }^{14} \mathrm{C}$ from contaminated soil.

For the vegetable, milk, and meat pathways, the use of transfer factors given in the NRC's Regulatory Guide $1.109^{46}$ generally is not recommended, unless there are no data available from other sources. Most of these data either were derived inappropriately or have been superseded by later compilations.

In selecting plant-to-soil concentration ratios, as well as consumption rates of contaminated vegetables and consumption rates of pasture grass by dairy and beef cattle, attention must be given to whether the data are reported on a dry-weight or fresh-weight basis. Either basis is acceptable, but the concentration ratios and consumption rates used in a dose assessment must be given on a consistent basis. Factors for converting fresh weight of vegetation to dry weight are discussed in the compilations by Baes et al. ${ }^{56}$ and Peterson. ${ }^{57}$ This conversion factor is quite different for leafy vegetables and nonleafy vegetables. For example, Baes et al. ${ }^{56}$ recommend generic conversion factors of 0.07 for leafy vegetables and 0.43 for nonleafy vegetables. The generic conversion factor of 0.25 recommended in the NRC's Regulatory Guide $1.109^{46}$ thus appears to be only a crude approximation for all types of vegetation.

In selecting plant-to-soil concentration ratios, attention also must be given to whether the data apply to leafy or nonleafy vegetables. As discussed previously, the Team believes it is adequate in dose assessments for low-level waste disposal to select a single set of plant-to-soil concentration ratios that would apply to all vegetables consumed by humans. Because intakes of 
nonleafy vegetables should be considerably higher than intakes of leafy vegetables (e.g., see Table 2.2 of Baes $e t a l .^{56}$ ), it is reasonable to base a single set of concentration ratios for all elements on the values for nonleafy vegetables. Such values are given, for example, in Figure 2.2 of Baes et al. ${ }^{56}$ and are denoted by $\mathrm{B}_{\mathrm{r}}$ Alternatively, values of $\mathrm{B}_{\mathrm{v}}$ for leafy vegetables could be selected, e.g., from Figure 2.1 of Baes et al., ${ }^{56}$ because the concentration ratios for leafy vegetables on a dry-weight basis are always higher than the corresponding concentration ratios for nonleafy vegetables. However, the concentration ratios for leafy vegetables may not be greater when the values for both types of vegetables are converted to fresh weight of vegetation. For consumption of pasture grass by livestock, concentration ratios for leafy vegetables generally are the most appropriate.

If an exposure pathway involving irrigation of food crops or pasture grass with contaminated water is included in a dose assessment, a model describing the long-term retention of radionuclides deposited in surface soil may be needed. For chronic irrigation, such a model can be used to estimate the equilibrium concentrations of radionuclides in surface soil relative to the concentrations in the contaminated water, and the leaching model of Baes and Sharp ${ }^{59}$ is recommended for estimating this concentration ratio. An important parameter in the model for retention of radionuclides in surface soil is the solid/solution distribution coefficient, usually denoted by $\mathbf{K}_{\mathbf{d}}$.

Because of the considerable variability in measured distribution coefficients for many elements, site-specific data should be used whenever they are available and relevant. In the absence of site-specific data, recommended sources of generic data on $\mathrm{K}_{d}$ include the compilations by Baes $e t$ al. ${ }^{56}$ and Sheppard and Thibault. ${ }^{60}$ These compilations provide default data for most elements, and the data were derived in an internally consistent manner with a relatively uniform bias. Compilations of $K_{d}$ values by the Nuclear Energy Agency also may be useful, but the references for these data are presently unavailable to the Team.

The Team notes that the values of $K_{d}$ that might be selected for use in a leaching model (or in any other part of a performance assessment, such as estimating release rates of radionuclides from a disposal facility and transport of radionuclides in water in the unsaturated and saturated zones) are likely to be highly uncertain for many elements. Therefore, to the extent reasonable, generic values adopted for a performance assessment should be selected from a minimum number of sources, so that the values for different elements will at least be chosen in an internally consistent manner. For application to a soil leaching model, it is also important to recognize that $K_{d}$ generally is correlated with the plant-to-soil concentration ratio, $B_{v}$ (i.e., high values of $K_{d}$ are associated with low values of $B_{v}$, and vice versa, because radionuclides in soil generally are available for root uptake only if they are in solution in soil water). Therefore, it is not reasonable to choose values of $K_{d}$ and $B_{v}$ that are both at the upper end of the expected ranges of values in order to maximize the dose estimates for terrestrial foodchain pathways following irrigation with contaminated water.

For consumption of contaminated fish, concentration factors for freshwater fish can be obtained from the NRC's Regulatory Guide $1.109^{46}$ and the compilation by Peterson. ${ }^{57}$ An extensive data set also is contained in a report documenting the GENII computer code, ${ }^{61}$ but these data should be used with caution because the sources of the data are not documented in the report. 
For the inhalation pathway involving suspension of radionuclides in particulate form in surface soil, a recommended average atmospheric dust loading for use in a mass loading model of about $4 \times 10^{-8} \mathrm{~kg} / \mathrm{m}^{3}$ is given by Anspaugh et al. ${ }^{62}$ This value often is rounded up to $10^{-7} \mathrm{~kg} / \mathrm{m}^{3}$ for use in generic dose assessments. However, judgment should be used in applying such an average dust loading to particular sites and activities. If a model based on the resuspension factor is used, a typical generic value for this parameter, which is the ratio of the concentration in air at $1 \mathrm{~m}$ above ground to the areal concentration on the ground surface, is $10^{-9} \mathrm{~m}^{-1}$. For particular sites and activities, however, the resuspension factor is highly uncertain, and a judgment regarding the depth of surface soil that is subject to resuspension (typically about $1 \mathrm{~mm}$ in undisturbed soil) also is required. On the other hand, the generic value for the resuspension factor given above probably is conservative for most reasonable exposure scenarios, particularly at humid sites. If a model based on a resuspension rate is used, information on this approach can be obtained from the discussion by Healy. ${ }^{63}$ Again, the Team recommends use of the mass loading model, particularly in dose assessments for inadvertent intruders. If a diffusion model is used for airborne releases of volatile radionuclides, then judgments on the diffusion coefficient for different elements are needed.

In summary, a variety of options is available for selecting transfer factors for ingestion and inhalation pathways. The Team emphasizes that widely varying values of particular transfer factors are found in the literature for some radionuclides, and that the application of generic data for these parameters to site-specific dose assessments may be highly uncertain. Thus, considerable judgment may be required in selecting parameter values for a particular assessment. However, the Team also recognizes that, given the absence of site-specific data for most parameters, there is little that can be done to reduce uncertainty and increase confidence in the reasonableness of the resulting dose estimates. It is partly because these parameters are highly variable and uncertain that the Team recommends that a minimum number of different sources of data be used in selecting the parameter values. The large uncertainties also provide an argument in favor of selecting values that are likely to be conservative, although care must be taken that selection of unreasonably conservative values does not result in unreasonable and unnecessary restrictions on acceptable waste disposals.

\subsubsection{Rationale}

The rationale for many of the specific recommendations on the development and application of exposure scenarios for offsite individuals and inadvertent intruders was presented in discussing the recommendations themselves.

Many of the recommendations of a general and specific nature are based essentially on recommendations developed previously by the Team on the issue of "reasonable assurance" in demonstrating compliance with the performance objectives for low-level waste disposal. Inherent in the concept of reasonable assurance is the notion that dose assessments for demonstrating compliance with the performance objectives for offsite individuals and inadvertent intruders should be based on assumptions judged to be reasonable for each disposal site.

While it is generally recognized that site-specific considerations are particularly important for such aspects of a performance assessment as release rates of radionuclides from disposal units and transport of radionuclides in the environment, site-specific considerations also are potentially 
important in developing exposure scenarios and estimating doses to individuals based on those scenarios. For example, the assumption of an agriculture (homesteader) scenario for inadvertent intruders probably is reasonable at humid sites and even at an arid site if local groundwater can be used for domestic and agricultural purposes. However, at an extremely arid site, which may be uninhabitable by homesteaders, because of the difficulty in obtaining usable groundwater by conventional drilling methods, it may be unreasonable to assume an agriculture scenario in a dose assessment. The importance of airborne releases of radionuclides in particulate form also may differ greatly between humid and arid sites.

Although standardization of some parts of a dose assessment is appropriate, the Team believes it is important to take site-specific factors into account in developing exposure scenarios and dose assessment models. Otherwise, particularly in regard to dose assessments for inadvertent intruders and their application to developing limits on concentrations of radionuclides that would be acceptable for disposal, the results of an assessment essentially would be the same at all sites. If this were the case, then it is possible that the DOE sites with greater waste isolation capabilities would be unnecessarily and unreasonably restricted in their disposals.

In recommending that the definitions of exposure scenarios, choice of exposure pathways and pathway models, and selection of model parameter values not be standardized for use at all DOE disposal sites, the Team recognizes that this recommendation, particularly in regard to dose assessments for inadvertent intruders, differs from the approach used by the NRC in 10 CFR Part 61 in developing the waste classification system for near-surface disposal of radioactive waste. The NRC used a single set of scenarios, models, and parameter values to establish limits on concentrations of radionuclides that would be generally acceptable for near-surface land disposal. While a certain uniformity in the approaches used by the NRC and DOE could be desirable (e.g., in improving public perception of the DOE's waste disposal activities), the Team believes it is important to recognize the different purposes in the two cases. In essence, the purpose of the NRC's analysis was to develop a generic standard to be applied in licensing any disposal facility at unknown locations, whereas the purpose of the DOE's analyses will be to assist in judging the acceptability of disposals in a variety of facilities at known locations.

In summary, with proper justification, the Team believes that the use of different assumptions regarding exposure scenarios, exposure pathways and pathway models, and model parameter values in performance assessments at different DOE sites is reasonable. The Team believes that any seeming inconsistencies in dose assessment methodologies among the different sites should not be construed as indicating a lack of credibility in the DOE's approach to performance assessment.

The Team recognizes that these recommendations on the development and application of exposure scenarios place a considerable burden on performance analysts to develop modeling approaches that are appropriate for the specific disposal sites and to justify the assumptions used in the assessment. Issues that will confront the analyst include the degree of conservatism to be built into the assessment, including the impact of any such conservatisms on the acceptability of waste disposals, and the applicability of both generic and site-specific data to the particular disposal facility and site. However, these judgmental considerations are no different than those that arise in all other aspects of a performance assessment for low-level waste disposal facilities, and the Team believes that placing responsibility for these judgments in the hands of the analysts, 
rather than prescribing certain assumptions and calculational procedures at all sites, is the best approach to achieving defensible and reasonable dose assessments.

\subsection{Waste Characterization}

\subsubsection{Issue}

The data that support waste characterization, particularly radionuclide inventory (both types and concentrations of isotopes), are often highly uncertain. The issue is to identify the type of data necessary to provide reasonable assurance that PA-derived WAC will not be exceeded.

\subsubsection{Background}

Waste characterization was identified as a key item in performance assessment, since it provides the initial inventory for radionuclide transport. After discussing the issue, the Team held a workshop in connection with the twelfth meeting, with speakers from several sites discussing characterization requirements and practices, manifesting, analysis methods, process knowledge, and verification. It became apparent that the issue would continue, not subject to immediate closure recommendations, and that the issue affected many activities, not just performance assessment. Therefore, the Team recommended that characterization be addressed by a broader forum. The issue was also under consideration by DOE-HQ, with a workshop held in April 1993. The Waste Management Operations Committee was also discussing the issue. These efforts were then focused through a Waste Characterization Working Group formed by DOE-HQ; this Working Group continues to study the issue. The Team maintains liaison with the Working Group and has provided presentations at their meetings. The recommendations below are interim, representing current thought; the issue will remain open, with liaison to the Working Group and discussion of site developments continuing.

\subsubsection{Recommendations}

For the purpose of performance assessment, the following recommendations are provided:

- Waste must be grouped into separate waste streams, with inventories provided for each waste stream. If the waste from one waste stream consists of more than one package, the inventory in each package must be provided.

- The inventory data must be provided as the identification of specific isotopes present in the waste stream and their concentrations.

- Other physical and chemical characteristics of the waste stream that can enhance radionuclide mobility in the geohydrologic environment (primarily chelating agents) must be reported.

- All isotopes with half lives less than or equal to 5 years and that are potentially existent in a waste stream do not need to be included in the inventory evaluation. 
- Screening assessment of doses to offsite members of the public or inadvertent intruders can be used to establish thresholds below which quantities of specific radionuclides do not need to be reported.

- The precision of the concentration estimates for specific nuclides must be sufficient to determine whether dose limit performance objectives can be satisfied by the given disposal facility.

\subsubsection{Rationale}

A primary output of a PA analysis of a disposal facility is the calculation of potential dose to man resulting from the release of radionuclides from that facility. Because isotopes differ in the type and amount of radiation and dose they can provide, it is necessary to complete the analyses on a radionuclide specific basis.

The first five recommendations have been defined to ensure that all significant sources of potential dose are identified in the analysis. Some typical reporting practices are clearly not sufficient to accomplish this goal. These include inventory designations such as mixed fission products, total alpha, total beta, and total gamma. Each of these terms includes multiple isotopes and does not allow a designation of concentration from separate isotopes. Similarly, the practice of reporting only isotopes that comprise greater than $1 \%$ of the current activity in the waste can lead to the omission of radionuclides with potential long-term impact. For waste streams with mixtures of long-lived and short-lived nuclides, the activity of short-lived nuclides may be sufficient to make up greater than $99 \%$ of the current activity and mask concentrations of long-lived nuclides, which contribute a large fraction of potential dose over a long period.

The cutoff of radionuclides with half lives of 5 years or less is based on the assumption of a minimum of 100 years of institutional control allowing 20 half-lives of decay. General knowledge of low-level waste inventories suggests that exceedingly large concentrations of radionuclides with less than 5-year half-lives is unlikely. Therefore, contribution to dose from these isotopes should be insignificant. On the other hand, longer lived isotopes may be present in waste streams at inconsequential concentrations or quantities. The screening analysis can be used to limit the need for quantification of these radionuclide inventories to avoid unnecessary expense in sampling, analysis, and reporting. It is necessary to ensure that the assumptions controlling dose estimates are clearly conservative so that the limiting radionuclide concentrations or quantities contribute a very small fraction of allowable dose, as defined by performance objectives.

A determination of the appropriate precision necessary for inventory estimates is important for completion of PA analyses, waste characterization costs, and acceptance of waste at the disposal facility. From the performance assessment perspective, the need for greater precision increases as the quantities and concentrations of specific radionuclides or sets of radionuclides approach inventory limits defined for a given facility. Two general types of situations have been observed. In the first case, a facility is designed to accept wastes from a single waste stream or a small number of waste streams that are well defined in terms of inventory source and location. In this case, a subset of radionuclides generally is predicted to provide the primary source of predicted dose. Accuracy and precision for the inventory of these nuclides would be more important than the other nuclides, which are not predicted to contribute a significant portion of 
the dose. In the second case, a facility is designed to accept wastes from a large variety of sources, some of which can be very poorly defined in terms of inventory. In this situation, a subset of nuclides, which most likely provide a significant contribution to dose, is defined through the PA process. These nuclides (typically, long-lived and mobile in a disposal facility and geohydrologic environment) are likely to require greater characterization particularly as concentrations approach inventory limits defined by the PA analysis for a given facility.

Both process knowledge and sampling and analysis are expected to be useful in providing acceptable waste characterization data. If process knowledge is very good (e.g., a mass balance calculation can be achieved for the waste generating facility), minimal sampling and analysis should be required. As process knowledge becomes less precise and the potential for significant dose-contributing radionuclides in the waste increases, more extensive sampling and analysis are required. Inventory limits for specific radionuclides will vary as a function of the disposal facility features and the geohydrologic location in which the facility is placed. Therefore, it is necessary to establish communication among the waste generator, the disposal facility operator, and the PA analyst to determine allowable limits and acceptable characterization data.

\subsection{Quantification of Waste Form Release Rates}

\subsubsection{Issue}

The data base that supports quantification of radionuclide release rates from waste materials and waste forms is often highly uncertain. The issue is to determine what recommendations should be proposed to generate consistent and defensible data that reduce uncertainty in the parameter values used in PA analyses.

\subsubsection{Recommendations}

1. A project should be established to collect and evaluate current data, summarize the data in a document for analysts in this field, and recommend those continuing, or additional, studies that may be necessary to support PAs for LLW disposal. A Statement of Work has been provided to DOE-HQ for consideration.

2. Performance assessments shall identify continuing work activities needed to support and verify assumptions made and reduce uncertainties in key parameters. These activities would include experimental programs needed to verify performance assessment assumptions and improve projections, such as lysimeter (and other) tests to establish infiltration rates, cover performance, release rates, and parameters affecting migration of radionuclides from the disposal facility.

\subsubsection{Status}

The commonly used treatment of waste form release rates in PA analyses is to use highly simplified mathematical models (e.g., constant concentration, fractional release rate, diffusion rates), which are generally considered to estimate conservatively high radionuclide release fluxes from the waste volume. This leads to the assumption that maximum groundwater concentrations and dose estimates will be estimated by the PA analysis. However, it is important to remember 
that waste form behavior is being treated empirically and the data base used to support these assumptions is generally not representative of a real environmental condition (e.g., the ANSI 16.1 leach test protocol).

When using an empirical approach to represent a complex set of physical and chemical processes such as waste leaching, it is desirable to develop a data base that represents the real system as closely as possible. This data base improves confidence in the assumptions of conservatism and provides some quantitative estimate of the relative degree of conservatism actually assumed. A variety of field experiments with this concept in mind have been underway at various DOE sites over the last two decades. To synthesize the work that has been done in this area to date, the Team held a one-day workshop on August 6, 1992 (in connection with the eleventh meeting) with experts from the various DOE sites who have been working on these projects.

Discussion of past and ongoing field tests of waste form leaching were provided by representatives from Hanford, Savannah River, Oak Ridge, Los Alamos, Nevada Test Site, and INEL. Two kinds of approaches have been taken across the complex. One approach has been to place large-scale waste forms (55-gal drum or larger) in lysimeters surrounded by native soil. Lysimeters are instrumented to monitor movement of water and contaminants through the experimental system. These types of experiments have been in progress at Hanford, Savannah River, and INEL for nearly a decade. Waste materials were provided by the NRC and encapsulated in cement, bitumen, and manmade organic polymers. In recent years, funding for these projects has diminished considerably; consequently, the frequency of sample collection and completeness of chemical analysis have diminished. In some cases, monitoring activities have ceased.

Savannah River is conducting a different set of field experiments, in conjunction with the saltstone disposal facility, in which three large blocks of saltstone $(-27,000 \mathrm{~kg})$ containing technetium, tritium, and nitrate, have been placed in the ground. Covers that are being considered for use in these situations have been placed over two of the blocks to study the effect of such covers on radionuclide release rates. Oak Ridge has constructed a new lysimeter system, with the intent of adding waste material to the lysimeter and monitoring contaminant release from the waste material. The lysimeter system could accommodate other types of experiments as well (e.g., waste imbedded in soil).

A second approach is to monitor radionuclide release from already disposed waste materials in burial trenches. Los Alamos is collecting moisture samples and gas analyses taken from boreholes drilled underneath burial trenches. This approach is well suited for a disposal site like Los Alamos where the waste is buried in competent rock rather than loose soil and sits on top of a mesa so that horizontal drilling under the burial site is feasible. This type of monitoring approach will be difficult at other sites where waste is disposed of in loose soil.

\subsubsection{Discussion}

Two approaches can be taken to define source term release rates for groundwater release and transport analyses. The first approach is make simplifying assumptions to define a single mathematical expression for release estimates. Common methods for defining source term release 
values are (a) assume that the complete inventory is available for release at some initial concentration (e.g., the total inventory divided by the volume of pore space in the waste material/waste form) and release is defined by the hydrologic properties of the disposal system;

(b) assume an initial concentration as described above and some fixed fractional release rate; and

(c) assume some fixed initial concentration and a fixed diffusional release rate.

This approach has the advantages that these assumptions are considered conservative (i.e., overestimates expected release and, therefore, dose estimates) and can be easily inserted into the computer code for release and transport. Also, a laboratory-scale data base can be determined fairly quickly for the diffusion rate assumption. In fact, for numerous cementitious wastes, such data are available in the literature. The disadvantage of this approach is that the accuracy of the data compared to real environmental conditions cannot be established unequivocally.

The second approach is to develop an empirical data base that consists of radionuclide release measurements completed under site-specific conditions with the expected waste form or waste material. Key parameters to be simulated are a closer approximation to the size of the waste form, the chemistry of the infiltrating groundwater, and the infiltration characteristics of a real system (e.g., the effects of a protective cover). This data base can then be used to define a mathematical approximation of contaminant release and provide a comparison with laboratory-scale release data. The advantage of this approach is that a closer approximation of the real condition is provided, and the observed release rates will provide greater confidence that the modeling assumption is good. This objective is highly desirable when reliance is placed on the empirical approach to describing complex natural phenomena. The disadvantages to this approach are greater costs to establish the experiment and longer times required to generate the data (probably a decade or more). A long-term commitment of funding would be necessary to derive full benefit from the experiment.

An additional benefit to be gained from completing this work is application of the results to future disposal concerns that exist at most DOE sites but are not necessarily considered by DOE Order 5850.2A. In particular, these kind of data should be applicable to the CERCLA process for already buried waste. These data would be extremely valuable in evaluating the no treatment or in situ remediation options.

One method for achieving this goal is to conduct experiments on a pilot-scale basis during the period of low-level waste disposal (several decades). A goal should be to create the disposal facility conditions (e.g., a protective cover) that are expected to be used. By comparing long-term data with the data provided in short-term laboratory experiments and calculating relative release rates, an excellent idea of real versus assumed waste release assumptions can be achieved. These long-term projects may require completion as a DOE complex-wide program rather than as a site-specific program.

The lysimeter workshop summarized tests in progress that are completing parts of this kind of experiment. At the end of the workshop it was agreed that a review of these various activities would be useful to plan for further large-scale experimental work. There was a consensus that the intent of these past activities may have been different than the current PA analysis objectives. The review should therefore focus on acquiring missing information and suggesting necessary 
changes in approach to satisfy the data needs of PA analyses. This focus will require the input of experimentalists, modelers, and PA integraters in order to be successful. This activity should be considered an integral part of the maintenance phase of the PA activity described in DOE Order 5820.2A.

\subsection{Radionuclide Screening}

\subsection{1 lssue}

Screening models are often used as a tool to obtain a conservative estimate of the potential radiological impacts of releases from a facility used for permanent disposal of low-level radioactive wastes. Screening analyses have been used for performance assessments of several DOE facilities to reduce large lists of radionuclides to more manageable lists of radionuclides for consideration in more detailed analyses. Based on the results of these calculations, it is apparent that screening analyses can be taken more seriously in the process of determining waste concentration (or inventory) limits for LLW disposal facilities.

\subsubsection{Recommendation}

A number of benefits can be obtained by using screening calculations to establish an initial set of "trigger levels" for radionuclides at a given site. Trigger levels provide waste generators and facility operators with an indication of what constitutes a potentially significant concentration (or inventory) for a given radionuclide in a given disposal facility in regard to meeting performance objectives for protection of public health and the environment. If the concentration (or inventory) of a radionuclide in the incoming waste is expected to be below the trigger level, then no additional calculations or data collection activities are necessary for that radionuclide. However, if the concentration (or inventory) of a radionuclide is expected to be larger than the trigger level, then more detailed calculations and/or data collection activities would be required for that radionuclide. Such an approach also emphasizes the need to clearly communicate the conservative basis for a set of trigger levels and subsequent waste concentration (or inventory) limits based on more detailed analyses.

\subsubsection{Rationale}

Screening models have been used for a number of years to obtain initial conservative estimates of potential doses to the public from facilities processing or disposing of radioactive materials. The most common use has been for assessing atmospheric releases at operating facilities; however, with the increasing efforts related to PAs for design of waste disposal facilities and risk assessments for cleanup decisions at contaminated sites, broader applications for screening analyses have become apparent. This rationale will focus on the use of screening models to establish conservative radionuclide concentration (or inventory) limits, hereafter termed trigger levels, for waste generators and operators to use at a given LLW disposal facility.

The primary objectives of this rationale are to discuss the benefits of using screening analyses to establish conservative trigger levels for radionuclides to be placed in a disposal facility and to present an approach for establishing the trigger levels. Another important objective is to emphasize the need for analysts and PA managers to clearly state the underlying assumptions for 
the analysis on which a set of trigger levels or waste concentration (or inventory) limits is based. Background material discussing DOE and NRC approaches to PA is provided first. This is followed by a discussion of the benefits of using screening models. A third section presents example screening approaches for intruder and groundwater analyses. This is followed by a summary of the more important conclusions from the paper.

\subsubsection{Background}

DOE Order 5820.2A requires that each site establish waste acceptance criteria for materials to be disposed of in a LLW disposal facility. Typically, as part of these criteria, each site establishes concentration limits of radionuclides for acceptable waste disposal based on PA calculations. Although the current approach is logical and defensible, a more efficient approach has been considered based on experiences in PAs at DOE sites and discussions at Team meetings. Experience has shown that the use of a screening approach increases the cost-effectiveness of PAs.

An underlying basis for the use of screening analyses is the iterative nature of PA calculations. The iterative nature of PA has been recognized in DOE requirements, DOE-sponsored guidance, and NRC-sponsored guidance. DOE Order 5820.2A specifically addresses the iterative nature of PA by stating the "each site shall prepare and maintain (emphasis added)" a PA for the purpose of demonstrating compliance with the performance objectives. DOE-sponsored guidance ${ }^{64,65}$ and $\mathrm{NRC}$-sponsored guidance ${ }^{66}$ have also identified the iterative nature of PAs. Recognition of the iterative nature and the need to maintain a PA is a key element in the increased use of screening analyses. Use of screening analyses would help optimize the expenditure of resources and avoid unneeded efforts on evaluating trivial aspects of facility performance.

Understanding the purpose of a PA also contributes to the basis for the use of screening analyses. References 64 and 66 have emphasized that a PA is a compliance calculation, the purpose of which is to demonstrate that the potential dose will be below a given performance objective, rather than a calculation to provide best estimates of actual doses that might occur. This is an important distinction that greatly affects the manner in which a PA is conducted. Since the goal is to demonstrate that the dose is below a given performance objective, the tendency is to use conservative assumptions as long as the performance objective is met. The cost of collecting data and defending assumptions for a conservative model can be much less than for a more realistic model.

These two concepts have a large impact on the way PAs are conducted and how the results of PAs need to be interpreted. Because of the iterative and conservative nature of PAs, concentration (or inventory) limits may change over time as new data are obtained and new analyses are conducted. The fact that PAs tend to be biased toward conservative assumptions, rather than actual predictions of dose, suggests that limits based on PA results are not actually requirements that must be met to protect public health and the environment, but are targets that are dependent on the conservative assumption made in the PA models. Nevertheless, the public may view these as actual concentration (or inventory) limits, which, if exceeded, would result in doses in excess of allowable levels. Benefits of using screening models and proposed approaches for screening analyses are provided in the following paragraphs. 


\subsubsection{Benefits of Using Screening Models}

The use of screening models to establish conservative trigger levels provides a number of benefits over the short and long term. The two items discussed in the previous section directly suggest potential benefits from a public perception perspective. If firm limits are established based on conservative models, outsiders may feel that any wastes in excess of the limits are not safe for disposal, when in reality the wastes can be demonstrated to be safe for disposal with an investment of time and funding to use less conservative assumptions. This also leads to benefits from a cost-effectiveness perspective that can also be realized by using screening models. These benefits are discussed below.

As stated previously, it is well recognized that PA is an iterative process. A logical way to conduct the iterations is to start with simple models with minimal requirements for site-specific data. In this regard, screening offers a simple and straightforward approach to obtain a set of conservative trigger levels for radionuclides. The trigger levels are used to identify which radionuclides need to be considered in more detailed analyses (i.e., the next iteration). Experience to date with PAs at DOE LLW disposal sites suggests that up to $90 \%$, or more, of all radionuclides reported in waste inventories can be eliminated from further consideration using simple spreadsheet or hand calculations based on bounding values for site parameters.

Cost-effectiveness can be significantly increased by using screening calculations. As stated previously, screening calculations can remove as many as $90 \%$ of the radionuclides in an inventory from consideration in detailed analyses. The cost of conducting screening calculations is relatively small in terms of time to conduct, check, and document the calculations. Additional savings are recognized when defending the results and when obtaining the data necessary to defend results. Data costs should be minimal, given that very conservative assumptions are used. After the first round of screening calculations, the analyst will be able to identify the radionuclides of concern in the inventory. Thus, detailed data collection and analysis efforts will be directed only at the potentially important radionuclides.

A less tangible but critical long-term benefit relates to perception of results. We expect that a baseline set of trigger levels, obtained with a clearly conservative and easy to understand model, will encourage assumptions used for subsequent results to be considered more carefully. This will help to emphasize the dependence of concentration (or inventory) limits based on the more detailed calculations on the assumptions used. It is important to recognize that limits simply reflect the conditions that were modeled. For example, new containers may be developed that will provide a large increase in isolation capability. Limits based on calculations using assumptions for lesser containers would likely be too restrictive if the new containers were used.

The above paragraphs have identified some benefits of using screening analyses to establish an initial set of trigger levels as an interim step before setting waste concentration (or inventory) limits using more detailed calculations. Cost savings and improved efficiency are important benefits that can be appreciated by all parties, but a less tangible benefit may be more important in the long term. Given the large amount of public scrutiny of waste disposal projects, the need to clearly identify the basis for conclusions cannot be ignored. It is important to understand that limits obtained by conducting a PA usually are based on conservative analyses conducted within budget and time constraints. In many cases, some additional data collection and/or more detailed 
analysis could demonstrate that it is indeed safe to dispose of larger concentrations (or inventories). However, in the interest of cost effectiveness, expenditures on additional analysis or data collection should not be made unless there is a forecasted waste form that would require a larger limit.

\subsubsection{Proposed Approach}

Performance objectives for LLW disposal facilities at DOE sites address protection of offsite members of the public, inadvertent intruders into the disposal site following loss of active institutional control, and groundwater resources. The groundwater pathway is generally expected to be the most important for offsite releases. A requirement for protecting groundwater in accordance with drinking water standards is expected to be more restrictive in regard to determining allowable releases than the requirement for protecting offsite individuals from all exposure pathways. Thus, the simplified approach discussed in this paper focuses on the drinking water pathway. Intrusion scenarios generally address exposures to average concentrations of wastes brought to the surface as a result of excavating a basement into the waste or drilling a well through the waste.

The primary emphasis of the approach is to use simplified intruder and groundwater pathway screening to identify trigger levels that result in acceptable performance without the need for detailed analysis. Rather than limits, screening analyses would provide a set of waste concentration (or inventory) trigger levels below which safe performance is virtually ensured. The derived trigger levels could be used to provide guidance for operators of disposal facilities concerning waste concentrations (or inventories) of any radionuclides that would require reevaluation in a detailed PA. The primary benefit is the ability to identify readily acceptable wastes based on screening, while judging the acceptability of wastes with activities in excess of the trigger values on a generator-specific basis (i.e., inventory, waste form, and container) and avoid a large expenditure for analysis and data collection of wastes that could not contribute significantly to the overall performance of the disposal facility.

Three approaches for screening are discussed in this section. The first approach is for intruder dose analyses and the second and third approaches are for analyses of releases to groundwater. The intruder case is presented in a form so that no analyses would even be required. Early decisions concerning the acceptability of wastes can be made based on a simple criterion. The groundwater pathway is slightly more complicated but can still be done on a spreadsheet. A number of different approaches can be used. The two approaches presented here are provided as examples. The general rule of thumb is that the approaches should require minimal data and should be unquestionably defensible in regard to the conservative nature of the assumptions used in the calculations.

2.18.6.1 Intruder Pathway. At many sites, an agriculture scenario will be used to set concentration limits for radionuclides that would provide protection of inadvertent intruders. Previous experience with PAs at DOE sites has indicated that the dose to an inadvertent intruder from any radionuclide will be a small fraction of the dose limit (generally less than $10 \%$ and in most cases much less than 10\%) if the average concentration in the waste is less than $1 \mu \mathrm{Ci} / \mathrm{m}^{3}$. Therefore, an initial trigger level to identify radionuclides requiring more detailed consideration for intrusion scenarios would simply be a concentration of $1 \mu \mathrm{Ci} / \mathrm{m}^{3}$. 
It is important to note that the trigger level given above is an average concentration, and the facility operator can interpret the trigger level in two ways. The first and simplest interpretation is for the facility operator to assume that this is a package limit (i.e., any packages with radionuclides present in quantities less than $1 \mu \mathrm{Ci} / \mathrm{m}^{3}$ need not be considered in subsequent analyses). A second interpretation is to apply the trigger level to the average concentration in all waste packages. This interpretation requires the facility operator to keep track of the concentrations in individual waste packages, but it would permit concentrations in individual packages to be above the trigger level, while still not requiring more detailed analysis. In this case, radionuclides with average concentrations in all wastes less than $1 \mu \mathrm{Ci} / \mathrm{m}^{3}$ need not be considered in subsequent analyses.

The approach to screening is particularly simple for the case of intruder dose analyses, because the total dose to an intruder is just the sum of the predicted doses from all radionuclides. Therefore, the sum-of-fractions rule can be applied to mixtures of radionuclides in a straightforward fashion.

2.18.6.2 Groundwater Pathway. Two general approaches essentially based on the assumption that an individual consumes 2 liters/day of pore solution in the waste are envisioned in the screening analysis for the groundwater pathway. The fundamental difference between the two approaches is the time period for radionuclide decay prior to consumption by a potential receptor. Each approach would consider a combination of inventory, half-life, radiotoxicity (i.e., the dose per unit intake by ingestion), and environmental mobility (in the form of a retardation coefficient and/or solubility). In either approach, the results would be readily obtainable using a spreadsheet that requires minimal time to be revised for numerous radionuclides. Thus, the approaches could readily consider changes in the inventory or account for the addition of a radionuclide to the inventory.

One equation can be used to conduct the screening calculations for both approaches by using the parameter $t$, to represent the time after disposal at which consumption of contaminated water occurs. The appropriate values for $t$ depending on the particular approach, are discussed in the following paragraphs. An equation that can be used for determining trigger levels for the groundwater pathway is:

$$
T_{i}=\frac{D_{s t d} \theta R_{d}}{D_{i n g} C_{r} e^{-\lambda t}}
$$

where

$$
\begin{aligned}
& \mathrm{T}_{\mathrm{i}}=\text { trigger level for radionuclide } \mathrm{i}(\mathrm{Ci} / \mathrm{liter}) \\
& \mathrm{D}_{\text {std }}=\text { dose limit, typically assumed to be } 4 \mathrm{mrem} / \mathrm{yr} \\
& \mathrm{D}_{\text {ing }}=\text { ingestion dose conversion factor for radionuclide } \mathrm{i}(\mathrm{mrem} / \mathrm{Ci}) \\
& \mathrm{C}_{\mathrm{r}}=\text { consumption rate, } 730 \text { liters/yr }
\end{aligned}
$$




$$
\begin{aligned}
& \lambda=\text { decay constant for radionuclide } \mathrm{i}(1 / \mathrm{yr}) \\
& \mathbf{t}=\text { time at which consumption takes place }(\mathrm{yr}) \\
& \boldsymbol{\theta}=\text { porosity of aquifer }(-) \\
& \mathbf{R}_{\mathbf{d}}=\text { retardation coefficient for radionuclide } \mathrm{i} \text { in the aquifer }(-) .
\end{aligned}
$$

The first approach assumes that the radionuclides are consumed at the time immediately following institutional control. That is, the entire waste inventory at 100 years is assumed to be dumped in the same volume of aquifer at the disposal site, with no releases assumed to have occurred before that time. Thus, the screening concentration in groundwater would be obtained by allowing decay for the time up to institutional control and considering solid/solution partitioning in the aquifer; e.g., $t$ from Equation (1) is set equal to $100 \mathrm{yr}$. Distribution coefficients or solubilities for radionuclides should be selected conservatively to ensure that the possible concentration in groundwater is bounded. Also, if multiple radionuclides are present in quantities close to, but not exceeding, the trigger levels, then the analyst will need to either to consider the radionuclides in the next phase of the PA or provide further justification before deciding not considering the radionuclides in the next iteration.

The second approach assumes that the radionuclides are consumed at the time based on the radionuclide-specific travel time to a well $100 \mathrm{~m}$ downstream from the facility; e.g., $t$ from Equation (1) is set equal to a conservative groundwater travel time multiplied by the retardation factor for the radionuclide of concern. Concentrations would be calculated in the same way as in the previous approach, except for the different decay time. In this case, conservative assumptions must be made regarding the groundwater travel time and the distribution coefficients assumed for the radionuclides. Selection of a conservative distribution coefficient for determining the concentration will also result in a conservative value for determining the radionuclide travel time.

A critical consideration when specifying a delay time is defensibility and justification of the assumptions. Potential sources of delay include: institutional control, groundwater travel time, retardation, and containment by engineered barriers. The emphasis during screening should be placed on making conservative bounding assumptions for all inputs used to determine the delay time and radionuclide concentrations in the aquifer. This will be necessary because there is a lack of sufficient data during the early stages of the analysis. It is also advisable because the intent of screening is to minimize the need for detailed justification and defense of models and inputs.

When using the approach based on radionuclide travel time to the downstream well, some special considerations exist. For example, for short-lived radionuclides, a larger dispersion coefficient may be more conservative, because the contaminant arrives earlier (i.e., a radionuclide may decay completely at the time of arrival for plug flow, but may not decay completely when the front edge of the dispersed plume arrives). Thus, the travel time should address possible dispersion. However, it should be noted that if a travel time based on dispersion is used, then the concentration at the front of the plume should also be adjusted for dispersion. Thus, a concentration lower than that used for a plug flow calculation should be used commensurate with the amount of dispersion assumed. Justification for a given retardation factor is also critical in 
this case. Daughter products are generally assumed to travel with the parent. However, the analyst will need to determine the adequacy of this assumption on a radionuclide-specific basis.

The institutional control period approach has less chance for misuse, given the considerations discussed in the previous paragraph. However, the travel-time-based approach incorporates some features that must be addressed in the more detailed calculations. This can provide some early insight into the factors that will affect the detailed calculations. Both approaches have been used with success at DOE sites. Other approaches can and have been successfully applied. The approaches discussed in this section are provided as examples; selection of an approach to be used at a given site is at the discretion of the analyst. However, analysts must use caution to ensure defensibility and conservatism of results.

\subsubsection{Summary}

In conclusion, it is recommended that the results of screening analyses be taken seriously. Screening analyses can be used to establish a set of trigger levels that are not intended to be limits but are intended to indicate a concentration (or inventory) above which more detailed analyses will be required in order to demonstrate compliance with the performance objectives for LLW disposal. Three approaches for establishing trigger levels based on the results of screening analyses were provided. The calculations are simple enough to be conducted with a spreadsheet or hand calculations.

The use of screening calculations is consistent with the iterative nature of a PA and tends to increase the cost-effectiveness of data collection and analysis in support of a PA. This is also consistent with the DOE requirement that each site must prepare and maintain a PA. Use of screening analyses may also help to place the results of PAs in better perspective. It is important to recognize that PAs are conservative by nature. When limits are established it is critical to emphasize the conservative assumptions used in the calculations, and thus, the conservative nature of the limits. For example, recognition that limits are a function of the assumptions on which they are based will help people understand that limits may change if future waste forms or containers can be shown to provide additional isolation capability for certain radionuclides.

\subsection{The Intruder and the All-Pathways Analyses}

\subsubsection{Issue}

Chapter III of DOE Order 5820.2A requires that performance assessments for LLW disposal facilities provide reasonable assurance of compliance with the performance objectives listed in Section III.3.a. These performance objectives include a requirement to limit the annual dose to individuals assumed to inadvertently intrude into the disposal facility following an assumed end to an active institutional control period, and a requirement to limit possible release of radioactive material to the environment. Limits for release to the environment are specified in terms of an annual dose to members of the public based on consideration of all pathways of exposure.

For the intruder analysis, one assumes that the intruder performs a limited set of construction and homesteading activities. The issue is whether, when performing all-pathways 
analyses, one should consider the possible disruptive effects of these construction and homesteading activities on barriers to release and transport of radioactive material.

\subsubsection{Recommendation}

In performance assessments, pursuant to Chapter III of Order 5820.2A, the intruder protection analyses should be considered separately from the all-pathways analyses. The hypothetical effects of an intruder on barriers to release from disposal units need not be explicitly considered in all-pathways analyses. Rather, all-pathways analyses should consider reasonably foreseeable, naturally occurring processes (e.g., erosion, burrowing animals, plant roots) that also may have disruptive effects on barriers to release and transport of radioactive material.

\subsubsection{Rationale}

This recommendation derives from the following information:

1. Inadvertent intrusion has been used historically as a hypothetical device, originally as a tool for defining general categories or classes of radioactive waste, and later as a mechanism for deriving criteria for LLW acceptance and facility design and operation.

2. The recommendation is consistent with federal regulatory requirements for disposal of other kinds of waste.

3. Because intrusion scenarios stem from hypothesized projections of human activities (which may never occur), countless scenarios could be envisioned. However, natural processes should be expected to occur, and the kinds of natural processes that could affect the performance of the disposal facility can be reasonably bounded.

2.19.3.1 Use as a Hypothetical Device. There are no legal mandates to consider protection for an inadvertent intruder into a radioactive waste disposal facility-this is in contrast to legal mandates to protect the air and ground and surface waters, and in contrast with the charter of the EPA to set generally applicable environmental standards. Intrusion was originally conceived for use in studies estimating the relative "hazard" of different categories of radioactive waste. Intrusion scenarios were later modified and used by the NRC to establish general waste acceptance and facility design and operating requirements for LLW disposal. Under DOE Order 5820.2A, intrusion must be considered in LLW performance assessments to set similar requirements on a site-specific basis.

Traditionally, the principal objective for achieving safe disposal of low-level waste has been to limit releases to the environment to some acceptably low level. This was the basis for the siting and original operation of all commercial LLW disposal sites, as well as the basis for siting and operating existing DOE disposal areas. The concept that one should limit radiation exposures to a potential inadvertent intruder arose during the late 1970s in the context of defining general categories or classes of radioactive waste.

At that time, different ways of estimating and comparing the relative hazard of different radioactive wastes, and thereby classifying the wastes according to a hierarchy, had been used or 
considered. Waste might be classified according to the generator or process that produced the waste, or according to operational considerations such as surface dose rates. Waste might be classified by the heat that was generated from decay. Waste might be classified by dividing radionuclide inventories by maximum permissible concentration limits from 10 CFR Part 20, thereby deriving a hypothetical measure of the volume of air or water required to dilute the waste to meet public dose limits.

Because these classification schemes seemed nebulous or incomplete, there arose an interest in categorizing different radioactive wastes in terms of disposal hazard. To this end, a number of "waste classification" studies were completed, including those by Leddicott, ${ }^{67}$ Adam and Rogers, ${ }^{68}$ Healy, ${ }^{69}$ and Cohen. ${ }^{70}$ These studies were generic rather than site-specific, and generally independent of regulatory requirements for disposal of the various categories of waste. These studies calculated human exposures by considering a limited number of scenarios involving direct intrusion into disposed waste (assuming that at the end of an institutional control period the disposal facility would be released for unrestricted use), as well as scenarios involving release into the environment. These assumptions and scenarios were then used to set concentration limits for categories of radioactive waste based on comparison to a limiting dose objective.

For the Part 61 rulemaking, NRC departed from previous waste classification studies. First, the NRC abandoned the notion of a general classification of radioactive waste, limiting its consideration to LLW as it had been defined by exclusion in the Low-Level Radioactive Waste Policy Act of 1980. Second, the NRC assumed that, although there may be some breakdowns in passive institutional control following the end of an active institutional control period, unconditional release of a LLW disposal facility was unlikely. Intrusion was envisioned as a hypothetical event-an accident, and very likely a temporary accident-triggered by bureaucratic bungling. Third, the NRC gave greater emphasis to waste form than had been the case for pervious waste classification studies and had previously been the practice for LLW disposal.

The NRC used the concept of inadvertent intrusion as a tool to establish a general waste classification system for commercial LLW disposal. Intrusion scenarios were used as a basis for the system because these scenarios were thought to be relatively independent of the disposal site environment, and because intrusion scenarios involving direct contact with disposed waste could be used directly to establish concentration limits. Given the hypothetical nature of intrusion, the NRC did not try to evaluate the almost boundless range of human actions that could be imagined, but limited the consideration to a few representative scenarios. In this way, a simple system was derived that could be used by potentially thousands of waste generators.

Despite the use of intrusion scenarios to derive concentration limits, the main emphasis in the Part 61 rulemaking was-and is-to minimize releases to the environment and to avoid situations requiring future remedial actions. The classification system was designed to ensure that most of the waste activity (in practice, greater than 90\%) would be disposed of in a structurally stable form, which reduces the potential for release to the environment. Applicants for Part 61 licenses need not perform analyses to calculate hypothetical doses to hypothetical intruders. About the only times an applicant might consider intrusion in a performance assessment for a LLW disposal facility would be if the waste to be disposed of differed significantly from that assumed for the rulemaking, or if the disposal method differed radically from those considered in the rulemaking. 
More recently, DOE published Order 5820.2A, in which protection of an inadvertent intruder is considered on a site-specific rather than a generic basis. Analyses are to be used to establish waste acceptance and facility design and operating requirements.

2.19.3.2 Consistency. The recommendation is consistent with federal regulatory requirements for other types of waste. The only federal regulatory requirement to consider the effects of an intruder on the performance of a disposal facility is Section 191.13 of EPA's standard for disposal of high-level and transuranic waste, 40 CFR Part 191.

The intruder need not be considered in disposing of hazardous or municipal solid waste. An applicant for a disposal permit need not consider the possible health effects on a hypothetical intruder into a hazardous waste disposal facility or municipal landfill, nor the disruptive effects the intruder might have on the disposal facility or landfill.

For low-level radioactive waste, two regulatory citations of note include 10 CFR Part 66 and draft 40 CFR Part 193. The Part 61 regulation is silent about whether intrusion should be considered for compliance with 10 CFR 61.41, "Protection of the General Population from Release of Radioactivity." So is the NRC's standard format and content guide for a Part 61 application. ${ }^{19}$

In the draft ${ }^{10}$ and final ${ }^{35}$ environmental impact statements for the Part 61 rule, the NRC nominally considered the possible effects an intruder might have on a LLW disposal facility, in that an assumption was made that an inadvertent intruder would disturb some of the trench caps at the disposal facility. However, no basis was given for the assumption, and the possible disruptive effects the intruder might have were lumped with those that could occur from natural processes such as erosion or plant and animal intrusion.

The April 1989 version of the EPA draft standard for LLW disposal, 40 CFR 193, contains a dose limit for release to the environment, plus a groundwater protection requirement. ${ }^{71}$ In this draft standard, the EPA is not explicit about whether one should consider potential disruptions by the intruder when demonstrating compliance with the draft disposal standard. It does not appear that the EPA means that the intruder should be so considered, because they did not consider the effects of intrusion in the draft Background Information Document written to provide technical support to the draft standard. ${ }^{72}$

For disposal of uranium mill tailings, the EPA has indicated that intrusion need not be considered when demonstrating compliance with 40 CFR Part 192, "Health and Environmental Protection Standards for Uranium Mill Tailings." 73 Promulgating these standards on January 5, 1983 (58 FR 590), the EPA set standards for control and remedial action at inactive uranium processing sites. These standards set criteria for stabilization and control of tailings, limits for release of radon from residual materials, concentration limits for radium in soil, and limits for radiation levels in buildings. As stated by EPA ${ }^{73}$ (see 48 FR 597),

We consider the single most important goal of control to be effective isolation and stabilization of tailings for as long a period of time as is reasonably feasible, because tailings will remain hazardous for hundreds of thousands of years. The longevity of tailings control is governed chiefly by the possibility of intrusion by man and erosion by 
natural forces. Reasonable assurance of avoiding casual intrusion by man can be provided through the use of relatively thick and/or difficult-to-penetrate covers (such as soil, rock, or soil-cement). No standard can guarantee absolute protection against the purposeful works of man and these standards do not require such protection ...

On September 24, 1987, the EPA proposed amendments to 40 CFR Part 192 to add groundwater protection requirements. ${ }^{33}$ A final rulemaking has not been published, although the rule has been drafted in final form and submitted to the Office of Management and Budget. Because the EPA does not address intrusion in the Federal Register Notice (FRN) for either the proposed or draft final rule, this suggests that their position on intrusion, as stated in their 1983 FRN, is still applicable. The EPA does indicate that a judgement about meeting the standard would "necessarily be based on site-specific analyses of the properties of the sites, candidate disposal systems, and the potential effects of natural processes over time. ${ }^{n 33}$

The existing EPA standard for high-level and transuranic waste disposal, ${ }^{7} 40$ CFR Part 191, includes individual, groundwater protection, and containment requirements. For the individual and groundwater protection requirements (Sections 191.15 and 191.16), EPA indicated that compliance could be demonstrated, assuming that the disposal system was not disrupted by human intrusion or the occurrence of unlikely natural events. Similar to draft 40 CFR 193, these requirements prescribe limiting doses to individuals outside the disposal facility.

The containment requirements in Section 191.13 represent the only federal regulatory mandate to consider the possible impact of an intruder on a disposal facility. In Section 191.13, the EPA requires a probabilistic analysis for which intrusion is considered an event having a cumulative probability exceeding 0.1 over 10,000 years. But even in this case, consideration of intrusion is constrained: First, intrusion must be considered not for compliance with a dose limit to a small group of individuals, but for an abstracted release limit from a repository given as curies released per time per unit of nuclear fuel. The purpose of the containment requirements is to provide a level of protection for very large populations. ${ }^{7}$

Second, there are limits to the assumptions that need be made about the nature and extent of intrusion. For example, an implementing agency need not assume use of more exotic technology than that existing today-namely, use of standard well drilling techniques. Caps are specified for the number and frequency of well boreholes that need be assumed. In Appendix B of 40 CFR Part 191, the EPA states that "implementing agencies can assume that passive institutional controls or the intruders' own exploratory procedures are adequate for the intruders to soon detect, or be warned of, the incompatibility of the area with their activities." This suggests that as long as one can assume that the intruders are smart enough to quickly recognize that they are dealing with a radioactive waste disposal facility, one should also be able to assume that the intruders are smart enough to realize that any damage to the facility should be repaired.

In any event, the EPA's inclusion of the intruder requirement in 40 CFR 191 is controversial. In Federal Register Notices for the draft ${ }^{74}$ and final ${ }^{75} 10 \mathrm{CFR}$ Part 60, the NRC remarked that consideration of intrusion into a geological repository was of "no use" and "fanciful." Since that time, DOE, NRC, NRC's Advisory Committee on Nuclear Waste, and others have recommended that the EPA regard intrusion as a very unlikely event for purposes of 
compliance with the Part 191 standard. A National Research Council Symposium has also addressed the issue. ${ }^{76}$

Two recent actions of Congress have restricted the application of 40 CFR Part 191. In the Waste Isolation Pilot Plant (WIPP) Withdrawal Act, Congress has mandated that, except for certain sections of Part 191 (Sections 191.15 and 191.16, to be re-proposed by EPA), 40 CFR Part 191 is in effect for WIPP. Therefore, Section 191.13 is in effect for WIPP. However, the Act stipulates that 40 CFR Part 191 does not apply to the Yucca Mountain site under investigation for possible disposal of high-level waste and spent fuel.

For that site, under the National Energy Strategy Act, the EPA must promulgate regulations for release of radioactive material to the general environment in terms of "the maximum annual effective dose equivalent to individual members of the public." The regulations must be consistent with findings and recommendations of the National Academy of Science (NAS) on reasonable standards for protection of public health and safety. NAS is to specifically consider (1) whether a health-based standard based on dose to individuals represents a reasonable standard; (2) whether active institutional controls can preclude intrusion into the disposal facility; and (3) whether the probability of intrusion can be predicted over 10,000 years.

2.19.3.3 Intrusion versus Natural Processes. Although it could be argued that inadvertent intrusion and natural processes both involve events that could degrade the effectiveness of infiltration barriers over LLW disposal units, or could enhance possible transport through environmental pathways, only the latter is reasonable for consideration in all-pathways analyses.

Because all inadvertent intruder scenarios involve assumptions about the actions of humans in the future, countless numbers of possible scenarios could be envisioned. There is no way to authoritatively predict the kinds of human actions that might occur in the future, nor the levels of technologies nor social structures. Thus, there is no way to authoritatively predict the effects an intruder might have on infiltration barriers and environmental pathways. If one did consider intrusion as part of the all-pathways analyses, a Catch-22 situation could result. No matter how favorable the site environment or how extensive the natural or engineered barriers, releases to the environment could be speculated merely by assuming that favorable site characteristics and barriers are bypassed. (It is in the nature of intrusion calculations to assume that barriers are bypassed.)

On the other hand, although intrusion events are hypothetical by nature, and may never occur, natural processes should be expected to occur. To be sure, there are large uncertainties in projecting natural processes into the distant future. However, it is believed that the kinds of natural processes that need to be considered can be reasonably bounded, as can their effects. (For example, one can project typical activities and burrowing depths of animals such as gophers without having to consider whether the gophers will employ heavy construction equipment.) By considering possible degradation to the disposal system caused by natural processes, one is also effectively considering the kinds of possible degradation effects that can be hypothesized as resulting from inadvertent intrusion. However, one is on firmer footing for the performance assessment. 


\subsection{Inadvertent Intruder Dose Objective}

\subsection{1 lssue}

The Team has debated two options for the intruder dose objective in DOE Order 5820.2A. The order states this as a performance objective, parallel to the objective for protection of the general public, requiring an analysis of intrusion scenarios against the specified dose objective. The alternative suggested is to use an analysis of potential dose to a hypothetical inadvertent intruder as the basis for setting site-specific waste acceptance criteria (WAC), similar to the NRC procedure for developing waste classes for $10 \mathrm{CFR} 61 .^{6}$

\subsubsection{Discussion}

The current direction of Team opinion is toward using potential dose to a hypothetical intruder as the basis for setting site-specific WAC, but the issue remains under discussion as the revision of DOE Order 5820.2A proceeds.

\subsection{Near-Surface Disposal of Uranium and Thorium}

This issue remains under discussion, since it appears that more information will be required for resolution. Some interim recommendations are provided below.

\subsubsection{Issue}

At the present time, two distinctly different approaches are taken in determining acceptable near-surface disposals of low-level waste containing uranium and thorium, depending on whether the waste is generated at DOE sites or in the commercial sector. The two approaches could result in quite different limits on concentrations of uranium and thorium that are acceptable for near-surface disposal.

At DOE sites, the present performance objective in DOE Order 5820.2A, Chapter III for protecting inadvertent intruders, particularly the limit on effective dose equivalent of 100 mrem per year for chronic exposure scenarios, would determine acceptable near-surface disposals of uranium and thorium, provided the performance objectives for protection of offsite members of the public and groundwater resources also would be met. The performance objective for inadvertent intruders could result in very low concentration limits for disposal of uranium and thorium.

The possibility of very low concentration limits of uranium in low-level waste for disposal at DOE sites arises from the long-term buildup of radium and its decay products, principally Rn-222. It is known that the average concentration of naturally occurring uranium in surface soil of only about $1 \mathrm{pCi} / \mathrm{g}$ results in an average effective dose equivalent of about $200 \mathrm{mrem}$ per year, most of which is due to $\mathrm{Rn}-222$. Now, for disposal of chemically separated uranium, a very long time is required for buildup of the radiologically more significant decay products. For example, the time required for radium and its decay products to reach equilibrium with initially pure uranium is on the order of $10^{5}$ years for U-238 plus U-234 and $10^{6}$ years for U-238 only. However, since the 
current DOE order does not impose a time limit for protection of inadvertent intruders and does not exclude doses resulting from radon from the performance objective, it is clear from the known dose from natural background that near-surface disposal of uranium essentially could be precluded by the order if the uranium is highly insoluble and reduction of the inventory in the disposal facility by mobilization and transport is expected to be unimportant during the time period for significant buildup of radium. That is, the concentration limit for disposal of uranium could be on the order of $1 \mathrm{pCi} / \mathrm{g}$, which is well below practical detection limits in low-level waste and presumably is too low to allow disposal of most uranium-contaminated waste.

The possibility of low concentration limits of thorium in low-level waste for disposal at DOE sites also arises primarily from the buildup of radon ( $R n-220$ in this case). However, thorium differs from uranium in one important respect. For disposal of chemically separated thorium, all decay products reach equilibrium within about 50 years, so the decay products will always be present and in equilibrium at any time after loss of active institutional controls, when exposures of hypothetical inadvertent intruders are assumed to occur. Since thorium is expected to be relatively insoluble in most environments, depletion of the waste inventory as a result of mobilization and transport before the time that intrusion scenarios could occur is not expected to be important. Since the average concentration of naturally occurring thorium and its decay products in surface soil of about $1 \mathrm{pCi} / \mathrm{g}$ results in an average effective dose equivalent of about 40 mrem per year, about two-thirds of which is from $\mathrm{Rn}-220$, the current requirements in the DOE order for protecting inadvertent intruders presumably would result in concentration limits for disposal of thorium of no more than a few $\mathrm{pCi} / \mathrm{g}$. This limit may also be too low to allow disposal of most thorium-contaminated waste.

For commercial low-level waste, the NRC's licensing requirements in 10 CFR Part 61 do not specify dose limits for hypothetical inadvertent intruders. Rather, protection of inadvertent intruders is provided by the NRC's waste classification system which specifies limits on concentrations of radionuclides that are generally acceptable for near-surface disposal. However, uranium and thorium are not included in the waste classification system. Therefore, if the performance objective for limiting dose to off-site members of the public would be met, commercial low-level waste containing uranium and thorium in any concentrations would be classified as Class-A waste and would be acceptable for disposal in a near-surface facility, in spite of the possibility that the resulting doses according to hypothetical scenarios for inadvertent intrusion could be very high (e.g., dose estimates exceeding 10 rem per year can be obtained).

In summary, the present performance objective in DOE Order 5820.2A for protecting inadvertent intruders may be so restrictive in regard to acceptable disposals of low-level waste containing uranium and thorium that near-surface disposal of waste containing these radionuclides essentially could be precluded, particularly in the case of uranium. On the other hand, the NRC's licensing criteria in 10 CFR Part 61 essentially permit disposal of any concentrations of uranium and thorium in a near-surface facility, regardless of the possible doses to hypothetical inadvertent intruders.

The Team is concerned about the implications of the two approaches to determining acceptable near-surface disposals of uranium and thorium in low-level waste. The current DOE approach, which is potentially quite restrictive, could result in very high costs for disposal of waste containing relatively low concentrations of these radionuclides (i.e., concentrations comparable to 
those that occur naturally in surface soil), especially if the volume of waste that would not be acceptable for near-surface disposal is high. On the other hand, the current NRC approach, which is quite unrestrictive, could result in unacceptable risks to hypothetical future inadvertent intruders, especially if large volumes of waste containing relatively high concentrations of uranium or thorium were placed in near-surface disposal facilities. Thus, the implications of both of these approaches may be unsatisfactory.

\subsubsection{Recommendations and Discussion}

The Team believes that the development of policies for determining acceptable near-surface disposals of low-level waste containing uranium or thorium should be pursued, with the objective of providing alternatives to the two extremes represented by the current DOE and NRC approaches described above.

Within the context of the present requirements of DOE Order 5820.2A, the Team offers three recommendations or possible approaches, for addressing disposal of low-level waste containing uranium or thorium.

First, if a performance objective for protecting inadvertent intruders in the form of dose limits is retained, the Team recommends that the performance objective explicitly exclude the dose from radon and its short-lived decay products.

The rationale for this recommendation is that the present performance objective for protecting inadvertent intruders is based directly on current radiation protection standards for the public, but such standards explicitly exclude the dose from natural background, of which radon is the principal component. Rather than leave radon unregulated, a reasonable alternative might be to establish a performance objective for the release rate of radon from low-level waste disposal facilities. For example, a release rate of $20 \mathrm{pCi} / \mathrm{m}^{2} \mathrm{~s}$ for radon would be consistent with EPA requirements for airborne emissions in 40 CFR Part $61^{77}$ and with design objectives for disposal of uranium and thorium mill tailings in the EPA's 40 CFR Part 192. ${ }^{32}$ If doses from radon were excluded from the performance objective for inadvertent intruders, calculations such as those contained in the draft performance assessment for the E-Area Disposal Facilities at the Savannah River Site suggest that the concentration limits for near-surface disposal at DOE sites would be increased by about a factor of three for thorium and about a factor of $\mathbf{3 0}$ for uranium. Absent significant mobilization and transport of the disposed waste, the resulting concentration limits would be roughly consistent with the concentration limits in the NRC's Branch Technical Position of $1981^{78}$ on unrestricted disposal or onsite storage of residual thorium or uranium from past operations, which the NRC essentially uses as cleanup criteria for unrestricted use of contaminated sites.

Second, the Team recommends that performance objectives for low-level waste disposal be applied for only 10,000 years after disposal. The Team notes that such a time limit would have no effect on acceptable disposals of thorium in regard to the current requirements for protection of inadvertent intruders but could result in substantial increases in concentration limits for uranium, because such long times are required for the buildup of radium and its decay products. 
For disposal of U-238 and U-234 in equilibrium, the concentration of radium at 10,000 years after disposal would be about $10 \%$ of the concentration of uranium. Since most of the dose from uranium and its decay products results from radium and its decay products, this time limit would increase the concentration limit for disposal by about a factor of ten. For disposal of U-238 only, the concentration of radium and its decay products at 10,000 years after disposal would be about $1 \%$ of the concentration of uranium, and this time limit would increase the concentration limit for disposal by about a factor of 40 . These example results assume that the dose from radon is excluded.

Third, particularly in regard to determining acceptable disposals of uranium, the Team emphasizes that consideration of mobilization and transport from a disposal facility is important, again because of the primary importance of radium and its decay products in an intruder dose analysis and the long times required for radium to achieve significant activity concentrations in the waste. For example, even in the absence of a time limit for application of the performance objective for inadvertent intruders, an average release rate of uranium of $0.01 \%$ per year (i.e., a mean residence time in the disposal facility of 10,000 years) would greatly reduce the importance of radium and its decay products at very long times in the future (e.g., at $10^{5}$ years and beyond).

The recommendations and possible approaches described above address only disposal of LLW containing uranium and thorium at DOE sites, but do not address the question of whether or not current policies regarding commercial waste containing uranium or thorium are reasonable (i.e., whether it is reasonable that commercial LLW containing any concentrations of uranium and thorium is generally acceptable for near-surface disposal). Although recommendations regarding disposal of commercial LLW are not the purview of the Team, the Team believes that a more consistent approach to determining acceptable near-surface disposals of uranium and thorium in commercial and defense waste than exists at present could be desirable.

Therefore, the Team recommends first, that data be collected regarding expected concentrations of uranium and thorium in commercial and defense LLW and the associated waste volumes. Then, if significant volumes of waste would be of concern, the Team recommends that the NRC and DOE seek a reasonably consistent approach to regulating near-surface disposals of waste containing uranium and thorium. Development of a more consistent approach presumably would take into account such factors as background levels of uranium and thorium in surface soil, the potential risks to human health and the environment and the time periods of concern for evaluating potential risks, and alternatives for waste disposal and their associated costs. 


\section{BENCHMARK SUBTEAM}

A Benchmarking Subteam was established, with the task of comparing computer codes and exposure scenarios for dose calculations in performance assessments. The subteam has completed the task, and a report, which covers the activities and findings of the subteam, is being prepared. A summary of the report follows.

The report is divided into three sections: (1) comparison of inputs used to define scenarios, (2) benchmark comparison for unit concentration in groundwater, and (3) benchmark comparison for unit concentration in soil. The first section is a discussion of differences in assumptions used to define the dose scenarios at the different sites (e.g., dilution factors for waste mixed with soil, breathing parameters for inhalation pathway, and consumption parameters for the ingestion pathway). The second and third sections use a standard set of inputs to demonstrate that similar results can be obtained using the two computer codes, as well as by using hand calculations. Differences in default inputs or models discovered during the comparison are discussed. The benchmark parameters were simply selected as a baseline for these comparisons and are not intended to be a recommended list. Each analyst should evaluate the applicability of input values for a specific site.

The PATHRAE and GENII computer codes were compared for the ingestion, inhalation, and external pathways for unit concentration in soil and water. Hand calculations were also conducted using a spreadsheet to compare with the computer code predictions. External pathway calculations were also conducted with the Microshield and ISOSHLD-PC computer codes for an additional point of reference. Numerous tables, with many combinations of the results, are provided to allow detailed consideration of the reasons for differences. Input files used in the simulations are also provided in the appendices to aid with reproduction of the results. The comparisons provided feedback regarding inherent differences in the computer codes as well as minor errors in the codes or documentation.

In general, the computer codes compared very well for most of the pathways. Treatment of uptake of C-14 and H-3 was different in the two codes and warrants close attention when conducting calculations with PATHRAE and GENII. Treatment of stored feed consumed by cattle is also different in the two codes. This results in differences for a few radionuclides. The differences were generally $10 \%$ or less as a result of the assumptions related to sorted feed. Some large differences in predicted doses were observed when the results using GENII average default inputs were compared with results using the benchmark parameters assumed for this analysis (note that no recommendation is implied for the benchmark values; any inputs for an analysis should be determined based on site-specific considerations). This reflects the potential for bias in default parameters for a computer code.

The largest consistent differences were observed between PATHRAE and the other codes considered for the external pathway. PATHRAE uses a fundamentally different approach to calculate external doses that yielded results significantly different from the other codes and from Federal Guidance Report Number 12 (FGR 12). Results in FGR 12 are the most up-to-date and should be considered a reasonable benchmark for other computer codes. The best agreement was obtained between GENII and FGR 12. Microshield also provided relatively good agreement with 
FGR 12, while ISOSHLD agreed with FGR 12 better than PATHRAE, but not as well as Microshield and GENII.

During the life of the activity, several changes were made to approaches used at different sites, based on interim findings of the subteam. The changes effected scenario definition, selection of computer codes, and parameter values used for PAs. Subtle differences in the computer codes and default inputs were identified; these need to be understood by potential users of the codes. These differences are discussed in the text of the subteams's report. 


\section{INTERNATIONAL ATOMIC ENERGY AGENCY COORDINATED RESEARCH PROGRAM}

The Team is supporting DOE participation in the IAEA Coordinated Research Program for intercomparison of PA codes and methods. The program involves having analysts from several nations analyze predefined test cases, compare results, and examine the reasons for differences. The results will improve the consistency of analysis using different codes and identify improvements that may be useful. As the comparisons improve, the credibility and defensibility of codes and analytical methods will be strengthened. For the first test case, the NRC was supported by Sandia National Laboratories, and DOE was supported by the ORNL Grand Junction (ORNL-GJ) office in Colorado.

The definition of Test Case 2a was distributed in July 1992, and DOE participation was through the Team, represented by EG\&G-Idaho and ORNL-GJ. Results were presented and discussed at a research coordination meeting in Augusta, Georgia, in October 1992.

Specifications for Test Case $2 b$ were prepared by a Team member (RRS), and analysis is in progress. Results will be presented and discussed at a Research Coordination Meeting in Spain in April 1994.

A Team member (RRS) helped to organize and schedule the lectures for an IAEA training course on Safety Assessment Approaches to be held in Argonne, Illinois, in February-March 1994. Participants from roughly 25 countries are expected to attend. The Team member and the chairman will also conduct lectures for the course. 


\section{DOE WASTE CLASSIFICATION SYSTEM}

An early issue addressed by the Team was a DOE system wide waste classification system. Discussion revealed that the rationale for not having a DOE system wide waste classification system in DOE Order 5820.2A was not well-known. It was decided that the background should be collected and documented to answer potential future questions, so a task was specified for the TSP at EG\&G-Idaho. A summary of the information collected by the TSP follows.

The Defense Low-Level Waste Management Program (DLLWMP) in 1986 initiated rewriting DOE Order 5820.2, Chapter III. DOE-HQ expanded this initiative and issued formal direction to rewrite the entire order.

In early 1987, DOE began research to establish a LLW classification system. DOE set up a working group to draft a prescriptive or a performance-objective-oriented revision of the LLW chapter of DOE Order 5820.2. The simplest option was to adopt the NRC's classification system, based on concentration of certain radionuclides as specified in 10 CFR 61.55. ${ }^{6}$ August 1987 was the goal for completing a working draft of the revised LLW chapter.

The consensus at preliminary meetings was that DOE should follow the NRC 10 CFR 61 classification system as closely as possible. The goal in adopting this system was that DOE should modify the NRC waste classification system according to the DOE system approach, existing policy, and special needs. Also, DOE should adopt an inadvertent intruder approach, the classification system should be cost effective, and it should reduce the burden placed on the waste disposal operators. The DLLWMP was interested in establishing Class I, II, and III limits based only on protection of the inadvertent intruder.

DOE site operators met in May 1987 to review the draft DOE approach to waste classification and to establish overall performance objectives. In calculating draft DOE limits, the same scenarios and assumptions identified by the NRC for 10 CFR 61 were used, with two exceptions. The exceptions were to use (a) performance objectives of $100 \mathrm{mrem} / \mathrm{year}$ effective dose equivalent for continuous exposures and $500 \mathrm{mrem} / \mathrm{year}$ effective dose equivalent for shortterm exposures, and (b) internal dose conversion factors based on ICRP-30, ${ }^{79}$ whereas NRC used earlier models. In addition, the DOE limits did not incorporate the factor of 10 used for the NRC Class $\mathrm{C}$ limits. These changes accounted for the majority of the differences between the DOE and NRC waste classification limits.

A waste classification table was developed at PNL and sent to the sites for review and comment. In general, comments on the waste classification table in DOE Order 5820.2A, Appendix A, Chapter III, were (a) the limits were lower than the NRC limits, and (b) certain radionuclides ( ${ }^{129} \mathrm{I},{ }^{226} \mathrm{Ra}$, thorium, and uranium) might be handled as greater-than-Class III. With cooperation from a working group of representatives from each DOE disposal site, the DLLWMP drafted a revised Chapter III dated September 30,1987, which was further revised at DOE-HQ on November 27, 1987.

The changes in the November 27, 1987, draft altered the September 30, 1987, Chapter III draft significantly. As changed, the classification system did not cover all radionuclides reported as significant by the major DOE waste disposal sites. Additionally, the November 27, 1987, draft 
omitted about $60 \%$ of the table from the September 30, 1987, version of Appendix A, "Waste Classification Guidelines." Some of the radionuclides omitted were uranium, thorium, and radium. The logic used for omitting the radionuclides was to make the table the same as the table in 10 CFR 61. This created problems for DOE sites using the table in Appendix A, because those radionuclides listed in the November 27,1987 , draft revision more closely represented waste streams from commercial reactors than those in DOE waste streams.

The major NRC concern with the proposed waste classification system was that the draft DOE dose limits were different from those of the NRC, thereby putting two federal agencies in differing public positions. Additionally, the Low-Level Radioactive Waste Policy Amendments Act incorporated by reference the existing Class $\mathrm{C}$ limits, thus placing those limits in law. A potential path forward was to use the NRC limits to define operating guidance for DOE waste disposal and still rely on the DOE performance objectives. The concerns raised by the NRC pointed out that incorporating the new dose models into the classification limits might be a very lengthy process in view of the time constraints placed on the revision. Another argument given to defer hasty adoption of a DOE-specific waste classification system was that it was thought to be internally inconsistent. For example, the upper limit for transuranics calculated with the parameters in ICRP-48 would not be the same as the transuranics waste concentration limit of $100 \mathrm{nCi} / \mathrm{g}$.

Although there was much support for establishing a DOE waste classification system from a credibility standpoint, the system was not completed. The result was that sections in Chapter III of the proposed revision on waste classification were deleted, as was Appendix A, "Waste Classification Guidelines for Management of Low-Level Waste."

The NRC waste classification system was not adopted because (a) dissimilarities of waste forms, waste streams, and disposal methods existed between DOE sites; (b) DOE's proposed limits were more stringent than those of the NRC, in some cases; and (c) the basis of the NRC system was a generic disposal scenario.

The classification effort evolved into a requirement for each disposal site to develop limits on radionuclide inventories and concentrations according to the specific characteristics of each site. Performance objectives are set, and waste acceptance criteria for each disposal facility are to be based on a PA with site-specific environmental conditions and engineered disposal systems. 


\section{FUTURE PLANS}

As the Team proceeds through 1994, the activities will include

- Continued discussion of issues that have not reached closure. Some of these can be closed; others deserve more discussion that will be useful even if complete closure is not reached.

- Continue analysis and reporting of IAEA test cases.

- Guide and coordinate field test programs (if approved).

- Coordinate existing and ongoing PAs at the sites. Past surveys have indicated a desire for a forum for discussion among the analysts, and that need could be filled. The meetings have generated a broader understanding of common issues, which has been useful.

- Provide briefings to DOE-HQ and related working groups, on request.

- Coordinate with parallel NRC and EPA developments.

- Provide coordinated input to the revision of DOE Order 5820.2A.

- Complete preparations for IAEA training course and provide lectures.

Additional issues under consideration for future discussion are

- Uncertainty analysis and probabilistic analysis

- Waste form release rates

- Engineered barriers

- Waste disposal limits and conversion to waste acceptance criteria

- Guidance for waste acceptors ("gatekeepers") to bridge the gap between performance assessors and field disposal site operators

- Need and justification for DOE active controls beyond 100 years

- $\quad$ Possible guidance document for DOE Order 5820.2B. 


\section{REFERENCES}

1. U.S. Department of Energy, DOE Order 5820.2A, Chapter III, "Low-Level Waste Management," 1988.

2. R. Shuman, DOE Site Performance Assessment Activities, DOE/LLW-99, prepared for the Radioactive Waste Technical Support Program by Rogers \& Associates Engineering Corporation, 1990.

3. B. A. Napier et al., GENII - The Hanford Environmental Radiation Dosimetry Software System, PNL-6584, Vols. 1 and 2, 1988.

4. V. Rogers, and C. Hung, PATHRAE-EPA: A Low-Level Radioactive Waste Environmental Transport and Risk Assessment Code, EPA 520/1-87-028, Environmental Protection Agency, Washington, DC, 1987.

5. U.S. Code of Federal Regulations, 10 CFR Part 60, "Disposal of High-Level Radioactive Wastes in Geologic Repositories," 1992.

6. U.S. Code of Federal Regulations, 10 CFR Part 61, "Licensing Requirements for Land Disposal of Radioactive Waste," 1992.

7. U.S. Code of Federal Regulations, 40 CFR Part 191, Environmental Radiation Protection Standards for Management and Disposal of Spent Nuclear Fuel, High-Level and Transuranic Radioactive Wastes," 50 FR 38066-40003, 1985.

8. M. McKenzie-Carter, Recommended Format and Content for DOE Low-Level Waste Disposal Facility Radiological Performance Assessment Reports, DOE/LLW-81, EG\&G Idaho, Inc., 1989.

9. U.S. Nuclear Regulatory Commission, Draft Environmental Impact Statement on 10 CFR 61, NUREG-0782, Vol. 1, 1981.

10. See page 38073 of Reference 7.

11. U.S. Department of Energy, DOE Order 5400.5, Radiation Protection of the Public and Environment, 1990.

12. International Commission on Radiological Protection, $A$ Compilation of the Major Concept and Quantities in Use by ICRP, ICRP-42, Pergamon Press, 1984.

13. U.S. Department of Energy, DOE Order 1330.1C, Computer Software Management, 1990.

14. National Research Council, Committee on Ground Water Modeling Assessment, Ground Water Models - Scientific and Regulatory Applications, National Academy of Sciences, National Academy Press, 1990. 
15. American Society of Mechanical Engineers, Quality Assurance Requirements of Computer Software for Nuclear Facility Applications, NQA-2-1989 Edition, Draft (Part 2.7), 1989.

16. American Society of Mechanical Engineers, Part 11S-2, Supplementary Requirements for Computer Program Testing, NQA-1-1989 Edition, 1989.

17. American National Standards Institute/Institute of Electrical and Electronic Engineers, Software Test Documentation, ANSI/IEEE-829, 1983 and Software Verification and Validation Plans, ANSI/IEEE-1012, 1986.

18. J. L. Bryant, and N. P. Wilburn, Handbook of Software Quality Assurance Techniques Applicable to the Nuclear Industry, NUREG/CR-4640, 1987.

19. U.S. Nuclear Regulatory Commission, Standard Format and Content of a License Application for a Low-Level Radioactive Waste Disposal Facility, NUREG-1199, Revision 1, 1988.

20. U.S. Nuclear Regulatory Commission, Standard Review Plan for the Review of a License Application for a Low-Level Radioactive Waste Disposal Facility, NUREG-1200, Revision 1, 1988.

21. S. A. Silling, Final Technical Position on Documentation of Computer Codes for High-Level Waste Management, NUREG-0856, 1983.

22. G. F. Wilkinson and G. E. Runkle, Quality Assurance (QA) Plan for Computer Software Supporting the U.S. Nuclear Regulatory Commission's High-Level Waste Management Program, NUREG/CR-4369, 1986.

23. R. R. Seitz, S. D. Matthews, and K. M. Kostelnik, Guidelines for Acquisition, Installation, and Testing of Performance Assessment Software, DOE/LLW-102, EG\&G Idaho, Inc., 1990.

24. P. K. M. van der Heijde, "Quality Assurance in Computer Simulations of Groundwater Contamination," Environmental Software, Vol. 2, No. 1, 1987, also issued as an EPA report, EPA/600/J-87/084, 1987.

25. P. A. Davis, N. E. Olague, and M. T. Goodrich, Approaches for the Validation of Models Used for Performance Assessment of High-Level Nuclear Waste Repositories, NUREG/CR-5537, 1991.

26. S. O. Magnuson, R. G. Baca, and A. J. Sondrup, Independent Verification and Benchmark Testing of the PORFLO-3 Computer Code, Version 2.0, EGG-BG-9175, prepared for Westinghouse Hanford Company by EG\&G Idaho, Inc., Idaho Falls, ID, 1990.

27. Notice of Proposed Rulemaking, 40 CFR 141, National Primary Drinking Water Regulations, 56 FR 33050, 1991.

28. U.S. Department of Energy, Richland Operations Office, RLID 5820.2A, Radioactive Waste Management, 1993. 
29. U.S. Environmental Protection Agency, Criteria for Radioactive Wastes, 43 FR 53262, 1978.

30. U.S. Nuclear Regulatory Commission, "Summary of Comments on 10 CFR Part 61, 47 FR 57540," 1982.

31. U.S. Environmental Protection Agency, Final Rule, 40 CFR Part 191, Environmental Radiation Protection Standards for Management and Disposal of Spent Nuclear Fuel, High-Level and Transuranic Wastes, 58 FR 66398, 1993.

32. U.S. Environmental Protection Agency, Final Rule, 40 CFR Part 192, Environmental Standards for Uranium and Thorium Mill Tailings at Licensed Commercial Processing Sites, 48 FR 45926, 1983.

33. U.S. Environmental Protection Agency, Proposed Rule, 40 CFR Part 192, Standards for Remedial Action at Inactive Uranium Processing Sites, 52 FR 36000, 1987.

34. U.S. Nuclear Regulatory Commission, Draft Technical Position, Information Needs to Demonstrate Compliance with EPA's Proposed Groundwater Protection Standards in 40 CFR Part 192, Subparts $A-C, 1988$.

35. U.S. Nuclear Regulatory Commission, Final Environmental Impact Statement on 10 CFR Part 61, NUREG-0945, 1982.

36. K. F. Eckerman, A. B. Wolbarst, and A. C. B. Richardson, Limiting Values of Radionuclide Intake and Air Concentration and Dose Conversion Factors for Inhalation, Submersion, and Ingestion, Federal Guidance Report No. 11, EPA-520/1-88-020, Oak Ridge National Laboratory and U.S. Environmental Protection Agency (1988).

37. U.S. Department of Energy, Internal Dose Conversion Factors for Calculation of Dose to the Public, DOE/EH-0071 (1988).

38. International Commission on Radiological Protection (ICRP), 1990 Recommendations of the International Commission on Radiological Protection, ICRP Publication 60, Ann. ICRP 21, No. 1-3 (1991).

39. International Commission on Radiological Protection (ICRP), Age-Dependent Doses to Members of the Public from Intake of Radionuclides: Part I, ICRP Publication 56, Ann. ICRP 20, No. 2 (1989).

40. K. F. Eckerman and J. C. Ryman, Dose Coefficients for External Exposure to Radionuclides Distributed in Air, Water, and Soil, Federal Guidance Report No. 12, Oak Ridge National Laboratory and U.S. Environmental Protection Agency (1993).

41. D. C. Kocher and K. F. Eckerman, External Dose-Rate Conversion Factors for Calculation of Dose to the Public, DOE/EH-0070, U.S. Department of Energy (1988). 
42. D. C. Kocher and A. L. Sjoreen, "Dose-Rate Conversion Factors for External Exposure to Photon Emitters in Soil," Health Phys. 48, 193 (1985).

43. D. M. Hamby, "Site-Specific Parameter Values for the Nuclear Regulatory Commission's Food Pathway Dose Model," Health Phys. 62, 136 (1992).

44. E. M. Rupp, "Age Dependent Values of Dietary Intake for Assessing Human Exposures to Environmental Pollutants," Health Phys. 39, 151 (1980).

45. Y.-Y. Yang and C. B. Nelson, "An Estimation of Daily Food Usage Factors for Assessing Radionuclide Intakes in the U.S. Population, Health Phys. 50, 245 (1986).

46. U.S. Nuclear Regulatory Commission, "Calculation of Annual Doses to Man from Routine Releases of Reactor Effluents for the Purpose of Evaluating Compliance with 10 CFR Part 50, Appendix I," Regulatory Guide 1.109 (1977).

47. U.S. Environmental Protection Agency, Exposure Factors Handbook, EPA/600/8-89/043 (1990).

48. R. W. Shor and D. E. Fields, "Agricultural Factors Affecting the Radionuclide Foodchain Pathway: Green Forage Consumption of Dairy Cows," Health Phys. 39, 325 (1980).

49. International Commission on Radiological Protection (ICRP), Reference Man: Anatomical, Physiological and Metabolic Characteristics, ICRP Publication 23, Pergamon Press, Oxford, U.K. (1975).

50. U.S. Nuclear Regulatory Commission, Draft Environmental Impact Statement on 10 CFR Part 61 "Licensing Requirements for Land Disposal of Radioactive Waste," Appendix G, NUREG-0782, Vol. 4 (1981).

51. O. I. Oztunali and G. W. Roles, Update of Part 61 Impacts Analysis Methodology, NUREG/CR-4370, Vol. 1, Envirosphere Company and U.S. Nuclear Regulatory Commission (1986).

52. Y. C. Ng, "A Review of Transfer Factors for Assessing the Dose from Radionuclides in Agricultural Products," Nucl. Saf. 23, 57 (1982).

53. Y. C. Ng, C. S. Colsher, D. J. Quinn, and S. E. Thompson, Transfer Coefficients for the Prediction of the Dose to Man Via the Forage-Cow-Milk Pathway from Radionuclides Released to the Biosphere, UCRL-51939, Lawrence Livermore Laboratory (1977).

54. Y. C. Ng, C. S. Colsher, and S. E. Thompson, Soil-to-Plant Concentration Factors for Radiological Assessments, NUREG/CR-2975, UCID-19463, Lawrence Livermore National Laboratory (1982). 
55. Y. C. Ng, C. S. Colsher, and S. E. Thompson, Transfer Coefficients for Assessing the Dose from Radionuclides in Meat and Eggs, NUREG/CR-2976, UCID-19464, Lawrence Livermore National Laboratory (1982).

56. C. F. Baes III, R. D. Sharp, A. L. Sjoreen, and R. W. Shor, A Review and Analysis of Parameters for Assessing Transport of Environmentally Released Radionuclides through Agriculture, ORNL-5786, Oak Ridge National Laboratory (1984).

57. H. T. Peterson, Jr., "Terrestrial and Aquatic Food Chain Pathways," Chap. 5 in Radiological Assessment, NUREG/CR-3332, ORNL-5968 (1983).

58. M. I. Sheppard, S. C. Sheppard, and B. D. Amiro, "Mobility and Plant Uptake of Inorganic ${ }^{14} \mathrm{C}$ and ${ }^{14} \mathrm{C}$-Labelled PCB in Soils of High and Low Retention," Health Phys. 61, 481 (1991).

59. C. F. Baes III and R. D. Sharp, "A Proposal for Estimation of Soil Leaching Constants for Use in Assessment Models," J. Environ. Qual. 12, 17 (1983).

60. M. I. Sheppard and D. H. Thibault, "Default Soil Solid/Liquid Partition Coefficients, $\mathrm{K}_{\mathrm{d}} \mathrm{s}$, for Four Major Soil Types: A Compendium," Health Phys. 59, 471 (1990).

61. B. A. Napier, R. A. Peloquin, D. L. Strenge, and J. V. Ramsdell, GENII - The Hanford Environmental Radiation Dosimetry Software System, PNL-6584, Vol. 3, Battelle Pacific Northwest Laboratory (1988).

62. L. R. Anspaugh, J. H. Shinn, P. L. Phelps, and N. C. Kennedy, "Resuspension and Redistribution of Plutonium in Soils," Health Phys. 29, 571 (1975).

63. J. W. Healy, "Review of Resuspension Models," p. 209 in Transuranic Elements in the Environment, ed. by W. C. Hanson, U.S. Department of Energy (1980).

64. R. R. Seitz, R. S. Garcia, K. M. Kostelnik, and R. J. Starmer, Performance Assessment Handbook for Low-Level Radioactive Waste Disposal Facilities, DOE/LLW-135, National Low-Level Waste Management Program, 1992.

65. M. J. Case and M. D. Otis, Guidelines for Radiological Performance Assessment of DOE Low-Level Radioactive Waste Disposal Sites, DOE/LLW-62T, National Low-Level Waste Management Program, 1988.

66. M. W. Kozak, M. S. Y. Chu, C. P. Harlan, and P. A. Mattingly, A Performance Assessment Methodology for Low-Level Waste Facilities, NUREG/CR-5532, U.S. Nuclear Regulatory Commission, 1989.

67. G. Leddicott, W. Rodger, R. Frendberg and H. Morton, Suggested Quantity and Concentration Limits to be Applied to Key Isotopes in Shallow Land Burial, Nuclear Safety Associates Report, 1977. 
68. J. A. Adam, and V. L. Rogers, A Classification System for Radioactive Waste Disposal-What Waste Goes Where?, NUREG-0456, Ford, Bacon, and Davis, Utah, for U.S. Nuclear Regulatory Commission, March 1978.

69. J. W. Healy, and J. C. Rodger, Limits for the Burial of the Department of Energy Transuranic Wastes, LA-UR-79-100, Los Alamos Scientific Laboratory, January 15, 1979.

70. J. J. Cohen, and W. C. King, Determination of a Radioactive Waste Classification System, UCRL-52535, Lawrence Livermore Laboratory, March 1978.

71. U.S. Environmental Protection Agency, Environmental Standards for the Management, Storage, and Land Disposal of Low-Level Radioactive Waste (40 CFR Part 193) and Naturally Occurring and Accelerator-Produced Radioactive Waste (40 CFR Part 794), draft, April 1989.

72. U.S. Environmental Protection Agency, Low-Level and NARM Radioactive Wastes: Draft Environmental Impact Statement for Proposed Rules, Volume 1, "Background Information Document," EPA 520/1-87-012-1, Office of Radiation Programs, June 1988.

73. U.S. Environmental Protection Agency, 40 CFR Part 192, Health and Environmental Standards for Uranium Mill Tailings, 48 FR 590, 1983.

74. U.S. Nuclear Regulatory Commission, 10 CFR Part 60, Disposal of High-Level Radioactive Waste in Geological Repositories: Technical Criteria, Proposed Rule, 46 FR 35280, 1981.

75. U.S. Nuclear Regulatory Commission, 10 CFR Part 60, Disposal of High-Level Radioactive Waste in Geological Repositories: Technical Criteria, Final Rule, 48 FR 28194, 1983.

76. National Research Council, "Radioactive Waste Repository Licensing," Synopsis of a Symposium Sponsored by the Board on Radioactive Waste Management, National Academy Press, 1992.

77. U.S. EPA, Final Rule, 40 CFR Part 61, National Emission Standards for Hazardous Air Pollutants: Radionuclides, 54 FR 51654, December 15, 1989.

78. U.S. NRC, "Disposal or Onsite Storage of Residual Thorium or Uranium (Either as Natural Ores or without Daughters Present) from Past Operations," SECY 91-576, October 5, 1981.

79. International Commission on Radiation Protection, Limits for Intakes of Radionuclides by Workers, ICRP-30, 1978. 
Appendix A

Glossary

A-1 



\section{Appendix A}

\section{Glossary}

Aquifer

Benchmarking

Calibrating

Computer code

Dose

Dose equivalent

Exposure

Exposure pathways

Inventory

Low-level waste (radioactive)
A saturated, permeable geologic unit that can transmit significant quantities of water under ordinary hydraulic gradients.

Computational testing involving code-to-code comparisons in which simulations are used to provide assurance that the code calculations are consistent with results of other established codes.

The process of synchronizing the cause-and-effect relationships described in a computer model with the observed behavior of a real physical system or process. This process involves adjusting the uncertain model input parameters so that the computer simulation mimics, in a best-fit sense, the dynamics of the physical system.

A computer program that performs a solution of a set of governing equations and produces calculations of state variables (i.e., temperature, hydraulic head, concentration, etc.) over space and time.

A quantity, total or accumulated, of ionizing radiation received.

A term to express the biological effect of an absorbed dose of ionizing radiation relative to $x$-radiation. The dose equivalent is equal to the absorbed dose multiplied by the quality factor and other modifying factors. It is often expressed in units of rem.

The incidence of radiation on any living or nonliving material.

The potential routes of human exposure to radionuclides or radiation, such as ingestion, immersion, and inhalation.

The distribution and quantities of contaminants disposed of in the waste site.

Radioactive waste subject to the authority of the Atomic Energy Act of 1954, other than high-level waste, spent fuel, transuranic waste, or uranium and thorium mill tailings (i.e., by-product material as defined in Section 11e(2) of the Atomic Energy Act of 1954). 
Markers

Model

Migration

Performance assessment

Quality

Quality assurance

Reasonable assurance

Reasonable consistency

Saturated zone
Permanent monuments or other devices that are installed at a disposal site to indicate site boundaries and warn against intrusion.

A conceptual description and the associated mathematical representation of a system, subsystem, component, or condition. A model describes the relationships among state variables as a function of time and space, given initial, and/or boundary conditions.

Movement of contaminants from the place where disposed waste was initially emplaced, generally by groundwater transport.

The analytic process of modeling the behavior of a disposal system and its components under a variety of expected and hypothetical conditions. The modeling is conducted to develop an understanding of the events and processes that might affect the ability of disposal systems to limit releases to acceptable levels.

The totality of features and characteristics that bears on the ability to meet preset technical requirements.

A planned and systematic pattern of all actions necessary to provide adequate confidence that the product conforms to established technical requirements.

The degree of proof required in demonstrating compliance of LLW disposal systems with the performance objectives in the DOE Order 5820.2A. The term means that the acceptability of disposals shall be determined on the basis of the preponderance of all information available at the time a final decision is made and denotes that subjective judgements, rather than just the use of mathematical models, are an essential aspect of the relevant information.

A condition emphasizing that sites should provide clear explanations and references for all assumptions and parameters that go into an analysis and clear interpretations of results. This term refers to the use of the same computer codes and parameter data bases at different sites with differences only to the extent that can be justified on a site-specific basis.

The part of the earth's crust beneath the water table in which all voids are filled with water under pressure greater than atmospheric. 
Scenario

Sensitivity analysis

Source term

Transport pathway

Uncertainty analysis

Vadose zone

Verifying

Validating

Waste form
A particular chain of hypothetical circumstances that results in loss of containment and in release and/or transport of contaminants from the disposal site, or exposure of inadvertent intruders.

A computational exercise performed with a computer code that is aimed at identifying the model inputs that have the most influence on model predictions. Typically involves performing a set of computer simulations and monitoring the change in predictive output per unit change in an input parameter.

The kinds and amounts of contaminants that have been released from the waste package.

A route through which contaminants could migrate and reach the accessible environment.

A computational exercise that is aimed at identifying the impact of uncertainty in model inputs on the model predictions.

The unsaturated region of soil from land surface to the top of the water table. Also referred to as the zone of aeration.

Code testing consisting of comparisons between the computer code and known analytical solutions. Testing that is aimed at ensuring that the code performs the computations specified by the numerical algorithm.

Testing process aimed at determining the degree to which a model describes the behavior of a real-world situation or process. The testing is performed by comparing model predictions against data from laboratory and/or field experiments.

The radioactive waste materials and any encapsulating or stabilizing matrix. 
Appendix B

Meeting Agendas

B-1 



\section{MEETING AGENDA \\ DOE PERFORMANCE ASSESSMENT TASK TEAM}

July 25-26, 1990

Compri Hotel, Gaithersburg, MD

Wednesday, July 25, 1990

8:00 Introduction to meeting and attendees

Kirk Owens

8:15 DOE Headquarters remarks: charge to team

Leanne Smith

8:30 Chairman's introductory remarks

Don Wood

8:45 Status of site PAs and WAC

Site Reps (6)

9:45 Preliminary discussion of task, proposed schedule, and issues

All

10:15 Break

10:30 Technical approach, performance objectives, consideration of Orders $5820.2 \mathrm{~A}$ and 5400.5

All

11:30 Initial discussion of scenarios

All

12:00 Lunch

1:00 General scenario discussion. Identify common and site-specific aspects of scenarios. Tentative scenario list for review and agreement at next meeting.

All

Thursday, July 26, 1990

8:00 Identify key parameters for scenarios and approach to achieving consensus. Identify existing documents.

Propose format of list.

10:00 Break

10:15 Codes in use, benchmarking, level of acceptance 
11:15 Discuss schedule and deliverables, assignments, set next meeting, objectives, time and place (DOE-LLW

Mtg.-Chicago? - August 30).

12:00 Lunch

1:00 Start list of key parameters and identify ranges.

Outline report.

3:00 Adjourn 


\section{MEETING AGENDA}

\section{DOE PERFORMANCE ASSESSMENT TASK TEAM}

August 29-30, 1990

Westin Hotel, Chicago, IL

Wednesday, August 29, 1990

1:30 Review of assignments and status

2:00 Review of Work Plan and Table of Contents

2:30 Collect issues lists and group into TOC categories

3:15 Break

3:30 Review of NRC approach

4:00 Technical approach to compliance policy and rationale-performance objectives and scenarios

5:00 Adjourn

Thursday, August 30, 1990

8:00 Intrusion scenario comparisons

9:30 Exposure pathway consideration for groundwater

10:30 Break

10:45 Test case definition, selection, and assignment

12:00 Lunch

1:00 Issue paper discussion, selection, and assignment

2:00 Discuss schedule and deliverables, need for other invitees, set next meeting objectives, time and place

3:00 Adjourn 
MEETING AGENDA

PERFORMANCE ASSESSMENT TASK TEAM

December 4-6, 1990

Club House Inn, Knoxville, TN

Tuesday, December 4, 1990

8:00 Introduction, status of assignments, agenda

Don Wood

8:30 Oak Ridge PA activities and issues

Jeff Baldwin

9:15 Other sites-photos, descriptions, schedules

Members

10:00 Break

10:15 Intruder test case results

Members

11:15 Farming/drinking water comparison, well description

Bruce Napier/

Mark Wood

12:00 Lunch

1:00 Levels of consistency/standardization: hierarchy

Don Wood

1:45 Consistency/standardization: codes

Bob Baca/

Max Dolenc

2:30 NRC integration

Kirk Owens/

Fred Ross

3:00 Break

3:15 Compliance time

Don Wood

4:15 Passive controls

Wednesday, December 5, 1990

8:00 QA plan codes and data

Roger Seitz/

Bruce Napier 
8:30 Site characterization/data quality

9:15 Concrete durability

10:15 Break

10:30 Special case waste

11:15 Dose objectives - interpretation and modification

12:00 Lunch

1:00 Other issues - point of compliance, dose terminology, plume overlap, volume averaging

Don Wood

2:00 Work plan

2:45 Break

3:00 Report status and structure

3:45 New issues and topics for future meetings

Thursday, December 6, 1990

8:30 - Site tour

11:45
Bob Baca/

Marc Wood

John Walton

Don Wood
Members

Jeff Baldwin 


\section{MEETING AGENDA \\ PERFORMANCE ASSESSMENT TASK TEAM}

February 5-7, 1991

Las Vegas, NV

Tuesday, February 5, 1991

8:00 Introduction, agenda, opening remarks

Don Wood

8:30 Status of NTS performance assessment

Max Dolenc

8:45 Benchmark exercise, crop dose factor

Marc Wood/

Roger Seitz

10:00 Break

10:15 Status of commercial LLW program

Kevin Kostelnik

11:15 NRC activities

Fred Ross

11:30 Offsite well description

Jim Cook

12:00 Lunch

1:00 Point of compliance, buffer zone

Tom Buhl/

Mac Ennis

1:30 Time for compliance, passive control

Jeff Baldwin

2:45 Special case waste

Don Wood

3:00 Break

3:15 Post-drilling scenario for Pu-239

Don Wood

3:45 Reasonable assurance

Max Dolenc

4:00 Dose objectives and terminology

Don Wood

4:30 Future work plan and schedule

Kirk Owens

5:00 Adjourn 
Wednesday, February 6, 1991

8:00 NTS site tour

Max Dolenc

Thursday, February 7, 1991

8:00 Site-specific water pathway models

Bob Baca

9:00 Software testing and control

Roger Seitz

10:00 Break

10:15 Data quality

Bob Baca

11:00 Concentration averaging

Don Wood

11:30 New issues and topics for future meetings, site-specific waste acceptance criteria, apportionment, and report status and structure

Members

12:00 Adjourn 
MEETING AGENDA

PERFORMANCE ASSESSMENT TASK TEAM

April 17-18, 1991

Gaithersburg, MD

Wednesday, April 17, 1991

8:00 Introductions, agenda, opening remarks

Don Wood

8:15 Briefing and recommendations to DOE-HQ, dose terminology, reasonable assurance, SCW (PAL), passive controls

Don Wood

8:45 Benchmark exercise - intrusion scenarios, data, results

Marc Wood

10:00 Break

10:15 Interfaces

States workshops

NRC/IAEA/Sandia, NRC group, D\&D reg. guide DOE/IAEA, 5820.2A revision, NRC briefing

DOE groundwater task force

Peer review panel plans

Roger Seitz

Fred Ross

Kirk Owens

Ed Regnier

Elmer Wilhite

11:30 Overview of NAS modeling recommendations

Roger Seitz

Benchmarking option

Members

12:00 Lunch

1:00 Groundwater objective, offsite well

Don Wood

1:30 Time for compliance

Discussion

2:30 Break

2:45 Software testing and control

Roger Seitz

3:30 Point of compliance

Mac Ennis

4:15 Future work plan and schedule

Don Wood

5:00 Adjourn 
Thursday, April 18, 1991

8:00 Potential change in use of intruder objective

Don Wood

8:45 Site-specific waste acceptance criteriaintroduction

Background to 5820.2A

Survey

INEL draft WAC-overview

Don Wood

Art Flores

John Fowler

Roger Seitz

10:00 Break

10:15 Apportionment

Don Wood

10:30 Concentration averaging

Don Wood

11:00 New issues and topics for future meetings

Report status and structure

Members

12:00 Adjourn 
MEETING AGENDA

\section{PERFORMANCE ASSESSMENT TASK TEAM}

June 12-13, 1991

Gaithersburg, MD

Wednesday, June 12, 1991

8:00 Introduction, agenda, opening remarks, status, comments on SCW, passive controls, reasonable assurance, WM' '92, LLWM mtg.

Don Wood

8:30 Interfaces

NRC - working group, 10 CFR 20

Fred Ross

DOE - 5820.2A revision, IAEA, budget

Kirk Owens

40 CFR 193 comments

Gary Roles

Groundwater task force

PRP

Ed Regnier

Elmer Wilhite

9:15 Comments on Waste Classification Rationale paper

Bob Curl

Max Dolenc

10:00 Break

10:15 Benchmark exercise

1st meeting report

2nd meeting summary

Roger Seitz

Next actions

Jim Cook

11:15 Site-specific waste acceptance criteria,

Idaho Falls

Art Rood

12:00 Lunch

1:00 WAC, continued

SRP progress

Nevada

Jim Cook

Others

Max Dolenc

Implications for "orphan" waste

1:45 Intruder objective issue, scenario discussion

2:30 Break

B-12 
2:45 Long-term changes and effects

3:15 Groundwater

Depth averaging

Jim Cook

IAEA benchmark case

Discussion

4:00 Point of Compliance

Tom Buhl

4:30 Future work plan and schedule

Don Wood

5:00 Adjourn

Thursday, June 13, 1991

8:00 Time for Compliance

Discussion

9:15 Concentration averaging

Dave Kocher

10:00 Break

10:15 Sensitivity analysis

Brain Whorley

11:15 Comments on software testing issue paper

Roger Seitz

11:30 Report status

Don Wood

12:00 Lunch

1:00 Parameter discussion

Dave Kocher/

Bruce Napier

Issue papers deferred:

GW codes - rationale for not standardizing

Data quality 


\section{MEETING AGENDA \\ PERFORMANCE ASSESSMENT TASK TEAM}

August 27-28, 1991

Idaho Falls, ID

The Draft Progress Report will be sent out for review before the meeting. Please review and be prepared to offer revisions on Tuesday morning. Keep the requested changes to the minimum necessary, since at this stage, it a Progress Report, not a Final, so we need not have all issues and comments fully resolved. Thus, I hope that the comments are minor and might even be provided simply as a marked-up copy. If so, we can shorten the time allowed for revision and use that time more productively for other discussions. The TSP staff will work on the changes Tuesday afternoon, with the objective of delivering clean copies Tuesday night for review. Late Wednesday, a period of 2 hours is reserved for discussion, but again, I hope that we will not need all of it and can allow other discussions to be extended.

Tuesday, August 27, 1991

8:00 Introductions, agenda, opening remarks, status

Don Wood

8:15 Revisions to progress report

All

10:00 Break

10:15 Continue revisions

All

12:00 Lunch

1:00 Tour

Roger Seitz

5:00 Return

Wednesday, August 28, 1991

8:00 Interfaces - DOE-HQ, NRC, PRP

8:30 Report of IAEA meeting

Dave Thorne

9:15 Status of SRS waste acceptance criteria

Jim Cook

9:30 Groundwater transport code benchmarking

Roger Seitz

10:00 Break

10:15 Scenario and benchmark status

Subteam 
10:45 Parameter recommendations

Bruce Napier/

Dave Kocher

11:00 Point of compliance

Tom Buhl

11:15 Volume averaging

Dave Kocher

11:45 Future plans

12:00 Lunch

1:00 Source term

Marc Wood

1:30 Intruder protection

Dave Kocher

2:00 Time for compliance

Bob Baca

3:00 Review revised Progress Report

All

5:00 Adjourn 
MEETING AGENDA

\section{PERFORMANCE ASSESSMENT TASK TEAM}

October 29-30, 1991

Denver, CO

Tuesday, October 29, 1991

Performance Assessment Briefing

Wednesday, October 30, 1991

8:00

Joint Meeting, - PRP/PATT

Review of briefing and lessons learned

Compendium of foreign standards-TSP?

Discussion of approaches to open issues and direction

of future work

Benchmarking approach

Primary issues:

Time of compliance/analysis

Possible use of collective dose

Intruder protection-Use to generate

concentration limits?

Levels of conservatism and impact on other sites

Conversion from disposal limits to acceptance limits

Volume averaging-package limits

Interactions needed with gatekeepers and

generators-impacts on characterization, waste preparation, manifesting

Generator conference coming-Max?

Inform waste operations-ad hoc committee?

5820.2A Revision-participation

Future Panel/Team interactions

12:00 Lunch

1:00 PATT Meeting

Future plans and activities

Meeting times and places

Review of briefing and Meeting with PRP - new directions?

Reporting as issues close

New directions desired 
Benchmarking-intruder, groundwater, all pathways

Subteam

Next actions and schedule

Direct gamma-Dave?

Parameters-food chain, Tc-99, C-14-Bruce?

Interfaces

WM-92

Korea Meeting

Cook

NRC

EPA

Remedial action

Open issues review and assignments for later meetings

Time of Compliance/analysis

Possible use of collective dose

Use of intruder objective-level/intent of

intruder protection

Kocher/Roles

Long-term effects

Groundwater dose objective and compliance

demonstration

Vertical averaging

Scenario development and application

Long-term changes and effects

Source term

Waste inventory characteristics

Concentration averaging

Waste disposal criteria and conversion to acceptance

criteria

Generators/operators

Gatekeepers

Engineered barriers

Status of PAs

Adjourn 
MEETING AGENDA

\section{PERFORMANCE ASSESSMENT TASK TEAM}

January 21-23, 1992

Augusta, GA

Tuesday, January 21, 1992

8:00 Introductions, agenda, opening remarks, status

Don Wood

8:15 Closed issue statements-new

Don Wood

8:30 Interfaces

NRC - Working Group, 10 CFR 61

DOE Liaison to WG for Part 61 Rev. and RG

DOE - 5820.2A Revision, IAEA CRP liaison

IAEA case studies

40 CFR 191 Comments, response next EPRI WS

40 CFR 193 key issues-NRC, DOE, OMB

Any EPA action?

Groundwater Task Force

WOTSC interaction

PRP

GTCC program needs

Fred Ross

Kirk Owens

Kirk Owens

Dave Kocher

Gary Roles

Gary Roles

NCRP-Waste Classification

Ed Regnier

Kirk Owens

Bob Curl

Elmer Wilhite

Dave Kocher

9:45 Foreign Standards

Any further need - white paper for HQ?

Kocher, Roles, Cook, D. Wood

10:15 Break

10:30 Waste Generator Coordination

M. Wood, Dolenc, Seitz

11:00 Benchmark Subteam (Meeting 1/20/91)

Subteam

Finish intruder case, discuss all pathways, parameter guidance

12:00 Lunch

1:00 Uncertainty Considerations

Brian Whorley

1:45 Intruder Protection

Dave Kocher

2:30 Break 
2:45 Time for Assessment (includes long-term effects)

Don Wood

4:00 Point of Compliance-all pathways objective

Dave Kocher

4:15 Future work plan and schedule

Don Wood

Future Meeting Times

Recommendations to Field Offices

Generator/Operator Coordination

Benchmark Scenarios-Report?

Guidance needed for GTCC waste

5820.2A revision

Other future direction?

5:00 Adjourn

Wednesday, January 22, 1992

7:45 Depart hotel in cars for SRP

8:30 Arrive at SRP for badging and tour

3:30 Depart for hotel

Thursday, January 23, 1992

8:00 Savannah River WAC and PAs

WSRC Staff

9:00 Inventory Characterization and Manifesting

Marc Wood

9:30 Concentration Averaging

Dave Kocher

10:00 Break

10:15 Source Term

Marc Wood

10:45 Groundwater

Discussion

Depth Averaging

IAEA benchmark case

11:15 Age Dependence

Dave Kocher

11:45 Adjourn 
MEETING AGENDA

PERFORMANCE ASSESSMENT TASK TEAM

May 6-7, 1992

Gaithersburg, MD

Wednesday, May 6, 1992

8:00 Introductions, agenda, opening remarks, status Don Wood

8:15 Interfaces

NRC - Working Group, 10 CFR 61, TPP, RG

Fred Ross

DOE Liaison to WG for Part 61 Rev. and RG

Possible NRC/DOE joint WS

DOE - 5820.2A Revision,

75T Revision

10 CFR 834, 5480.5, Drafts?

PA in SAR issue:

NAS

40 CFR 191 - EPRI WS, comment draft, status

40 CFR 193

Groundwater Task Force

WOTSC interaction, Steering Group?

Generator Coordination

PRP

NCRP-Waste Classification. ANSI?

Report on WM'92

Any?

Ed Regnier

Gary Roles

Ed Regnier

Kirk Owens

Any

Elmer Wilhite

Dave Kocher

Don Wood

9:30 Program Management Aspects

9:45 Transmittal of Closed Issues and Recommendations

to Divisions and Field Offices for Review

Wood/Duggan

10:00 Break

10:15 Concentration Averaging - No comments Dave Kocher

10:30 PA a living document Don Wood

11:00 Scenario Development and Application $\quad$ Bruce Napier

Some accepted as is, but others wanted more

11:30 Point of Compliance-all pathways objective Dave Kocher 
1:00 Time for Assessment (includes long-term effects)

Don Wood

Subteam

2:00 Benchmark Subteam

2:30 Foreign Standards

Dave Kocher

2:45 Break

3:00 Intruder Protection

All-Pathways excludes intrusion - intrusion is not "expected"?

Options for intruder treatment

Seitz

Roles

Don Wood

4:00 Future work plan and schedule

Future Meeting Times-

11th: Aug 4-6 in Santa Fe? later?

12th: D.C., Dec 2-3? or January 93?

13th: April/May 93? Hanford?

14th: Sept 93?-Joint Briefing?

Competition:

Spectrum '92 - Aug 24-27, 92, Boise

IAEA RCM - Oct 12-16, 92, Augusta

DOE Model - Oct 19-22, 92

ANS-Nov 16-19, 92, Chicago

LLWLP - November 18-20, 92

WM'93 - February 28-Mar 4, 93, Tucson

ANS - June 20-24, 93, San Diego

Fuel Cycle Topical - Sept 12-17, 93, Seattle

ER'93 - Oct 24-27, 93, Augusta

ANS - 11/14-19, 93, San Francisco

5:00 Informal Discussions

Thursday, May 7, 1992

8:00 Waste Characterization

ANSI standard

Dave Kocher

Commercial approach

Gary Roles

NTS Practices

Max Dolenc

8:45 Source Term

Marc Wood

9:15 Rescue of old data programs

10:00 Break 
10:15 Screening Codes to Determine PA Scope and Content

Roger Seitz

ORNL key radionuclides and WAC

Limiting Radionuclides

Dave Kocher

Jim Cook

11:00 Dose Considerations-Age Dependence, Averaging

Dave Kocher

\section{1:30 New Issues}

Uranium daughter buildup

BRC/Exemptions

Release criteria

Monitoring

12:30 Action Items

1:00 Adjourn 
MEETING AGENDA

PERFORMANCE ASSESSMENT TASK TEAM

August 4-6, 1992

Santa Fe, NM

Tuesday, August 4, 1992

8:00 Introductions, agenda, opening remarks, status

Don Wood

8:15 Interfaces

NRC - PAWG, 10 CFR 61, TPP Joint NRC/DOE WS

DOE - 5820.2A revision

Fred Ross

Greg Duggan/

Kirk Owens

PA in SAR issue, 6430.1B problem

Dave Huizenga/

EPA rules

Gary Roles

Ed Regnier/

WMOC interaction

Gary Roles

Bob Curl

IAEA test case 2

Marc Wood/

Greg Duggan

Transmittal of closed issues recommendations

Marc Wood/

Greg Duggan

Waste characterization support

Don Wood

ANSI committee on waste characterization

Dave Kocher

Foreign standards

Meetings - LLWM '92, WM '93, ER '93, Praque '93

Dave Kocher

All

9:30 Review progress report

All

10:00 Break

10:15 Continue review

12:00 Lunch

1:00 Complete review

2:15 Time for compliance (if review complete)

Don Wood

3:15 Break

3:30 Concentration averaging

Dave Kocher 
4:30 Future work plan and schedule

Funding, reporting, directions, meeting schedule

Don Wood

5:00 Informal discussions

Wednesday, August 5, 1992

8:00 Point of compliance (all pathways)

Dave Kocher

8:30 PA review, approval, enforcement, maintenance

Don Wood

9:00 Benchmarking subteam - intruder test case

Jim Cook

9:30 Generator/operator/gatekeeper problems

Dan Taggart

10:00 Break

10:15 Scenario development and application

Bruce Napier

10:30 Options for intruder treatment

Gary Roles

11:15 Source term

Marc Wood

11:30 Comments/preparation for workshop

All

11:45 Action items summary

Bob Curl

12:00 Lunch

1:00 LANL tour

Tom Buhl

Thursday, August 6, 1992

8:00 Introductions

Don Wood

8:10 Welcome, expectations and comments

What does DOE expect from the Workshop?

Greg Duggan

8:20 Need, purpose and scope

Don Wood

Some lysimeter programs have been de-emphasized, but performance assessors need the data.

PA-driven-need input data for source term, and continuing tests to support and verify PA through facility closure.

DOE concern about continuing tests.

Focus-source release (waste form), although infiltration 
and near-field transport are related.

Maximum utility of past programs and determine what new data are needed.

Develop recommendations on need to continue past programs, and establish continuing programs, if needed.

8:45 Analysts needs for field data

How data is used, impact if not available (excess

conservatism or cost, credibility and

defensibility).

9:20 Current status and work in progress

Hanford

Savannah River

LANL

ORNL

10:00 Break

10:15 NTS

INEL

NRC

10:45 Need for continued programs

12:00 Lunch

1:00 Need for new programs

DOE-wide, or facility-specific?

2:30 Break

2:45 Development of recommendations

4:00 Wrap up and future plans (if any), action items

4:30 Adjourn 
MEETING AGENDA

PERFORMANCE ASSESSMENT TASK TEAM

December 8-10, 1992

Rockville, MD

Tuesday, December 8, 1992

8:00 Introductions, agenda, opening remarks, status

Don Wood

Field Data Project Status

LLWM Meeting, WM '93

8:30 Interfaces

DOE-HQ - Funding, Promulgation of recommendations

Revision of 5820.2A, DOE liaison to PAWG

Greg Duggan

NRC - PAWG, TPP, Joint NRC/DOE WS, D\&D Workshops,

Ed Regnier

"Harmonize" risk goals (EPA/NRC)

EPA - 40 CFR 191/193

WMOC

IAEA Meeting on Waste Disposal Criteria

PRP

Dave Kocher

Elmer Wilhite

10:00 Break

10:15 Benchmarking Subteam

Roger Seitz

11:15 External dose

11:30 Radionuclide Screening

Roger Seitz

12:00 Lunch

1:00 Scenario Development and Application Dave Kocher

1:30 IAEA CRP - RCM Report, Test Case 2a David Thorne

$\begin{array}{lll}2: 30 & \text { Test Case } 2 b & \text { Roger Seitz }\end{array}$

2:45 Break

3:00 Time for Compliance-I

4:30 Future Plans and Schedule, Reporting, Directions 
Wednesday, December 9, 1992

Waste Characterization Workshop

8:00 Introduction

Marc Wood-WHC

8:15 DOE LLW Manifesting and Information Survey

Lissa Sawyer-PNL

9:00 Summary of Hanford Characterization Requirements and Practices

Norm Willis-WHC

9:45 Verification of Waste Characterization at Hanford

Stan Neuder-Battelle

10:00 Summary of NTS Characterization Requirements

Bruce Becker-REECo

10:45 Break

11:00 Summary of INEL Characterization Requirements and Practices

Dale Wells-INEL

11:45 Lunch

12:45 Summary of ORNL Characterization Requirements and Practices

Bob Hydzik-ORNL

1:30 Summary of Savannah River Characterization

SRL Requirements and Practices

2:15 Break

$2: 30$

Discussion

Thursday, December 10, 1992

8:00 Concentration Averaging

Dave Kocher

8:30 Intruder Effect on All-Pathways Scenario

Don Wood

9:00 Intrusion, Waste Acceptance Criteria, et al.

10:00 Break 
10:15 Time for Compliance-II

As time allows: Other issues-U/Th, Release Criteria (non-rad, D\&D, BRC, etc.),

Monitoring, Active control beyond 100 years

12:30 Action Item Summary

1:00 Adjourn 
MEETING AGENDA

PERFORMANCE ASSESSMENT TASK TEAM

April 20-22, 1993

Richland, WA

Tuesday, April 20, 1993

8:00 Introductions, agenda, opening remarks, status

Don Wood

8:15 Status PATT Management Plan (sent out for review)

Don Wood

8:45 Interfaces

Transmittal of Closed Issue Recommendations

DOE-HQ-Field Office review of PATT Progress Report

Revision of 5820.2A-mtg 5/6

Don Wood

Duggan/Owens

Field Data Survey Project-Serne proposal to EM-50

DOE liaison to PAWG

IAEA Formal Contract, Budget needs

Systems Analysis Methodology (IT Corp)

NRC - PAWG, Reg Guide, TOC

Modeling-NEFTRAN, DITTY, distribution sampling

D\&D Workshops, any ACNW comments?

EPA - 40 CFR 191-status

10 CFR 834-copy distributed

Waste Certification Workshop

WMOC Meeting, Presentations, Waste Characterization

LLWMP Conference-Date, deadlines

CFP-PA portion of track?

Paper Review?

WM '93 Report and WM '94 Plan

9:30 PRP - Lessons Learned, PRP Directions, Coordination

Elmer Wilhite

10:00 Break

10:15 Developing DOE Regulatory Structure

Ed Regnier

11:00 Benchmarking Subteam

Direct Gamma

Report

Roger Seitz

RESRAD-any interest? 
IAEA CRP

Status and any new information

David Thorne

Test Case 2b

Roger Seitz

12:00 Lunch

1:00 Groundwater Modelling Workshop at Hanford Marc Wood

1:45 Radionuclide Screening-new paper 3/15 Roger Seitz

2:15 DOE-HQ Waste Characterization Issues and Activities Jeff Williams

3:00 Break

3:15 Analytical Methods Compendium and Data Base

Steve Goheen

Sandy Fadeff

4:15 Future plans and schedule, reporting, directions

Meeting frequency and times

Communication of PA issues and lessons

Future restructuring for FY-95-96

Round robin of shared experiences?

5:00 Adjourn

Wednesday, April 21, 1993

8:00 Waste Characterization-Process Knowledge at INEL $\quad$ Dale Wells

9:00 Process Knowledge at SRS Bob Hochel

10:00 Break

10:15 Commercial sector PA issues and experience Rick Hulse

11:15 PA Effects on Characterization $\quad$ Marc Wood

11:45 Any further action on characterization? All

12:00 Lunch

1:00 Scenario Development and Application Dave Kocher

1:15 Intruder Dose Objective, Waste Acceptance Criteria, et al. 
2:00 U/Th and daughters-long-term issues

Dave think piece

EPA BID for 40 CFR 191

Don Wood

NRC/Sandia assessment of $U$ disposal methods and limits

Fred Ross

3:00 Break

3:30 Time for Compliance

Don Wood

4:30 Action Item Summary

5:00 Adjourn

Thursday, April 22, 1993

8:00 Hanford site tour

Marc Wood 
MEETING AGENDA

PERFORMANCE ASSESSMENT TASK TEAM

August 3-5, 1993

Denver, CO

Tuesday, August 3, 1993

8:00 Introduction, agenda, opening remarks, status Arrangements-Tour, et al.

Don Wood

Bob Curl

8:15 Interfaces

Closed Issue Recommendation (Screening)

WMOC

Waste Certification Workshop

PEIS

FFCA Disposal Working Group

IAEA-Case 1, 2a and status

Contract Status

NRC Residual Radioactivity Criteria (D\&D)

Field Data Project and Data Summary

EPA Rulemaking status $(191,193)$

LLWM Conference-PA Track

WM '94

RESRAD—any benchmarking?

Don Wood

Bob Curl

Derek Widmyer

Dave Huizenga

Greg Duggan

Andy Campbell

Greg Duggan

Gary Roles

Don Wood

Don Wood

Dennis Armstrong

10:00 Break

10:15 Comments on PATT-Progress Report

Path forward

Owens/Wood

11:00 PRP Status and Lessons Learned

Elmer Wilhite

11:30 IAEA Program-Case $2 b$ and Consultants Group

Roger Seitz

12:00 Lunch

1:00 U/Th and daughters-long-term issues

Wood/Kocher

2:00 Briefing on Revision of Order 5820.2A

Discussion

Greg Duggan

All

3:00 Break 
3:15 Revision of 5820.A PA Chapter

George Sanders

Discussion

Guidance Document?

4:15 Future plans and schedule, reporting, directions

Meeting frequency and times, redirection

Communication of PA issues and lessons

Round robin of shared experiences?

5:00 Adjourn

Wednesday, August 4, 1993

8:00 Waste Characterization Working Group

Derek Widmyer

9:00 Waste Characterization Data Base

Marc Wood

9:30 Impact of PA on Waste Characterization

Marc Wood

10:00 Break

10:15 PA BTP and NRC Modeling Techniques

Andy Campbell

11:15 Benchmarking Subteam

Report

Direct Gamma Comparison

Roger Seitz

Kocher/Napier/

Seitz/Cook

12:00 Lunch

1:00 Concentration Averaging

Dave Kocher

1:30 Scenario Development and Application

Dave Kocker

2:00 Time for Compliance

Don Wood

2:30 Break

2:45 Intruders

3:30 Open for continued discussions-any topic

4:30 Summary, Actions

Wood/Curl

5:00 Adjourn 
Thunsday, August 5, 1993

8:00 Tour of Rocky Flats

End approximately noon 
FINAL AGENDA

\section{PERFORMANCE ASSESSMENT TASK TEAM}

November 16-18, 1993

Gaithersburg, MD

Tuesday, November 16, 1993

8:00 Introductions, agenda, opening remarks, status

Don Wood

8:15 Interfaces

Closed Issue Recommendations Sent

Don Wood

Closed Issues Ready to Send

Don Wood

8:30 Budget

Field Data Requirements

Greg Duggan

Kirk Owens

PEIS

FFCA Disposal Working Group (15 min)

Dave Huizenga

Dave Huizenga

9:00 EO/PHSSG (5 min)

Waste Characterization Working Group

Derek Widmyer

WMOC

PRP (15 min)

Mixed Waste TWG (15 min)

Jim Cook

10:00 Break

10:15 Interfaces, continued

RESRAD-Benchmarking?

EPA Residual Radioactivity Rulemaking

EPA TRU/HLW Rulemaking Status

LLWM Conference-PA Track

WM'94

Dennis Armstrong

Ed Regnier

Ed Regnier

Don Wood

Don Wood

11:00 Benchmark Subteam

Roger Seitz

Direct Gamma Comparisons

Final Report

IAEA-Case 1, 2a, 2b, and status

Roger Seitz

$\mathrm{PA}$ in China

Roger Seitz

12:00 Lunch

1:00 U/Th and daughters-long-term issues 
1:45 Time of Compliance

International

Issue statement

2:30 Waste Characterization

3:00 Break

3:15 Suggestions for new issues

4:00 Future Directions

FY-94

Finish most issues, Progress Report/Benchmark Report published Review of 5820.2B

Wednesday, August 4, 1993

8:00 Waste Characterization Working Group

9:00 Waste Characterization Data Base

9:30 Impact of PA on Waste Characterization

10:00 Break

10:15 PA BTP and NRC Modeling Techniques

11:15 Benchmarking Subteam

Report

Direct Gamma Comparison

12:00 Lunch

1:00 Concentration Averaging

1:30 Scenario Development and Application

2:00 Time for Compliance

2:30 Break

$2: 45 \quad$ Intruders

3:30 Open for continued discussions-any topic

4:30 Summary, Actions
Andy Campbell

Don Wood

Marc Wood
Derek Widmyer

Marc Wood

Marc Wood

Andy Campbell

Roger Seitz

Kocher/Napier/

Seitz/Cook

Dave Kocher

Dave Kocher

Don Wood

Wood/Curl 
Adjourn

Thursday, August 5, 1993

8:00 Tour of Rocky Flats

End approximately noon 